\title{
IUCN
}

Guidance for using the IUCN Global Standard for Nature-based Solutions

A user-friendly framework for the verification, design and scaling up of Nature-based Solutions

First edition

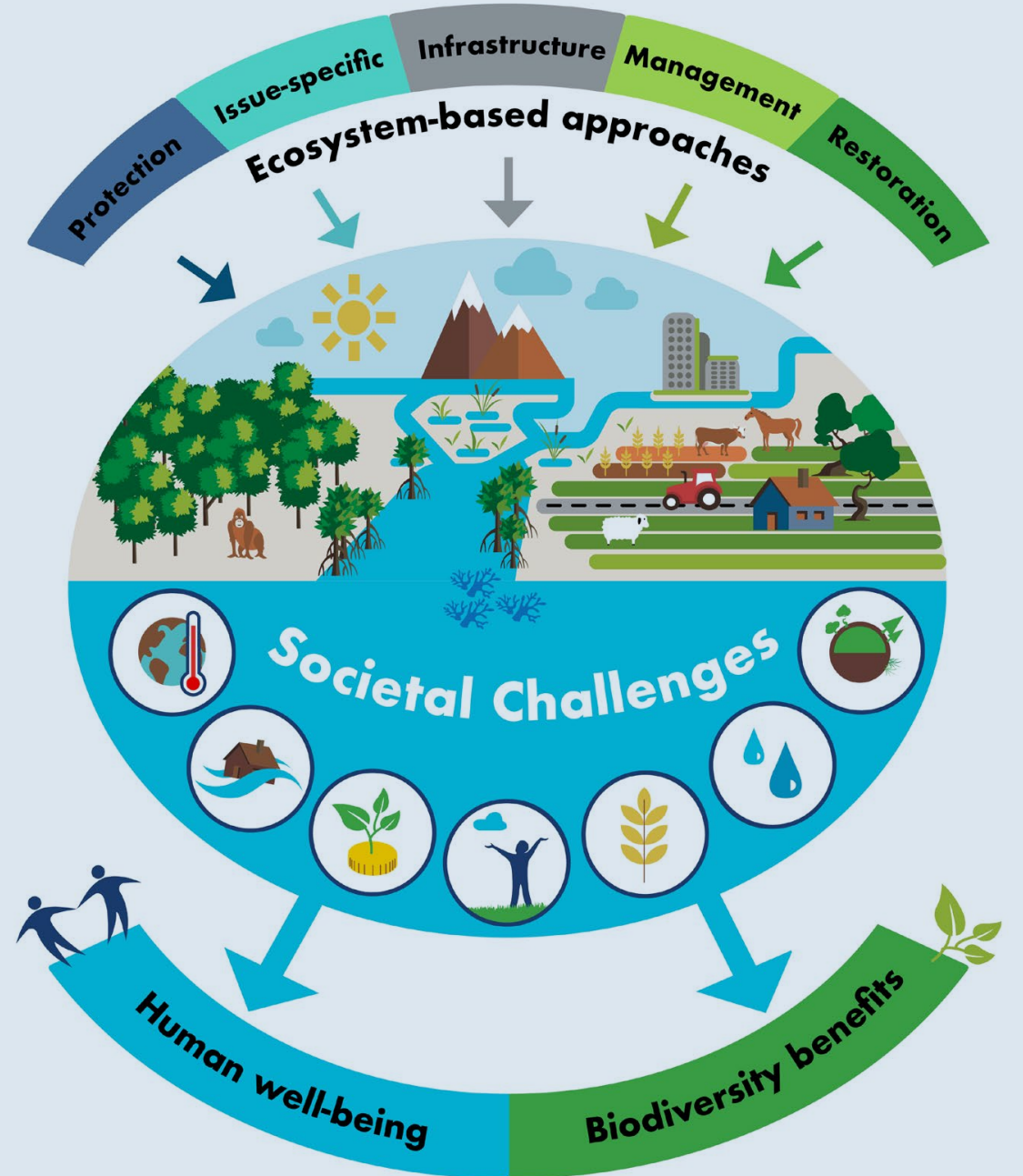




\section{About IUCN}

IUCN is a membership Union uniquely composed of both government and civil society organisations. It provides public, private and non-governmental organisations with the knowledge and tools that enable human progress, economic development and nature conservation to take place together.

Created in 1948, IUCN is now the world's largest and most diverse environmental network, harnessing the knowledge, resources and reach of more than 1,400 Member organisations and some 15,000 experts. It is a leading provider of conservation data, assessments and analysis. Its broad membership enables IUCN to fill the role of incubator and trusted repository of best practices, tools and international standards.

IUCN provides a neutral space in which diverse stakeholders including governments, NGOs, scientists, businesses, local communities, indigenous peoples organisations and others can work together to forge and implement solutions to environmental challenges and achieve sustainable development.

Working with many partners and supporters, IUCN implements a large and diverse portfolio of conservation projects worldwide. Combining the latest science with the traditional knowledge of local communities, these projects work to reverse habitat loss, restore ecosystems and improve people's well-being.

www.iucn.org

https://twitter.com/IUCN/ 
Guidance for using the

IUCN Global Standard for

Nature-based Solutions

A user-friendly framework for the verification,

design and scaling up of Nature-based Solutions

First edition 
The designation of geographical entities in this book, and the presentation of the material, do not imply the expression of any opinion whatsoever on the part of IUCN or other participating organisations concerning the legal status of any country, territory, or area, or of its authorities, or concerning the delimitation of its frontiers or boundaries.

The views expressed in this publication do not necessarily reflect those of IUCN or other participating organisations.

IUCN is pleased to acknowledge the support of its Framework Partners who provide core funding: Ministry for Foreign Affairs of Finland; Government of France and the French Development Agency (AFD); the Ministry of Environment, Republic of Korea; the Norwegian Agency for Development Cooperation (Norad); the Swedish International Development Cooperation Agency (Sida); the Swiss Agency for Development and Cooperation (SDC) and the United States Department of State.

This publication has been made possible in part by funding from Agence Française de Développement (AFD) Group, through the FranceIUCN Partnership for Nature and Development.

This Guidance accompanies the IUCN Global Standard for Nature-based Solutions (https://doi.org/10.2305/IUCN.CH.2020.08.en) and provides scientific basis and guidance for users.
Published by:
IUCN, Gland, Switzerland
Copyright:
(C) 2020 IUCN, International Union for Conservation of Nature and Natural Resources

Reproduction of this publication for educational or other non-commercial purposes is authorised without prior written permission from the copyright holder provided the source is fully acknowledged.

Reproduction of this publication for resale or other commercial purposes is prohibited without prior written permission of the copyright holder.

Citation:

IUCN (2020). Guidance for using the IUCN Global Standard for Nature-based Solutions. A user-friendly framework for the verification, design and scaling up of Nature-based Solutions. First edition. Gland, Switzerland: IUCN.

ISBN:

$$
\text { 978-2-8317-2061-6 }
$$

DOI: https://doi.org/10.2305/IUCN.CH.2020.09.en

Cover illustration:

Defining Nature-based Solutions (C) IUCN.

Layout by:

Imre Sebestyén jr / Unit Graphics

Available from:

IUCN, International Union for Conservation of Nature

Nature-based Solutions Group

Rue Mauverney 28

1196 Gland, Switzerland

NbSStandard@iucn.org

www.iucn.org/resources/publications 


\section{Table of contents}

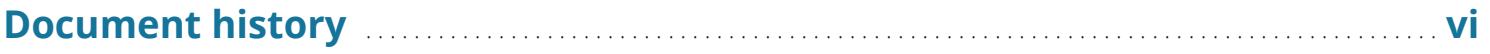

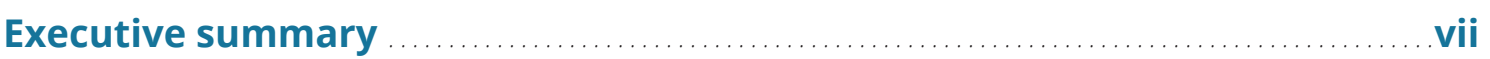

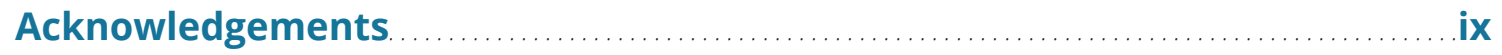

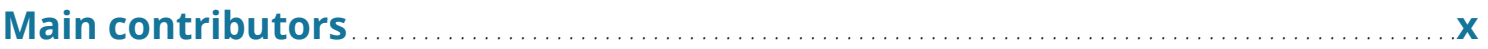

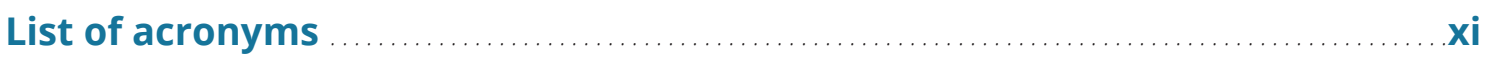

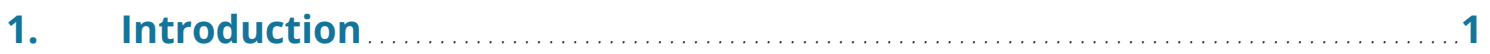

1.1 Development from initial concept to global approach ............................... 1

1.2 Nature-based Solutions as an umbrella framework to address societal challenges. 3

$1.3 \mathrm{NbS}$ in the context of the biodiversity crisis ...................................... 4

$1.4 \mathrm{NbS}$ in the context of the climate crisis............................................. 5

$1.5 \mathrm{NbS}$ in the context of the inclusivity crisis....................................... 7

2. Introducing the IUCN Global Standard for NbS ........................ 10

2.1 Need for a Global Standard....................................................... 10

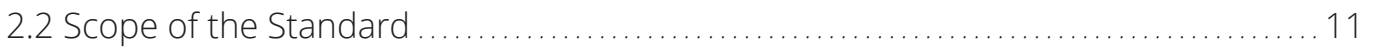

2.3 Use and target audience ....................................................... 11

3. Co-development process of the Global Standard ......................... 13

3.1 Foundation in the IUCN definitional framework for NbS ............................ 13

3.2 Overview of the co-development process ....................................... 14

3.3 International code for sustainability standards ................................... 14

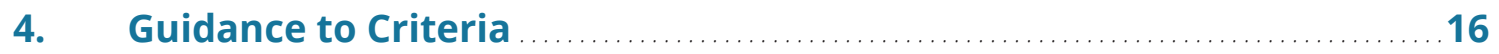

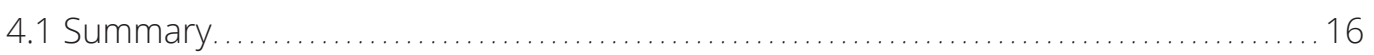

Criterion 1: NbS effectively address societal challenges ............................. 17

C- 1.1 The most pressing societal challenge(s) for rights-holders and beneficiaries are prioritised ........................................... 17

C-1.2 The societal challenge(s) addressed are clearly understood and documented ....................................................... 18

C-1.3 Human well-being outcomes arising from the NbS are identified, benchmarked and periodically assessed .................................. 18

Criterion 2: Design of NbS is informed by scale ....................................... 19

C-2.1 The design of the NbS recognises and responds to the interactions between the economy, society and ecosystems......................... 19

C-2.2 The design of the NbS is integrated with other complementary interventions and seeks synergies across sectors...................... 20

C-2.3 The design of the NbS incorporates risk identification and risk management beyond the intervention site 
Criterion 3: NbS result in a net gain to biodiversity and ecosystem integrity.

C-3.1 The NbS actions directly respond to evidence-based assessment of the current state of the ecosystem and prevailing drivers of degradation and loss

C-3.2 Clear and measurable biodiversity conservation outcomes are identified, benchmarked and periodically assessed.

C-3.3 Monitoring includes periodic assessments of unintended adverse consequences on nature arising from the $\mathrm{NbS}$

C-3.4 Opportunities to enhance ecosystem integrity and connectivity are identified and incorporated into the NbS strategy ...................... 24

Criterion 4: NbS are economically viable

C-4.1 The direct and indirect benefits and costs associated with the NbS, who pays and who benefits, are identified and documented

C-4.2 A cost-effectiveness study is provided to support the choice of NbS including the likely impact of any relevant regulations and subsidies ..... 27

C-4.3 The effectiveness of the NbS design is justified against available alternative solutions, taking into account any associated externalities ... 27

C-4.4 The NbS design considers a portfolio of resourcing options such as market-based, public sector, voluntary commitments and actions to support regulatory compliance.

Criterion 5: NbS are based on inclusive, transparent and empowering

governance processes.

C-5.1 A defined and fully agreed upon feedback and grievance resolution mechanism is available to all stakeholders before an NbS intervention is initiated

C-5.2 Participation is based on mutual respect and equality, regardless of gender, age or social status, and upholds the right of Indigenous Peoples to Free Prior and Informed Consent (FPIC)

C-5.3 Stakeholders who are directly and indirectly affected by the NbS have been identified and involved in all processes of the NbS intervention..... 30

C-5.4 Decision-making processes document and respond to the rights and interests of all participating and affected stakeholders

C-5.5 Where the scale of the NbS extends beyond jurisdictional boundaries, mechanisms are established to enable joint decision-making of the stakeholders in the affected jurisdictions

Criterion 6: NbS equitably balance trade-offs between achievement of their primary goal(s) and the continued provision of multiple benefits

C-6.1 The potential costs and benefits of associated trade-offs of the NbS intervention are explicitly acknowledged and inform safeguards and any appropriate corrective actions.

c-6.2 The rights, usage of and access to land and resources, along with the responsibilities of different stakeholders, are acknowledged and respected.

C-6.3 The established safeguards are periodically reviewed to ensure that mutually-agreed trade-off limits are respected and do not destabilise the entire NbS. 
Criterion 7: NbS are managed adaptively, based on evidence.

C-7.1 An NbS strategy is established and used as a basis for regular monitoring and evaluation of the intervention.

C-7.2 A monitoring and evaluation plan is developed and implemented throughout the intervention lifecycle

C-7.3 A framework for iterative learning that enables adaptive management is applied throughout the intervention lifecycle

Criterion 8: NbS are sustainable and mainstreamed within an appropriate jurisdictional context

C-8.1 The NbS design, implementation and lessons learnt are shared to trigger transformative change

C-8.2 The NbS informs and enhances facilitating policy and regulation frameworks to support its uptake and mainstreaming.

C-8.3 Where relevant, the NbS contributes to national and global targets for human well-being, climate change, biodiversity and human rights, including the United Nations Declaration on the Rights of Indigenous Peoples (UNDRIP)

5. How to use the Standard 


\section{Document history}

\section{Guidance for using the IUCN Global Standard for Nature-based Solutions}

\begin{tabular}{ll} 
Edition & 1.0 \\
\hline Source language & English. Official translations available. \\
\hline Responsible Unit & $\begin{array}{l}\text { Global Ecosystem Management Programme; IUCN Commission on Ecosystem } \\
\text { Management }\end{array}$ \\
\hline Developed by & IUCN Nature-based Solutions Group; IUCN Commission on Ecosystem \\
& Management \\
\hline Subject (Taxonomy) & Nature-based Solutions; Standard; Management Effectiveness; Assurance \\
\hline Date approved & February 2020 \\
\hline Approved by & IUCN Council \\
\hline Objective & To provide guidance and a global framework for the design, verification and \\
& SCaling up of Nature-based Solutions. The Standard includes globally consistent \\
& Criteria and Indicators, which are supported by the Principles for Nature-based \\
\hline Is part of & IUCN Nature-based Solutions Group \\
\hline Conforms to & IUCN Environmental and Social Management System (ESMS) \\
& ISEAL Standard-Setting Code of Good Practice \\
\hline Related Documents & IUCN Global Standard for Nature-based Solution Global Standard Background \\
& Document \\
\hline Distribution & IUCN COMPASS; IUCN Union Portal and IUCN website \\
\hline
\end{tabular}

\begin{tabular}{ccl}
\hline \multicolumn{2}{c}{ Document history } & Current first edition \\
\hline Version & Release date & Summary of changes \\
\hline 0.1 & 2018 Oct & Shared internally with IUCN Members, Commissions and Secretariat. \\
\hline 0.2 & $2018 \mathrm{Dec}$ & $\begin{array}{l}\text { Adjustments made from internal feedback and new version presented } \\
\text { in the first public consultation lasting one month. }\end{array}$ \\
\hline 0.3 & 2019 Jan & $\begin{array}{l}\text { Major adjustments made from external feedback and new version } \\
\text { presented in second public consultation lasting two months. }\end{array}$ \\
\hline 0.4 & $\begin{array}{l}\text { Adjustments made in line with feedback from second public } \\
\text { consultation then adopted by the IUCN Council which approved its } \\
\text { release during their 98th Meeting at IUCN World Headquarters, Gland, } \\
\text { Switzerland. }\end{array}$ \\
\hline 0.5 & \begin{tabular}{l} 
Revisions made based upon external peer review. \\
\hline
\end{tabular}
\end{tabular}




\section{Executive summary}

While the planetary crises we face today may seem overwhelming, society has also shown it can work together to solve major global threats. In the 1970s, the world successfully took action to halt and reverse the depletion of the ozone layer depletion. Failure to do so would have meant the "ozone hole" would now extend to the tropics, impacting people's health, ecosystem services and biodiversity. Changing the predicted trajectory of a crisis needs readily available, reliable and effective solutions. In this respect, Naturebased Solutions (NbS) offers the world a real chance to meaningfully address multiple sustainability crises, including climate change, food and water security, land degradation and biodiversity loss.

Working together, and guided by best practice experience we already have the capability to deliver durable and lasting solutions that can help us transition to a more just, equitable and sustainable way of inhabiting this planet. The IUCN's Global Standard on Nature-based Solutions is the result of over 800 experts combined insight and knowledge on how nature can be deployed as an effective ally in the fight against climate change and other major $21^{\text {st }}$ century challenges.

Protecting, sustainably managing and restoring nature can deliver substantive benefits for society. Yet, this is possible only if we have a shared vision of what such solutions entail, a consistent approach to how they are designed and implemented and importantly, a learning framework that helps us assess, adapt and improve so that can make future interventions even more effective.

The Standard is facilitative, with the aim not only to guide the user in design and implementation but also to continuously improve intervention's resilience and help prepare for the unanticipated. It is based on the premise that a solution inherently needs to be responsive to a context and the outcome may vary each time. The Standard offers a consistent approach that is capable of dealing with and adapting to a wide variety of individual circumstances and contexts in order to deliver results that are environmentally sound, socially just and economically feasible without leaving no one behind.

The 8 Criteria and 28 Indicators support users in 1) assessing the extent to which a proposed solution qualifies as an NbS and identifying what actions can be taken to further strengthen the robustness of the intervention, using a scale of strong, adequate, partial and insufficient; 2) enabling purposeful design of a solution to adhere to the Criteria and Indicators, while building in adaptive management mechanisms to maintain the relevance and robustness of the solution through its lifespan.

The Standard is developed for a wide range of users, particularly those from outside the traditional conservation sector. It is accompanied with an accessible and easy-touse self-verification toolkit while revisions and improvements to the Standard is overseen by an International Standards Committee. Aligned with this, IUCN will support the establishment of a global community of users who can collectively learn and help evolve the Standard. 
- Criterion 1 addresses the importance of clearly identifying the societal challenge to which the solution will respond. Sometimes, it can extend to more than one key priority. The intent of this criterion is to ensure that there is deliberate and purposeful design in terms of meeting human wellbeing needs.

- Criterion 2 guides the design of an NbS in terms of key spatial considerations, what is often referred to as a landscape approach.

- Criteria 3, 4 and 5 correspond of the three key dimensions of sustainable development - environment sustainability, social equity and economic viability.

- Criterion 6 addresses the practicalities of navigating and balancing the trade-offs that are inherent in most natural resource management decision-making including reconciling long-term and short term needs. It highlights that that trade-off decisions are made with full transparency, disclosure and consensus amongst all impacted stakeholders.
- Criterion 7 promotes an adaptive management approach, whereby learning and action complement each other for a standard user to evolve and improve the solution.

- Criterion 8 promotes mainstreaming within national policy, which is critical to underpin the long term sustainability and durability of an NbS. Through alignment with policies, national and global commitments as well as sharing lessons to inform other solutions, this could be achieved.

This Standard has been developed while the world struggles to contain and arrest the spread of the COVID-19. Attention is currently turning to the post-pandemic economic recovery. As World leaders contemplate how to build back better, Nature-based Solutions offer a unique opportunity to invest in societal well-being and vibrant economies without having to return to the mistakes of the past. 


\section{Acknowledgements}

Furthermore, this Standard publication is the collective effort of many committed individuals, groups and networks. We would like to thank everyone who contributed to the preparation of this report. Technical contributions were provided by a wide range of experts from the IUCN Secretariat and Commission on Ecosystem Management (CEM). In particular, we recognise the contributions of the following individuals - Ali Raza Rizvi, Madhav Karki, Barbara Nakangu, Fabrice Renaud, Lucilla Boito, Stephen N. Edwards, Bernal Herrera, Willem Ferwerda, Jonathan Davies, John Waugh, Mike Jones, Birguy Lamizana, Jenny Springer, Kelvin Passfield, Charles Lor, Wendy Atieno, Rebecca Welling, Anita Tzec, Edmund Barrow, Mirjam Kuzee, Leigh Ann Hurt and Jonathan Hughes. We thank those who provided comments on previous versions of the document including the hundreds of participants from 100 countries who took part in the two rounds of public consultations enriching the quality and scope of the Standard. We especially thank group contributions from the IUCN French National Committee, Conservation International, IUCN World Commission on Protected Areas, French Ministry for Agriculture, IUCN Environment Law Centre, Natural Capital Coalition and the European Commission.

This Standard was developed with technical knowledge and guidance on standard setting from Assurance Services International (ASI). We also convey our gratitude to Marnie Bammert of ASI for carrying out the peer review for this publication.

We also thank our external peer reviewer Chantal Van Ham for feedback that has greatly enhanced the quality and scope of this publication.

We thank Caroline Snow for editing, Imre Sebestyén (Unit Graphics) for the layout, and Efrat Bronstein for the graphics. The IUCN Global Communications Unit and NbS Communication Groups are thanked for their support on communications and graphics.

The report was made possible through the contribution of the Agence Française de Développement (AFD), through the France-IUCN Partnership for Nature and Development.

Any errors remain the responsibility of the lead authors. 


\section{Main contributors}

This Standard was developed in a consultative manner, drawing on scientific, editing and technical expertise of numerous people from within IUCN and the Commission on Ecosystem Management. The authors are listed in alphabetical order, below.

Andrade, Angela; Cohen-Shacham, Emmanuelle; Dalton, James; Edwards, Stephen; Hessenberger, Daisy; Maginnis, Stewart; Maynard, Simone; McElwee, Pam; Murti, Radhika; Nelson, Cara; Ruiz, Verónica; Siikamäki, Juha; Vasseur, Liette. 


\section{List of acronyms}

\begin{tabular}{|c|c|}
\hline AFD & Agence Française de Développement \\
\hline ASI & Assurance Services International \\
\hline CBD & Convention on Biological Diversity \\
\hline CEM & Commission on Ecosystem Management \\
\hline COMPASS & Community of Protected Areas Sustainability Standards \\
\hline CSR & Corporate Social Responsibility \\
\hline EbA & Ecosystem-based Adaptation \\
\hline ECO-DRR & Ecosystem-based Disaster Risk Reduction \\
\hline ESMS & Environmental and Social Management System \\
\hline FAQs & Frequently Asked Questions \\
\hline FLR & Forest Landscape Restoration \\
\hline FPIC & Free Prior and Informed Consent \\
\hline IGO & Intergovernmental Organisation \\
\hline InVEST & Integrated Valuation of Ecosystem Services and Trade-offs \\
\hline IPBES & Intergovernmental Science-Policy Platform on Biodiversity and Ecosystem Services \\
\hline IPCC & Intergovernmental Panel on Climate Change \\
\hline ISBN & International Standard Book Number \\
\hline ISEAL & International Social and Environmental Accreditation and Labeling \\
\hline IUCN & International Union for Conservation of Nature and Natural Resources \\
\hline LDN & Land Degradation Neutrality \\
\hline$M \& E$ & Monitoring and Evaluation \\
\hline NbS & Nature-based Solutions \\
\hline NBSAPS & National Biodiversity Strategies and Action Plans \\
\hline NDCs & Nationally Determined Contributions \\
\hline NRGF & Natural Resource Governance Framework \\
\hline OECD & Organisation for Economic Co-operation and Development \\
\hline RLTS & Red List of Threatened Species ${ }^{\mathrm{TM}}$ \\
\hline SDGs & Sustainable Development Goals \\
\hline SFDRR & Sendai Framework for Disaster Risk Reduction \\
\hline UN & United Nations \\
\hline UNCCD & United Nations Convention to Combat Desertification \\
\hline UNDRIP & United Nations Declaration on the Rights of Indigenous Peoples \\
\hline UNFCCC & United Nations Framework Convention on Climate Change \\
\hline USD & United States Dollar \\
\hline WHO & World Health Organization \\
\hline
\end{tabular}





\title{
1. Introduction
}

\author{
"Nature-based solutions are actions to protect, sustainably \\ manage and restore natural and modified ecosystems \\ in ways that address societal challenges effectively \\ and adaptively, to provide both human well-being and \\ biodiversity benefits."
}

In 2020, there is a growing acknowledgement of the role that nature plays in our society. However for most of the 20th century, decision makers treated the conservation of nature as peripheral to national and global agendas. At best, it was considered a worthy interest, at worst, an obstacle to development. However, a growing scientific consensus indicates that such views were deeply flawed and that "nature is essential for human existence and good quality of life". Failure to recognise this fact not only results in a model of economic growth that undermines future economies and significantly contributes to the loss of biodiversity, it also misses the opportunity to effectively deploy nature in helping resolve major societal challenges such as climate change, human health, food security, disaster risk reduction, etc. Doing so offers the possibility of mainstreaming conservation approaches into other sectors including agriculture, infrastructure, water, health, urban planning and rural development.

Most ecosystems are capable of providing multiple benefits to diverse beneficiaries, while simultaneously supporting the protection of the natural resource base. This fact means that ecosystem management is often the most promising route by which societal challenges can be addressed, securing the role of biodiversity in 'business as usual' within other sectors.

\subsection{Development from initial concept to global approach}

Several conservation approaches developed from the 1990s onwards are based on the purposeful management of ecosystems, including Forest Landscape Restoration, Sustainable Land Management, Integrated Water Resource Management, Integrated Landscape Management, Integrated Coastal Zone Management, Ecological Restoration and the IUCN Sustainable Use Initiative. Such operational approaches have been able to deliver conservation outcomes that provide tangible benefits to society including jobs, improved land productivity, erosion control and carbon sequestration. Behind each of these terms there is a foundation of research and a community of practice. 
Whether standalone or combined with other forms of solutions (e.g. technology and engineering), conservation approaches (e.g. protection, restoration and sustainable management) can also be implemented with human well-being as a primary objective. This evolution in thinking about conservation has led to the recognition of two broad domains of conservation interventions, those whose primary aim is to safeguard biodiversity for its own inherent values, and those whose primary purpose is to safeguard society - what is now called 'Nature-based Solutions' (NbS). Both domains adhere to the same set of conservation norms and principles, and while there are occasions where they overlap operationally, the starting points are often quite distinct.

Additionally, this paradigm shift also led to the recognition that various countries have a history of managing nature in ways that derive benefits for society, even if they did not use the term NbS to describe these interventions at the time. While all these conservation solutions have been useful, separately they are not enough to address the current challenges. Communities of practice and research have long been siloed, often competing for the same resources despite the similar principles, goals and applications of conservation approaches.

In bringing greater attention to the potential of conservation actions for the sustainable use of nature for people's needs, the NbS concept was developed as part of an ongoing paradigm shift that began in the 1980s, in which people are viewed as proactively protecting, managing or restoring ecosystems in addressing a range of major societal challenges, rather than as passive beneficiaries of nature (Cohen-Shacham et al., 2019). NbS acknowledges that biodiversity conservation and the protection of ecosystem services are essential for the various aspects of human well-being, including human health. While dealing with complex systems, NbS go beyond traditional mechanistic approaches to solving problems (Rogers et al., 2013). The NbS concept has its foundation in the Ecosystem

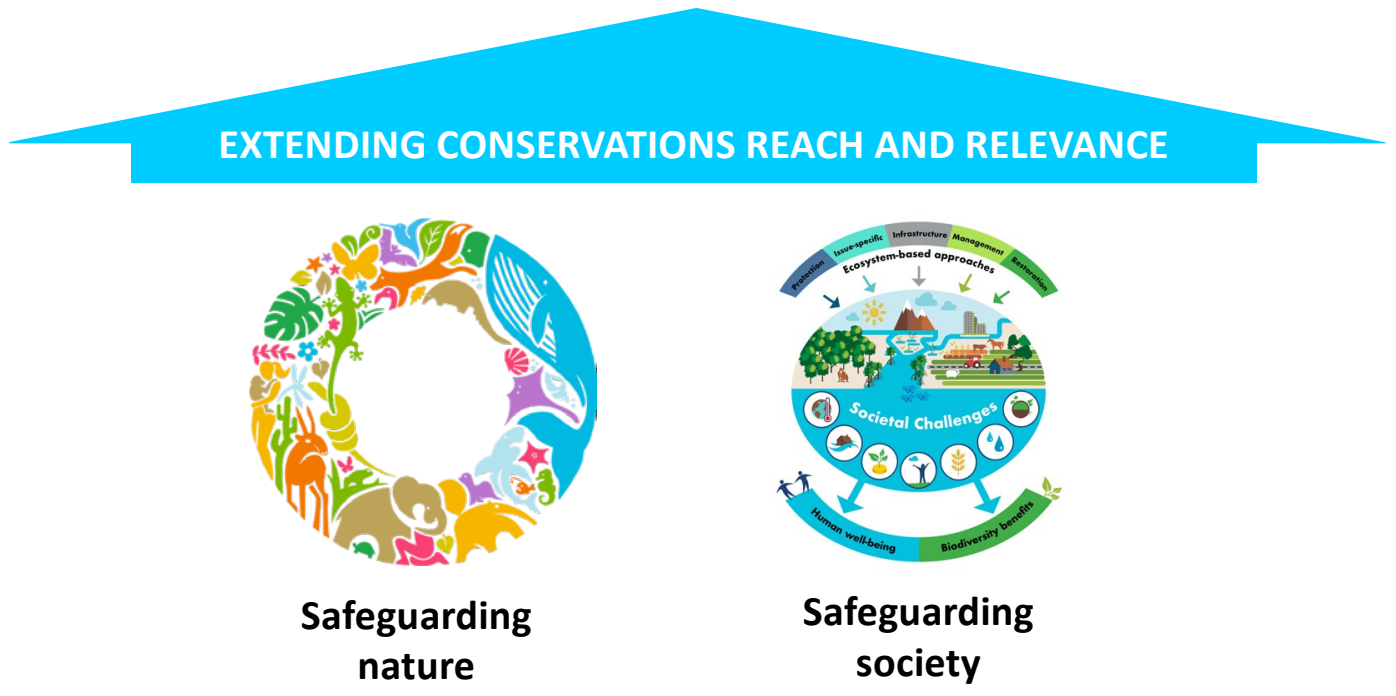

\section{Conservation norms and science}

Figure 1: Conservation interventions adhere to conservation norms and principles. There is a domain of conservation which focuses on safeguarding biodiversity for its irreplaceable value. Another domain focuses on safeguarding society, all the while following those conservation norms and principles. The latter are known as Nature-based Solutions. While there is some overlap, not all conservation interventions are Nature-based Solutions. (C) IUCN) 
Approach (CBD, 2004; Holling, 1973; Holling, 1978; Holling, 1986; Waltner-Toews \& Kay, 2005), which underpins the Convention on Biological Diversity (CBD) (Smith \& Maltby, 2003).

Now, in 2020, the conservation community and associated sectors find themselves at the centre of a global movement acknowledging, promoting and seeking out NbS. Over the past ten years since IUCN coined the term, the approach has gathered momentum with NbS incorporated into policy, calls for proposals, economic plans, research questions and national strategies for biodiversity and climate change. With this growing appreciation and investment, came a real demand to define the term and enable resilient cost-effective interventions.

\subsection{Nature-based Solutions as an umbrella framework to address societal challenges}

Nature-based Solutions are considered an umbrella framework for ecosystem-based approaches (e.g. the previously mentioned concepts) that are used to address major societal challenges (Cohen-Shacham et al., 2016) (See Figure 2). The term 'Nature-based Solutions' was first promoted by IUCN in 2009, and later put forward as an umbrella term to highlight the commonality of various conservation approaches, including those previously mentioned. Additional concepts falling under the NbS umbrella include: Natural Solutions (the role of protected areas in combating climate change); Ecosystem-based Adaptation (EbA);

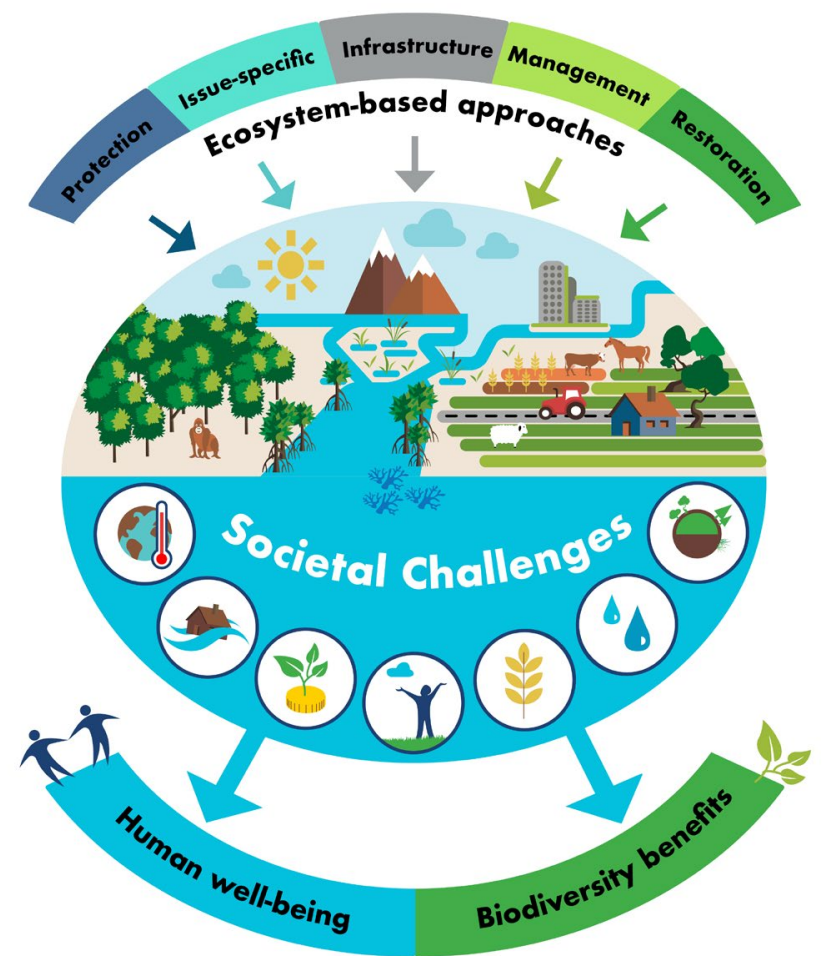

Figure 2: Defining Nature-based Solutions. (৫ IUCN) 


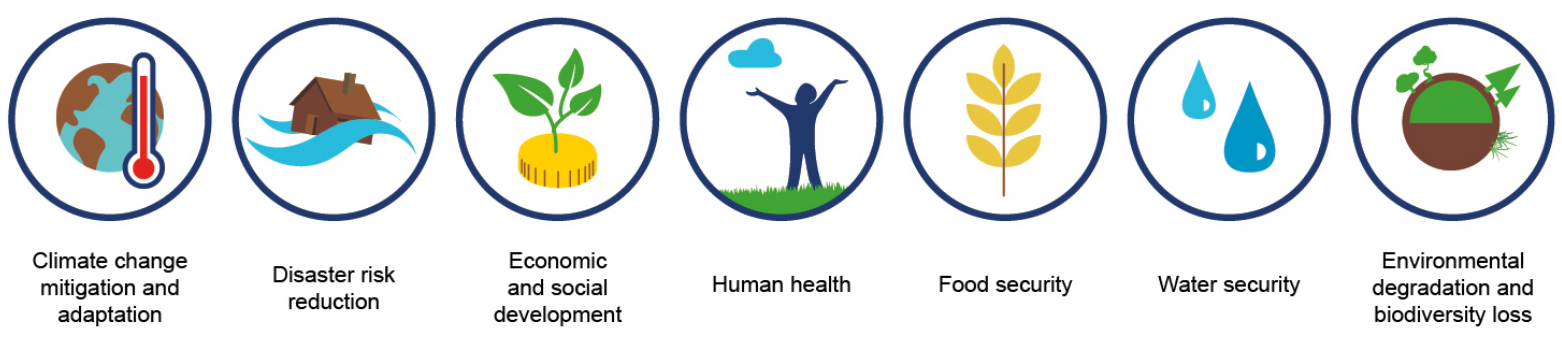

Figure 3: Major societal challenges addressed by NbS. (৫) IUCN)

Ecosystem-based Disaster Risk Reduction (EcoDRR); Green Infrastructure (for economic growth and investments, in the urban context); Natural Infrastructure (for a sustainable Integrated Water Resource Management); and Holistic or Regenerative Landscape management.

These approaches will continue to be highly relevant to implementing NbS. They serve as specific operational approaches that can be deployed in executing the solution to a societal challenge. A combination of different approaches may also be needed within an intervention, and complementarities may be sought to improve efficiencies and reduce redundancy.

For an intervention to be considered an NbS, it must address one or multiple societal challenges, in an integrated manner. IUCN currently refers to seven societal challenges - climate change adaptation and mitigation, disaster risk reduction, reversing ecosystem degradation and biodiversity loss, human health, socioeconomic development, food security and water security (see Figure 3). If the societal challenge of ecosystem degradation is being addressed, at least one other societal challenge must be part of the design of the solution, to differentiate the NbS intervention from a pure conservation action.

While still evolving, solutions to these societal challenges are currently being implemented. They are underpinned with scientific knowledge and good practices that can demonstrate the value of NbS as a response. As the NbS concept is rolled out for implementation, other societal challenges may be added to the list.

\section{$1.3 \mathrm{NbS}$ in the context of the biodiversity crisis}

The 2019 Intergovernmental Science-Policy Platform on Biodiversity and Ecosystem Services (IPBES) "Global Assessment Report on Biodiversity and Ecosystem Services" (IPBES, 2019a) paints a very bleak picture for biodiversity, with one million species of plants and animals categorised as threatened or extinct globally, and declining ecosystem services due to overexploitation and misuse. The rapid and dramatic loss of biodiversity erodes the capacity of ecosystems to deliver the services that are essential for human well-being. Current rates of loss of invertebrates and soil microorganisms, through intensive land use practices, are undermining the foundation of human livelihood. Nature's contributions to people play a vital role in support of human existence and quality of life, but are often distributed unequally across space and time (IPBES, 2019a). IPBES reports that negative effects are disproportionate and will especially affect marginalised and Indigenous peoples and rural communities, who directly depend on nature's benefits for their survival. IPBES also highlights that climate change is a direct driver 
that exacerbates the impact of other drivers on nature and human well-being (IPBES, 2019b); and it is becoming the main driver of biodiversity loss in the coming years, affecting species, habitats and ecosystems.

For a solution to be considered an $\mathrm{NbS}$, it is imperative for it to provide simultaneous benefits to biodiversity and human well-being. Therefore, each solution must either maintain or enhance biodiversity, without which an action cannot be classified as NbS. This is important for ensuring that the integrity and stability of the natural system is not undermined by practices that favour short-term gains, but compromise the ability of the system to provide for future generations. Therefore, as opposed to biodiversity conservation merely being an output of an NbS, it is a critical input that, if maintained or enhanced, validates a solution as an NbS (IUCN, 2016).

\subsection{NbS in the context of the climate crisis}

On the other hand, the Intergovernmental Panel on Climate Change (IPCC) "Global Warming of $1.5^{\circ} \mathrm{C}^{\prime \prime}$ report provides enough evidence that human activities have caused approximately $1.0^{\circ} \mathrm{C}$ of global warming above pre-industrial levels (IPCC, 2018). Global warming is likely to reach $1.5^{\circ} \mathrm{C}$ between 2030 and 2052, putting us in a very dangerous situation, if we do not achieve the target set by the Paris Agreement - to keep the global average temperature increase to "well below $2^{\circ} \mathrm{C}$ above pre-industrial levels" (see Box 1 for examples of main findings). As humanity faces a catastrophic climate tipping point, there is an urgent need for innovative approaches to complement nature conservation; as well as immediate transformational changes to reduce carbon emissions to limit global warming to $1.5^{\circ} \mathrm{C}$ (IPCC, 2018; Rockström et al., 2009; Steffen et al., 2015).

The NbS concept provides an integrated approach that can help nations meet crucial international agreements and targets, such as the United Nations Sustainable Development Goals (SDGs), the Paris Agreement, the Aichi Targets, the Bonn Challenge and the Sendai Framework for Disaster Risk Reduction. NbS was endorsed at the 2019 United Nations Climate Summit and highlighted in the IPCC's Special Report "Global Warming of $1.5^{\circ} \mathrm{C}^{\prime}$ (de Coninck et al., 2018), the IPCC Climate Change and Land Report (IPCC, 2019) and the IPBES Global Biodiversity Assessment Report (IPBES, 2019a) as having the potential to address major global societal and ecological challenges.

As the climate emergency deepens, both people and nature will be increasingly vulnerable to weather and climate extremes, and while the impact will be region-specific, overall people and nature will likely experience more frequent and intense negative impacts. The IPCC Climate Change and Land Report, reports that greater frequency of extreme weather events and changing precipitation patterns have already affected food security on land (IPCC, 2019), while the IPCC Special Report on Ocean and Cryosphere in a Changing Climate shows how the shrinking of the cryosphere since the mid-20th century has also predominantly negatively impacted food and water security (IPCC, 2019). The link between people and nature is clear in the face of climate change. For example, climate change exacerbates land degradation, which also negatively affects people living in degraded areas (IPCC, 2019). Similarly, climate change poses a 


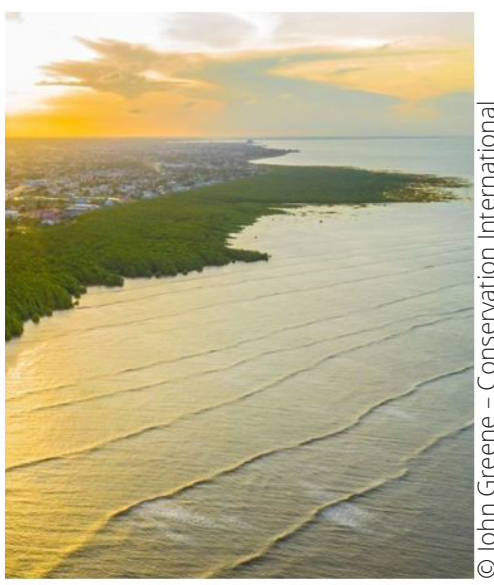

Nature-based Solutions

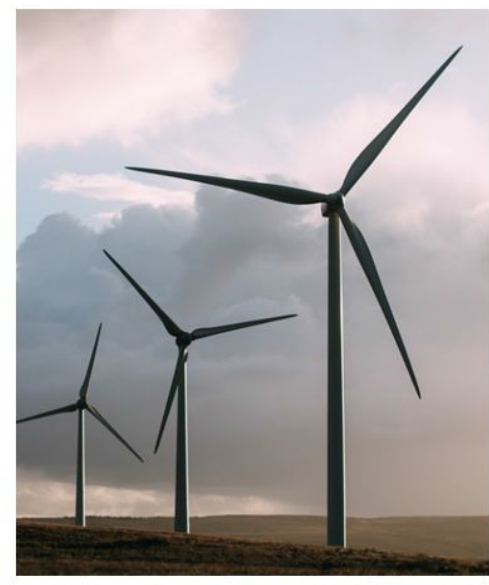

Nature-derived Solutions

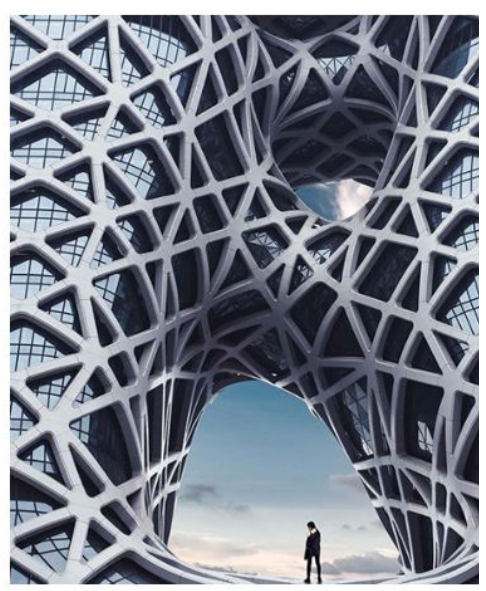

Nature-inspired Solutions

Figure 4: While Nature-based Solutions use the power of functioning ecosystems as infrastructure to provide natural services to benefit society and the environment, nature-derived and natureinspired solutions, which are also needed to achieve a low-carbon and sustainable future, are different. Nature-derived solutions include wind, wave and solar energy, all of which are derived from nature and help fulfil low carbon energy needs through production methods deriving from natural sources. Although these energy sources come from the natural world, they are not directly based on functioning ecosystems. Nature-inspired solutions include innovative design and production of materials, structures and systems that are modelled on biological processes and are nature-inspired. For example, biomimicry is a practice that learns from and mimics the strategies found in nature to solve challenges. These designs take inspiration from nature - such as specially made sticky gloves that mimic the wall-climbing adaptations of geckos. They are not based on functioning ecosystems.

high risk to coastal ecosystems such as seagrass meadows and kelp forests, where loss of habitat will lead to loss of species and diversity and degradation of ecosystem functions (IPCC, 2019) on which people depend.

This interlinkage between people and nature offers opportunity, in the shape of NbS, to address underlying societal challenges (such as food security) while contributing to climate adaptation and mitigation. The 2019 IPCC Report, Climate Change and Land Report, highlights sustainable land management, including ecosystem conservation as it "can contribute to reducing the negative impacts of multiple stressors, including climate change, on ecosystems and societies" (IPCC, 2019). Examples of ecosystem-based adaptation that can remove greenhouse gases and contribute to mitigation and adaptation include restoring natural ecosystems and improving biodiversity conservation (IPCC, 2019). To limit warming to $1.5^{\circ} \mathrm{C}$ or well below $2^{\circ} \mathrm{C}$, society requires a combination of nature-inspired, nature-derived and nature-based solutions, along with significant reductions in fossil fuel emissions (Figure 4).

The health of ecosystems on which we and all other species depend is deteriorating more rapidly than ever, threatening the health of the planet and people. We are eroding the very foundations of our economies, livelihoods, food security, health and quality of life worldwide. The report also recognises that climate change is becoming one of the main drivers of biodiversity loss after 2020. This makes necessary that both biodiversity and climate change crises are analysed and addressed simultaneously through NbS, which also play a key role in achieving the transformational change required to achieve the global sustainability goals. 
NbS may be part of the mitigation hierarchy approach, which is a decision-making framework involving a sequence of steps starting with the avoidance ofimpacts, followed bythe minimisation of inevitable impacts, on-site restoration and finally, where feasible and necessary, biodiversity offsets. The correct application of the mitigation hierarchy can potentially limit the adverse impacts of development projects on biodiversity and may deliver additional biodiversity conservation benefits. However, an improper application, especially if implemented with unresolved but fundamental knowledge gaps, and poor corporate, financial and regulatory policy, may undermine established approaches to managing biodiversity risk.

\section{Box 1: Examples of main findings coming from major global reports (IPBES, 2019b; IPCC, 2018, PWC \& WWF, 2020):}

- Natural ecosystems have declined by $47 \%$ on average, relative to their earliest estimated states.

- Approximately $25 \%$ of species are already threatened with extinction in most animal and plant groups studied, suggesting that around 1 million species already face extinction, many within decades, unless action is taken to reduce the intensity of drivers of biodiversity loss.

- Biotic integrity - the abundance of naturally present species - has declined by $23 \%$ on average in terrestrial communities.

- The global biomass of wild mammals has fallen by $82 \%$. Indicators of vertebrate abundance have declined rapidly since 1970.

- $\quad 72 \%$ of indicators developed by Indigenous peoples and local communities show ongoing deterioration of elements of nature important to them.

- Most international societal and environmental goals cannot be met by current trajectories, and goals for 2030 and beyond may only be achieved through transformative changes across economic, social, political and technological factors.

- The most impactful direct drivers of change are changes in land and sea use; direct exploitation of organisms; climate change; pollution; and invasion of alien species.

- Human activities are estimated to have caused approximately $1.0^{\circ} \mathrm{C}$ of global warming above pre-industrial levels, with a likely range of $0.8^{\circ} \mathrm{C}$ to $1.2^{\circ} \mathrm{C}$.

- Global warming is likely to reach $1.5^{\circ} \mathrm{C}$ between 2030 and 2052 if it continues to increase at the current rate.

- Climate change creates additional stresses on land, exacerbating existing risks to livelihoods, biodiversity, human and ecosystem health, infrastructure and food systems.

- The costs of inaction on biodiversity loss are an estimated US\$ 4-20 trillion per year in ecosystem services from 1997 to 2011, owing to land-cover change and an estimated US\$ 6-11 trillion per year from land degradation.

\section{5 $\mathrm{NbS}$ in the context of the inclusivity crisis}

Interventions can only be successful with the inclusion of different knowledge systems and participation of affected groups, including
Indigenous people, local communities, women and youth. Regretfully this has not always been the case in the history of conservation actions, 
leading to a crisis of inclusivity alongside that of biodiversity and climate. NbS, because of their intersectional approach and the integrated manner in which they are applied, strongly benefit from bringing together all the various actors who may be directly or indirectly affected by the intervention, and include different types of knowledge systems and worldviews, such as those embedded in traditional ecological or Indigenous knowledge. For example, existing adaptation efforts in Polar Regions have benefited from the inclusion of Indigenous and local knowledge, such as that around trends and patterns of landscape/seascape change and health and populations of species (IPCC, 2019).

When considering the diversity of stakeholders in an NbS, it is critical to ensure active, inclusive and transparent participation, regardless of gender, age or social, economic or cultural background, and that decision-making in the NbS is transparent and equitable to safeguard people and culture. This is also essential to achieve the full potential benefits that an NbS can offer. Aspects that may influence and marginalise potential contributors to the collaborative processes used in NbS are cultural bias and elitist perspectives. Where stakeholder groups are equally important (e.g. rural and non-rural), such perceptions may lead to certain groups disregarding inputs from lower social classes or less educated members of society. Such situations can be limited and improved with facilitated constructive discussions and collaborations, processes that are key for implementing an NbS.

Indigenous peoples and local communities in particular hold and manage a significant part of the Earth's most biodiverse regions and play a vital role in conserving lands, seas and resources and their sustainable uses. They cultivate strong economic, cultural and spiritual relationships with their natural environments and have developed and often maintain traditional management practices and knowledge that contribute to biodiversity conservation and to the sustainable use of natural resources. For example, Indigenous Protected Areas, where traditional and sustainable uses of natural resources are respected, may represent an NbS that will benefit the survival of traditional knowledge and Indigenous communities. Similarly, rural land stewards, whether they be Indigenous or not, will have a more informed understanding than anyone else of the land they are managing.

Regardless of which stakeholder group is being engaged, there will always be a gender component whereby taking a gender responsive approach is a prerequisite for sustainable development. Involving women in NbS supports their implementation, as nature conservation and women's rights are inextricably linked. For example, environmental degradation is exacerbating violence against women, and taking a gender responsive approach to NbS can contribute both to the biodiversity and inclusivity crisis. Meanwhile numerous studies show that engaging women brings their unique knowledge to natural resource management. More genderbalanced leadership and women's equal participation in NbS results in more benefits for nature and, therefore, people.

Alongside the rise in impact and visibility of NbS in the last few years, youth have risen and made their role in conservation actions visible. Children and youth have a tangible contribution to make in solving critical societal challenges, emphasising the intergenerational equity that is required. Interventions that place a greater impact on short-term costs and benefits and fail to take into account longer-term costs, benefits and trade-offs are likely to be less resilient; involving youth in an intervention bestows an appreciation and understanding of intergenerational and, therefore, long-term impact, building resilience. Specifically when considering solutions to climate 
change, there is a lack of sufficient attention to the protection, inclusion and empowerment of youth with only eight of the 160 Nationally Determined Contributions (NDCs) including a direct reference to intergenerational injustice or future generations. Incorporating youth into the global movement supporting NbS both supports the sustainability of these interventions and addresses the potential benefits that educating youth brings to climate adaptation and mitigation. 


\section{Introducing the IUCN Global Standard for NbS}

\subsection{Need for a Global Standard}

With the increasing uptake of the NbS concept, there is a corresponding need to ensure that the concept is clearly understood, communicated and implemented in a manner that operationalises the eight underlying NbS Principles (IUCN, 2016). Standards of practice are a common method to achieve these goals as fields of practice develop. Moreover, it is important to clarify that while NbS complement nature conservation, their main objective is to address one or several societal challenges, while benefiting both biodiversity and human well-being. This differentiation is very important in ensuring that 1) conservation continues to deliver targeted actions to halt or reverse biodiversity loss, where needed, and 2) conservation actions are deliberately and informatively designed as responses to one or more societal challenges, requiring innovative partnerships and the integration of multiple approaches (such as complementarities with grey infrastructure, i.e. hybrid solutions).

Consequently, with a rapidly growing global interest in NbS, there is a need to ensure that a relevant and robust Standard informs the design and implementation of every NbS, and that such a standard will ensure that:
- there is a common understanding and interpretation of the NbS concept across different sectors, users and geographies;

- deployment of NbS is carried out in a systematic coordinated manner with other affected sectors, users and geographies;

- there is quality control in the design and execution of interventions through standardised processes that enable accountability;

- existing relevant tools, approaches and methods are fully taken advantage of, in designing and executing a solution;

- risks related to the further unsustainable use of nature are minimised and actions that may be highly detrimental to biodiversity and society are not categorised as NbS; and

- multiple sectors engage in implementing and addressing societal challenges.

In this way, NbS will contribute to transformational change, by becoming an integral element in the planning and implementation of society's responses to such challenges. 


\subsection{Scope of the Standard}

The IUCN Global Standard for NbS is an overarching definitive concept that can be executed through existing ecosystem approaches and tools, especially those that are operational and participatory. Therefore, the interpretation and implementation of the NbS concept is very context specific, depending on a variety of factors influencing the societal challenges being addressed, including the ecosystem types in the landscape/seascape in which the NbS is being implemented, the socioeconomic-cultural system and the composition and relations of stakeholder groups. This being the case, it is only feasible to standardise the processes for the design and execution of NbS rather than expecting a prescribed standard outcome each time a solution is implemented. Hence, the Global Standard for NbS is a facilitative
Standard that is aimed at enabling wider uptake, and improving design and execution, rather than regulating processes to achieve specific results or outcomes. The NbS Standard implementation process is also envisaged to provide evidence on how to address the evolving environmental and social changes through time and contribute to improving policy development.

The Standard will enable practitioners to standardise the design and implementation of NbS, by: 1) Setting a common basis of understanding for what an NbS is and is not; 2) Contributing to transformational changes, by improving NbS practice, and supporting the clarification and development of NbS-related policy.

\subsection{Use and target audience}

The Standard is intended for use by anyone working on the verification, design and scaling up of NbS. Users may include project managers in the public and private sector, landscape planners, development practitioners and conservationists, governments or representatives of the finance sector (donors and investors), policy makers and planners. At this stage, the Standard has two functions - to help guide the design of an NbS and provide a means to verify that the design meets the requirements of the NbS Standard.

- Design - the eight process-oriented Criteria respond to the most important design (and future execution) aspects for an intervention to qualify as an NbS. As such, the Criteria respond to a project management cycle, while highlighting the critical aspects of thinking beyond the project's geographical space and timelines and the need to practise adaptive management, since NbS design is based on a theory of change that will inevitably contain assumptions to be tested during implementation.

- Verification - when a solution is designed, the Standard can be used to ascertain whether it qualifies as an NbS or not. This function of the Standard is important for users such as funders and investors who may call for the submission of solutions. Additionally, past and ongoing NbS that predate the development of this Standard can also be evaluated against the Standard's Criteria, if the intention is for the intervention to be recognised as an NbS. 
- Scaling up - some examples of NbS may be found to be in line with a good proportion of the eight Criteria of the Standard, lacking in just a few. Many of these will likely be pilots or interventions that currently have a limited timeline or represent a standalone approach. The Standard can be used to both identify strong candidates for scaling up and identify gaps to work on to transform the intervention into a strong $\mathrm{NbS}$.
Furthermore, the Standard is currently designed for use as a self-assessment or first-party verification process. Aligned with the approach of the Standard on facilitating wider uptake of the NbS concept, currently self-assessment provides a robust yet flexible approach to being able to design and execute such solutions. It provides space for iterative learning and reflection rather than a rigid normative certification process, given the world is still understanding and interpreting NbS for different needs and contexts. 


\section{Co-development process of the Global Standard}

\subsection{Foundation in the IUCN definitional framework for NbS}

The main objective of NbS is to support the achievement of society's development goals and safeguard human well-being in ways that reflect cultural and societal values and enhance the resilience of ecosystems, their capacity for renewal and the provision of services (IUCN, 2016). Alongside the IUCN definitional framework for NbS launched in 2016, in which NbS were defined as "actions to protect, sustainably manage, and restore natural or modified ecosystems, that address societal challenges effectively and adaptively, simultaneously providing human well-being and biodiversity benefits" (IUCN, 2016), eight Principles were adopted by IUCN's members (IUCN, 2016) as shown in Figure 5. Since then, a strong published literature base has also rapidly emerged which further substantiates this role of NbS in conservation.

A recent analysis of the NbS Principles (see above) found that the NbS framework goes beyond other similar approaches (e.g. Forest Landscape Restoration (FLR); EbA; Ecological restoration; Ecosystem Approach) through three of its Principles (2, 6 and 8, i.e., on

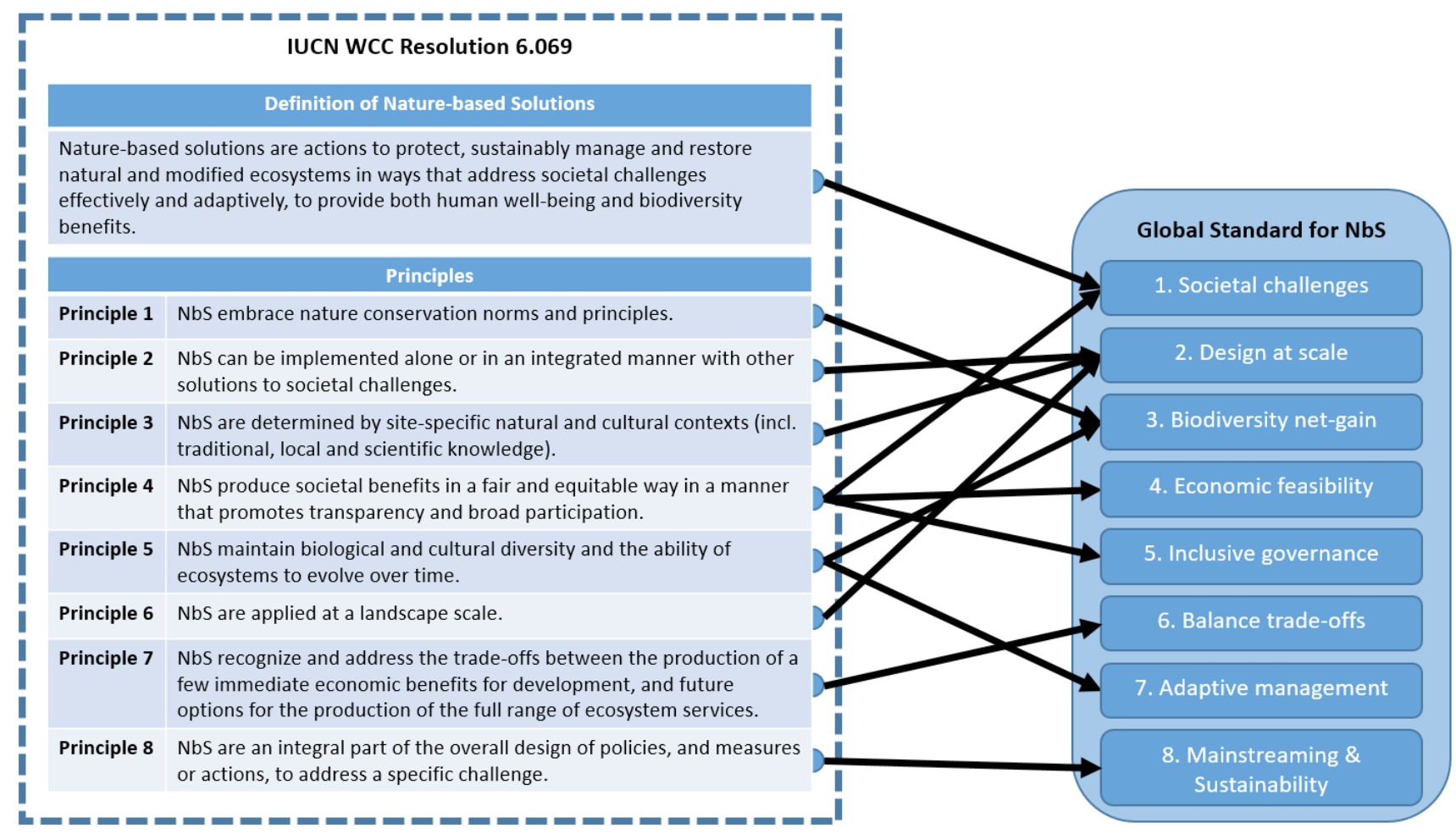

Figure 5: Link between the NbS Principles and the NbS Standard Criteria. (৫ IUCN) 
synergies of NbS with other types of solutions, implementation at landscape/seascape scale, and on policy integration). NbS can therefore be considered an umbrella framework for a series of well-established ecosystem-based and ecosystem related approaches (Cohen-Shacham et al., 2019).

\subsection{Overview of the co-development process}

IUCN facilitated the co-design of a standard for NbS by pooling expert knowledge, skills and experiences from a wide range of stakeholders. such crowdsourcing of the Standard has been important, given that NbS is a cross-cutting theme and, therefore, requires integration of multiple fields of knowledge (e.g. ecology, social sciences, political science, mathematics and economics) and different forms of knowledge (e.g. experiential knowledge, scientific knowledge and traditional knowledge) to inform good practice. There were two rounds of public consultations with more than 800 responses (public and private sectors, as well as non-governmental organisations) from 100 countries.

The consultation surveys were disseminated widely amongst IUCN members, partners, including multinational companies, coalition networks and donors. In addition, the Commission on Ecosystem Management (CEM) contributed to the scientific review of the main concepts, Criteria and Indicators in four steering committee meetings and convened two workshops in Washington DC with the participation of several members of the leadership team. Inputs were received in writing and through face-to-face discussions with focus groups. All inputs from the wide-reaching consultations greatly informed and shaped the scope and content of the Standard. This final iteration of the Standard was adopted at the 98th meeting of the IUCN Council. The Standard has been published by IUCN in 2020 .

With regards to the technical method for developing the Standard, the first step was mapping the eight NbS Principles, adopted through Resolution WCC-2016-Res-069-EN (IUCN, 2016) by IUCN members, to thirteen existing relevant Standards, approaches and guidelines for ecosystem management frameworks. Shared principles and gaps among the frameworks were mapped to establish both the common foundations of $\mathrm{NbS}$ and the elements unique to NbS, to allow the development of an IUCN Standard. Using this method, seven Criteria were originally developed for internal consultation, making use of IUCN's expertise and experience. Based on subsequent reviews and consultations eight Criteria for NbS are provided.

\subsection{International code for sustainability standards}

From the start of the development process of the Standard, IUCN committed to align the development of the IUCN Global Standard for $\mathrm{NbS}$, as much as feasible, to the International
Social and Environmental Accreditation and Labeling (ISEAL) Code of Good Practice: Setting Social and Environmental Standards. This version of the IUCN Global Standard for NbS is informed 
by the lessons learnt during the global public consultations carried out in 2018 and 2019.

The IUCN Global Standard for NbS lists the Criteria and Indicators, as adopted by the 98th Meeting of the IUCN Council in 2020. This document, the Guidance for using the IUCN Global Standard for
$\mathrm{NbS}$, accompanies this booklet to provide the scientific basis and guidance for users. A further document, Part III, will serve later as a user-guide, building upon the lessons of pilots and linked to a self-assessment tool with suggestions of means of verification and design and implementation tools. 


\section{Guidance to Criteria}

\subsection{Summary}

The Standard consists of eight Criteria, each with a set of Indicators. The Criteria strongly build on the NbS Principles as well as the feedback from consultations.

Criterion 1 outlines the process for determining the societal challenge(s) the stakeholders and rights-holders face, as well as establishing an understanding of associated opportunities and challenges. The design of the solution must aim to address the challenge, taking into consideration the wider social, economic and ecological contexts within which the challenge and solution exist, as per Criterion 2. Criterion

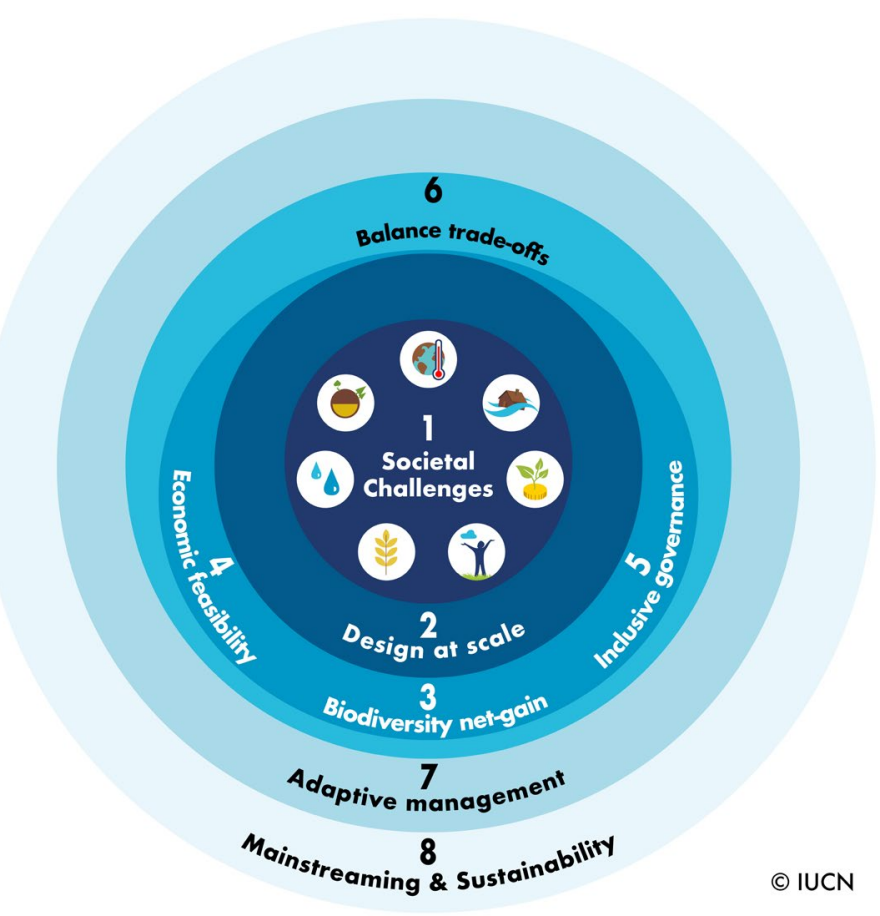

2 addresses the fact that even if the execution of the solution is at a site level or smaller scale, the larger scale level considerations can greatly inform the robustness and durability of the solution, beyond its implementation. Criteria 3, 4 and 5 outline processes that can enhance the chances of positive outcomes for biodiversity, society and the economy. However, in order to achieve these three Criteria with respect to both immediate, short-term and long-term outcomes, trade-offs need to be determined and made, which are directly addressed in Criterion 6, in order to give this issue visibility and importance. The decision-making processes for any tradeoffs that are made need to be transparent and equitable and could be within the context of one or more of Criteria 3,4 and 5. In addition, principles of adaptive management underpinned by a theory of change and iterative learning processes, as per Criterion 7, can also enhance the success of NbS. Criterion 8 focuses on processes for mainstreaming NbS in spatial and temporal scales, whereby actions and impacts may be sustained beyond stand-alone projects, in order to fully realise the potential of nature as a tool providing a solution to societal challenges.

The following sections provide guidance on the eight Criteria of the NbS Standard and their underlying Indicators. The guidance describes the elements of a strong NbS and also identifies where the different Criteria and Indicators are linked to one another.

Figure 6: The eight Criteria that make up the IUCN Global Standard for NbS are all interconnected (C) IUCN) 


\section{Criterion 1: NbS effectively address societal challenges}

The NbS should be designed to effectively and efficiently address specific societal challenges. These include climate change adaptation and mitigation, disaster risk reduction, ecosystem degradation and biodiversity loss, human health, socio-economic development, food security and water security. Three main types of effective conservation actions can be used (standalone or in combination) to address societal challenges - conservation through protection, restoration and restorative activities, and sustainable use. The design aims to achieve specific outcomes that directly and explicitly target societal challenges and contribute to a societal need, while maintaining ecosystem functions.

The prevailingsocial, economic and environmental conditions should be understood before the intervention is initiated. This is important so that the type of challenge being addressed and the appropriateness of the proposed NbS can be properly assessed and fully understood, and for improvements to be measured over time. The baseline can consist of a situation analysis, informed by published and/or grey literature. Additionally, the baseline should be developed through consultations with relevant stakeholders, intended beneficiaries and other actors such as government agencies, private sector companies, local academics and scientists with expertise on the climate and ecology of the site, as well as sub-national authorities with a specific mandate for the target site.

Even though NbS focus on addressing societal challenges, the activities defined should also aim to sustain and enhance ecosystem services while maintaining ecosystem structure, function and composition (see Criterion 3). This preserves the integrity and stability of the ecological system and thus improves the long-term effectiveness of the NbS in question to address the societal challenge(s). An NbS that simplifies ecosystem structure, function and composition reduces resilience, and while it may deliver short-lived outcomes, will eventually collapse. Holistic approaches with a multi-year duration will have the best chance of success.

\section{C-1.1 The most pressing societal challenge(s) for rights-holders and beneficiaries are prioritised}

While NbS can generate multiple benefits for a multitude of societal challenges, NbS interventions need to respond to at least one (or more) specific societal challenges.

A transparent and inclusive process (Criterion 5) must be used to identify the societal challenge. This is because what may be perceived as a priority challenge by external stakeholders may not be seen by the local populations as the most pressing and vice versa. Therefore, processes described in Criteria 5 and 7 need to inform the decision-making. Additionally, it is important to understand and recognise that, due to the inter-linked impacts of societal challenges on local stakeholders, solving a particular societal challenge may require addressing another challenge as well. For example, in some communities, it may be impossible to work on long-term climate change impacts if the communities lack the capacity to cope with seasonal disasters or even to have a safe place to live. Alternatively, if social and cultural challenges are not well addressed, such as employment or land tenure issues, it will be difficult to realise tipping points. A Theory of Change approach is needed to secure transformational change that will last for the next generations. References and tools on how to develop a theory of change will be made available as information complementary to this Standard. 


\section{C-1.2 The societal challenge(s) addressed are clearly understood and documented}

The NbS intervention should address the societal challenge(s) that directly affect a specific group of people (e.g. an NbS to control coastal erosion that is endangering a specific municipality) or indirectly impacts society as a whole (e.g. an $\mathrm{NbS}$ to sequester carbon as a climate mitigation option). However, an NbS intervention around one particular societal challenge often yields multiple societal benefits, such as job creation, other economic benefits and, wherever appropriate, the societal challenges these additional benefits address should be described, documented and accounted for.

Equally, not all conservation or restoration interventions can automatically claim to be an NbS. While conservation interventions may (directly or indirectly) generate ancillary societal benefits, many are not explicitly designed or managed to deliver such benefits. For an existing conservation intervention to be expanded or converted into an NbS would require that the mandate and the management plan be amended to respond to NbS criteria and objectives along with the establishment of requisite baselines to measure and account for delivery. Particularly, Criterion 7 (Adaptive Management) would need to guide such a transformation of a conservation action to an NbS intervention.

\section{C-1.3 Human well-being outcomes arising from the $\mathrm{NbS}$ are identified, benchmarked and periodically assessed}

Targets need to be developed for the intervention to deliver human well-being benefits (see Glossary for human well-being definition). This is pertinent in differentiating between conservation actions and NbS (Indicator 1.1). Ideally, targets for both the implementation and impacts of the intervention should be developed. While full impacts of the NbS may be realised beyond the intervention timeline, indicative targets or milestones may be developed. Such targets or milestones could incentivise long-term investment for the maintenance of the NbS, and would be useful for long-term monitoring of the intervention. 


\section{Criterion 2: Design of NbS is informed by scale}

Good NbS design is aware of and takes into account the interactions that occur across different social and ecological scales within a land or seascape - for example, the seasonal movement of a pastoralist community or seasonal out-migration of young men from rural communities to labour in a distant city or the inflow of remittances from distant family members. If not recognised in project design, interactions across scales may lead to misjudged or misplaced actions, duplication, conflict and project failure.

It is important to understand how different ecosystems within the same area (landscape) are arranged and interact. At each phase of the development and execution of NbS, the larger land/seascape should be considered.

NbS must be considered within a landscape/ seascape scale because ecosystems are affected by and have effects on the larger land and seascape in which they are embedded and cannot be managed in isolation. Furthermore, because some ecosystem goods and services are generated at the land- or seascape scale, NbS activities must be strategically deployed across the larger landscape/seascape.

In fact managing ecological processes at the landscape level - for example the recycling of nutrients - may be just as important as management decisions taken at the intervention site level, especially if the delivery of ecosystem services is an important objective.

Therefore, the long-term assessment, planning, implementation and monitoring of activities intended to impact ecosystem goods and services that benefit society at large (water, climate mitigation and adaptation, etc.) require landscape/seascape-scale approaches and integrated implementation and monitoring of site-specific measures. For these reasons, at each phase of the development and execution of $\mathrm{NbS}$, the larger land/seascape must be considered, as should the various social and economic processes taking place at these scales.

\section{C-2.1 The design of the NbS recognises and responds to the interactions between the economy, society and ecosystems}

All interventions, including those that occur at single sites or small spatial scales, should be developed in the context of the large landscape/ seascape through landscape/seascape planning, in order to ensure that activities are strategic and maximise benefits to people and ecosystems, while minimising adverse effects on adjacent ecosystems and human populations. Implementing innovative NbS at small scale is the basis for scaling-out as stakeholders in the landscape/seascape learn from and adopt the novel practices initiated by those willing to try something new. The context of the larger landscape/seascape includes ecological, economic and socio-cultural perspectives.

Rather than focusing on a specific ecosystem or a single set of stakeholders, the landscape/ seascape scale considers how ecosystems and their functions are connected to the values, rights and benefits of different stakeholders. NbS planning and decision-making should always be undertaken considering the landscape/seascape scale, and understanding the implications of interventions at the landscape/seascape scale. These considerations could help to ensure that NbS practitioners integrate the diverse needs, different sectoral plans, programmes and policies, and support the use of suitable traditional practices for implementation, into one single spatial context that has considered 
the trade-offs, options and scenarios. Such landscape/seascape level considerations will not only include measures of site-specific effects but also of cumulative impacts among sites and multiple stakeholders.

As the interactions between people and nature are complex and uncertain, NbS design can be created from a simple qualitative model developed in a participatory process. Typically, this would involve identification of primary interactions among stakeholders and their land uses, interactions between these stakeholder groups and the land- or seascape itself, and the interactions between the landscape/ seascape and jurisdictional policy and regulatory arrangements, including national laws and policies. This simple systems model can provide the foundation for participatory development of future scenarios that guide decision-making and enable proper integration of issues related to Criteria 3, 4, 6 and 8.

Understanding the influence of interactions across hierarchical scales (both within and across institutions that are participating in the NbS) has important implications for governance and consideration of the manner in which existing institutions (both formal and informal) may support or inhibit alternative NbS designs.

\section{C-2.2 The design of the $\mathrm{NbS}$ is integrated with other complementary interventions and seeks synergies across sectors}

NbS may be implemented alone, although commonly they are part of an integrated package that includes other types of solutions to address societal challenges (e.g. technological and engineering solutions, financial instruments). NbS synergies with other types of solutions could be explicitly planned for. It is important that all contributions have a solid basis in science and incorporate an integrative approach for monitoring as part of the design.

Links between a range of sectors to broaden the scope of the response to societal challenges may be identified to support synergies amongst different solutions. Such joint approaches enhance ownership of the approach, reduce the risks of negative unintended consequences and facilitate the overall mainstreaming of NbS into policies and sectors. While planning the NbS, it is important to actively seek potential synergies with diverse sectors (e.g. agriculture, forestry, water, health, etc.) that could contribute to the NbS, address livelihood needs and improve environmental quality. Some illustrative examples of such links could include the incorporation into the NbS of: a) the agriculture or crop insurance sectors, to better address food security; b) the health sector, to better address human health in urban landscapes; c) infrastructure, to address disaster risk from flooding on a coastline (through a mixture of protecting mangroves and seawalls).

\section{C-2.3 The design of the $\mathrm{NbS}$ incorporates risk identification and risk management beyond the intervention site}

Credible design processes require an assessment of the influence of social and ecological processes, and the risk of undesirable system change due to the occurrence of an external event (e.g. a natural hazard) and how this may influence the intended outcome of an intervention. This is especially so for negative impacts arising outside the borders of the intervention.

The risk assessment will also consider the potential for increased vulnerability of some stakeholders as an unintended consequence of the intervention design. This is important 
in the case of NbS where multiple sources can impact the long-term health and integrity of the underlying ecosystem services. Early action, such as risk and impact assessment, as well as proactive threats management, can make the difference between a successful and failed NbS. Basic key questions can be addressed through vulnerability and resilience assessments, such as:

- Are there competing national, sub-national or local policies that could undermine the NbS management objectives of the socioecological system in question?
- Are there competing claims over the socioecological systems and services provided that will underpin the NbS?

- Are there particular neighbouring or upstream land-use practices that could reduce the efficacy of the NbS?

- Is the NbS design sufficiently robust to absorb anticipated economic, demographic and climate-related changes?

- Does the NbS itself introduce potential risks or additional pressures on the support ecosystem (e.g. risk of introduction or spread of invasive species)? 


\section{Criterion 3: NbS result in a net gain to biodiversity and ecosystem integrity}

The current biodiversity crisis not only threatens rare species with extinction, but is also severely degrading many ecosystems, undermining both planetary health and broader human well-being. Regardless of which societal challenge(s) are targeted, all NbS must have a net positive impact on biodiversity; in other words, the biological diversity and the ecological integrity of the intervention area and its surroundings should be improved as a direct result of the NbS.

NbS should aim to conserve or restore ecosystem integrity and avoid further simplifying an ecosystem (such as replacing natural mixed woodland with a monoculture tree plantation). Although biodiversity (see full definition in Glossary) is a key component of ecological integrity, other equally important components include the structure and function of ecosystems and land/seascapes, as well as connectivity. In addition, NbS depend on the ecological condition of the supporting ecosystems; therefore, it is in the interest of the NbS practitioner to ensure that implementation measures will, at the least, maintain the ecological integrity of the target area over the long term. What is important is that conservation targets are agreed upon by the NbS proponents and incorporated into implementation plans, and that progress is accounted for during implementation monitoring, while not losing sight of the societal challenge the NbS aims to address.

It is prudent that NbS practitioners periodically assess adverse effects in target and adjacent ecosystems. An evidence-based review of the potential risks and impacts of the main NbS actions on the area's biodiversity should be detailed in the NbS operational plan. In addition, the first phase in planning an NbS should be understanding the baseline condition of the target land/seascape, with respect to biodiversity, composition, structure, function, connectivity and external threats. This baseline condition provides information on the degree of degradation and can be used to determine the specific objectives of the NbS as well as being a benchmark for determining efficacy and effects. Because all ecosystems and land/seascapes - including ones with no or only minimal degradation - are dynamic, the degree of degradation should not be evaluated based on the historic ecosystem or land/seascape, but rather the condition that the system would have been in at the present time, if degradation had not occurred. This can be characterised by creating models from existing reference sites or land/seascapes, theoretical information or traditional knowledge. Surveys and data collection can be expensive. Nevertheless, there is a need for baselines to characterise key components of ecological integrity and to determine ongoing drivers of degradation.

\section{C-3.1 The NbS actions directly respond to evidence-based assessment of the current state of the ecosystem and prevailing drivers of degradation and loss}

Surveys and data collection are expensive so there is always a risk that NbS practitioners limit baseline assessments exclusively to the ecosystem service(s) of interest (e.g. an initiative to sequester carbon through improved peatland management only assesses the carbon capture potential). However, as the delivery of ecosystem services is underpinned by the integrity and state of the ecosystem itself and, given that one of the key attractions of $\mathrm{NbS}$ is that it also contributes to biodiversity conservation, it is desirable that 
baselines are sufficient to guide these types of management decisions during implementation.

Basic information for a baseline, at a minimum, should include:

1. Structural information, including trophic dynamics and vegetation strata and their spatial distribution within ecosystems, and the spatial distribution (and patterns of distribution) of key ecosystem types within land/seascapes, according to the required scale in the interest area and their current conservation status;

2. Species composition, including the abundance of species from key taxonomic groups (e.g. vascular plants, mammals, birds and soil micro-organisms) and species' current conservation status (extinction risk)

3. Information on key ecosystem functions (e.g. rates of productivity, flows of water and nutrients, and biotic interactions);

4. Key aspects of the physical environment (e.g. water quantity and quality and information on the physical and chemical properties of soils and other substrates);

5. Connectivity, including corridors of natural or semi-natural vegetation across the land/ seascape that link protected and semiprotected areas and other refugia for biodiversity, and that allow for exchanges of propagules, water and materials among ecosystems;

6. External threats to the ecosystem or land/ seascape and risk of collapse for ecosystems, when possible as determined by the IUCN Red List of Threatened Species ${ }^{\mathrm{TM}}$ and Red List of Ecosystems respectively;;

7. Existing or ongoing conservation interventions for the species and ecosystems at risk in the landscape/seascape.

The baseline assessment should be used to determine the degree of degradation and design project objectives, as well as to understand the changes being driven by the NbS over time, which can then inform management objectives, including adapting NbS interventions to reduce negative outcomes. For this, it is necessary that the variables assessed and the unit of analysis are kept similar or identical to the baseline survey. Regular monitoring is necessary to evaluate improvements in ecosystem integrity and capacity to deliver desired services.

\section{C-3.2 Clear and measurable biodiversity conservation outcomes are identified, benchmarked and periodically assessed}

Given that NbS depend on the health and condition of the supporting ecosystems, it is in the interest of the practitioner to ensure implementation measures at least maintain, and ideally improve, the ecological integrity and species diversity of the target area over the long term. The scope and options for such improvements are context specific, being dependent on the agreement of other stakeholders, national and sub-national policies and available resources. In some situations, the NbS may include ecological restoration activities that remove degradation and allow the system to recover to the condition it would have been in without degradation. In others, the NbS may only aim to diversify the species composition of particular sites or improve the delivery of only a subset of key ecosystem functions. It is important that conservation targets are agreed upon and incorporated into implementation, and that efficacy and effects (including unintended consequences) are determined through monitoring while not losing sight of the societal challenge the NbS aims to address.

At a minimum, the NbS should include the following for each management target related 
to conservation and restoration of biological diversity and ecological integrity:

1. Specific measurable variable(s) associated with the management target (e.g. number of species / ha, \% canopy cover);

2. Action (e.g. increase, decrease, maintain);

3. Quantity (e.g. 50\%);

4. Time-period (e.g. 5 years).

\section{C-3.3 Monitoring includes periodic assessments of unintended adverse consequences on nature arising from the $\mathrm{NbS}$}

A plan for implementing a monitoring programme to determine the efficacy and effects (including unintended adverse effects) of the NbS should be developed at the time the NbS plan is developed.

Ecosystems are complex and dynamic. While a robust planning process (Criterion 2) will help anticipate and address negative secondary impacts, there is always a risk of unintended outcomes when working with natural systems and processes. It is therefore prudent that NbS practitioners periodically review for adverse effects in target and adjacent ecosystems. Towards that end, an evidence-based review of the potential risks and impacts of the main NbS interventions on the area's biodiversity should be detailed in the NbS operational plan. This should include the specified frequency of monitoring and a framework for responding if negative secondary impacts are detected.

The monitoring and evaluation plan must include the following:

1. The amount and sources of funding for each component of the monitoring programme (detailed below);
2. The design for data collection, including the variables to be assessed, the method of data collection, the replication needed to determine the effects of management interventions, frequency and duration of monitoring;

3. The types of analysis that will be used to evaluate the effects of management;

4. The location and protocols for managing and creating a permanent archive of data;

5. The manner in which lessons learned will be shared.

\section{C-3.4 Opportunities to enhance ecosystem integrity and connectivity are identified and incorporated into the NbS strategy}

Ecosystem connectivity refers to the twoway flows of biotic (i.e. living) components of ecosystems that otherwise would be separated across a landscape/seascape by physical barriers. Contributing to improved ecosystem connectivity may often be a conservation objective that can be relatively easily facilitated by NbS. The scale at which connectivity is addressed in the planning depends on the goals that have been set for the NbS intervention.

There is also a strong social perspective on ecosystem connectivity, and in this respect, some of the most promising opportunities for $\mathrm{NbS}$ interventions relate to the urban demand for green spaces not only for recreational and outdoor educational opportunities but also increasingly for public health and reduction of particulate matter and dust. Connections between urban ecosystems and hinterland are very good examples of the development of green spaces in urban areas.

Other examples of ways in which NbS can improve connectivity include planned corridors linking 
small biodiversity refugia such as hedgerows, wetlands and woodlots in otherwise modified ecosystems to accommodate movement of species across a landscape; or the conservation of linkages between headwater landscapes and urban areas that secure sustainable supplies of water for residents. NbS must be designed, implemented and monitored, considering connectivity and its effect on ecosystem integrity. 


\section{Criterion 4: NbS are economically viable}

One of the challenges facing many NbS practitioners today is the lack of economic or financial planning and long-term resources. Many interventions make the mistake of investing heavily early on and not considering the economic and financial viability beyond the timeframe of the intervention. Not only does this increase the risk of the NbS failing, it also fails to make use of the opportunities that NbS offer towards sustainable economic development. For example, the creation of green jobs and sustainable livelihoods can be integrated within the scope of an NbS intervention to provide incentives for further impact.

For $\mathrm{NbS}$ to be sustainable there must be a strong economic consideration (in addition to the other two pillars of sustainable development - environment and social). Otherwise we run the risk of implementations confined to their project lifetimes (for example, five years) where, upon closing, the solution and multiple benefits provided decline and, eventually, cease to exist, even possibly leaving the landscape/seascape worse off than before. Furthermore, NbS do not operate in a vacuum in terms of finance, so there must be some level of cohesiveness and integration with financial institutions and incentive structures. An understanding of whether economic policy and financial structures are complementary is necessary to ensure that the NbS offers its full range of benefits to nature and people.

Nature underpins our economy and society by producing benefits to people, both directly (e.g. food, timber and fibre) and indirectly (e.g. nutrient cycling, soil formation, pollination). Goods and services provided to humans by natural capital include a range of social and environmental benefits including clean air and water, climate change mitigation and adaptation, food, energy, places to live, materials for products, recreation and protection from hazards. While some of these benefits are transacted and priced through markets, many benefits from nature are non-market goods and services, including some available seemingly for free. When evaluating $\mathrm{NbS}$, a key challenge is to incorporate their multiple benefits into a common economic evaluation framework.

Central approaches to incorporate economic considerations include cost-effectiveness and cost-benefit assessments. When cost-effective, $\mathrm{NbS}$ achieve the set of desired outcomes (for example, $\mathrm{CO}_{2}$ sequestration, flood protection, water filtration, and biodiversity conservation) at a cost comparable to or lower than that of other possible solutions to the same societal challenge(s). Cost-effectiveness does not require monetisation of benefits; rather, it can incorporate both monetary and non-monetary benefit endpoints by using their physical quantities. Cost-effectiveness assessment does not require using a common currency, which helps incorporate non-monetary benefits but limits the options available to contrast different benefit outcomes. Multi-criteria assessment may complement the assessment of costeffectiveness by aggregating different benefit endpoints into a common evaluation and decision framework.

Cost-benefit analysis integrates multiple benefit outcomes, private and societal, by making them comparable using a common currency. When all benefits can be monetised, cost-benefit analysis helps extend beyond cost-effectiveness by not only evaluating the cost of achieving specific benefit outcomes (cost-effectiveness) but by also determining what level of investment in NbS is warranted in the first place (benefits exceed the costs). 


\section{C-4.1 The direct and indirect benefits and costs associated with the NbS, who pays and who benefits, are identified and documented}

The most basic requirement to understand the economic aspects of NbS involves identifying and documenting all the types of benefits provided (financial and non-financial; economic and non-economic), who receives them, what the costs of provision are, and who bears those costs. Benefits and costs can be assessed in non-economic (e.g. increase in air quality) or economic terms (e.g. reduced health costs), or both. Consideration of market and nonmarket aspects of NbS is essential to ensure a comprehensive assessment, to identify who is the payer, who will benefit and who is the doer. This will inform the consideration of trade-offs under the sixth Criterion (Indicator 6.1).

\section{C-4.2 A cost-effectiveness study is provided to support the choice of $\mathrm{NbS}$ including the likely impact of any relevant regulations and subsidies}

An analytical framework can be a basic costeffectiveness study, cost-benefit assessment, or a multi-criteria analysis. There are several methods and tools to help cost-effectiveness studies and, at the very least, an attempt to do so will assist greatly in informing Criterion 6 on trade-offs.

\section{C-4.3 The effectiveness of the NbS design is justified against available alternative solutions, taking into account any associated externalities}

The primary goal of an NbS is to effectively address at least one societal challenge in a manner that is economically viable. To identify the most effective and affordable solution, alternative solutions must be considered. Alternative solutions may be purely technological or engineered, structural solutions (grey solutions). Comparing various solutions can inform on the most effective way forward to address the societal challenge/s. This Indicator is strongly linked to the previous Indicator 4.2.

\section{C-4.4 The NbS design considers a portfolio of resourcing options such as market-based, public sector, voluntary commitments and actions to support regulatory compliance}

Adequate resourcing of NbS is necessary to ensure their sustainability. This is the case regardless of whether the intervention is profit driven or non-profit based. In the latter, the resourcing may at first rely on a grant but should consider future resourcing means outside of the intervention action timeframe. Currently, as demand grows for $\mathrm{NbS}$, so do resourcing options, especially innovative financing such as blended financing. Blended finance is the strategic use of development finance for the mobilisation of additional finance towards sustainable development in developing countries" (OECD, 2020). To ensure NbS offer the most effective solution to societal challenges in each case, a range of options should be considered, including, for example, circular economy, voluntary commitments, tax schemes, green jobs and social finance. Private sector financing of NbS, either through corporate social responsibility (CSR) or benevolent funding, offers options that should be taken into account as well.

A long-term business/financial plan should be considered to address the economic/financial feasibility and constraints of the NbS. This plan would look beyond the timeframe of the planning 
and initial grant-supported implementation phase. If longer-term financial considerations are not considered, the short-term cost could outweigh the long-term benefits. It is possible that such an analysis would conclude that the desired solution may then not be deemed economically viable over time. Therefore, planning should consider the implementation stage but also include a degree of forward-looking thinking with the above Criterion. 


\section{Criterion 5: NbS are based on inclusive, transparent and empowering governance processes}

Appropriate governance processes are critical in determining successful outcomes of NbS for people and nature. Equitable participation, power sharing, recognition and security of rights, and clarity of responsibilities, will ensure simultaneous benefit to people and nature in both the short and long terms. Governance of an NbS intervention involves opportunities for involvement in identification, decision-making, monitoring and feedback, and grievance processes for all stakeholders. All NbS should have an inclusive approach when identifying and establishing governance mechanisms, and recognise and respect pre-existing cultural practices and land uses where possible, throughout the lifecycle of the intervention and beyond. A rigorous stakeholder mapping process should be conducted in order to identify the range of stakeholders who will be affected by the NbS and how. All stakeholder groups should be represented and their stakes in the intervention considered when making decisions concerning the NbS. Doing so can minimise the risk of marginalising a particular stakeholder group or worse, affecting them negatively with the NbS intervention. On the other hand, a lack of such an inclusive approach will lead to decisionmaking based on limited, skewed and narrowed perspectives, which could lead to increased social and/or economic inequalities amongst stakeholders. It can lead to future conflicts with disaffected stakeholders who feel they should have been consulted. This is especially possible due to the inherent power differences or asymmetry amongst stakeholders who may be involved or affected. Furthermore, lack of an inclusive approach may exacerbate the risks highlighted in Indicators 2.3 and 3.3 (undesirable change beyond the intervention site and adverse consequences) and limit the extent to which adaptive management can be practised.
Transparency is also critical in ensuring that resources (financial, human and natural) are being used fairly and efficiently for the benefit of the beneficiary group(s) that have been collectively identified and agreed upon by all stakeholders involved. Transparency on the part of the external actors who may be driving the intervention is needed for local stakeholders and especially local communities to understand the immediate and long-term implications of the NbS interventions, whether ecological, economic or social (especially any potential negative impacts on cultural, local rights and practices). It is important that all stakeholders understand and have equitable opportunities to be part of the decision-making processes regarding how they would be affected by such implications, including by any trade-offs that need to be made (Criterion 6) in implementing NbS.

NbS also need to contribute to addressing structural, emotional and governance inequities that may exist, especially those that keep the most marginalised from decision-making power. Effective governance helps to avoid conflicts, and failures of conservation action. Using tools such as the Natural Resource Governance Framework (NRGF) can directly contribute to meeting the Criterion 5 because they are intended to guide the design and implementation of projects that achieve comprehensive, consistent and systematic consideration of inclusion, equity and rights.

To achieve participatory, equitable, transparent and accountable governance of NbS interventions, the approach needs to empower stakeholders, especially those who may be poor, less influential or marginalised, at the start of the process, through proactive capacity enhancement and knowledge sharing. 
Empowerment can provide the foundations for longer-term ownership, create self-sufficiency and ultimately, sustainability as well as scaling up of the intervention.

Communication and engagement are more effective when the needs and cultures of audiences are acknowledged and understood. Where relevant, it would be especially important to ensure that multi-ethnic communities plan and allocate resources for the translation and interpretation of contributions, so that all present know and understand what everyone is saying.

\section{C-5.1 A defined and fully agreed upon feedback and grievance resolution mechanism is available to all stakeholders before an $\mathrm{NbS}$ intervention is initiated}

A grievance or dispute settlement mechanism should be adopted early on, ideally when planning the intervention, whether it be a formal legal process or informal non-legal system, it should have agreed procedures, roles and rules for receiving and adjudicating such interventions. Reviews of existing redress mechanisms in international law for conservation activities have shown the importance of including contextually appropriate methods of address and redress. The grievance mechanism should be legitimate, accessible, predictable, equitable, transparent, rights-compatible, adaptively managed and based on engagement and dialogue.

\section{C-5.2 Participation is based on mutual respect and equality, regardless of gender, age or social status, and upholds the right of Indigenous Peoples to Free Prior and Informed Consent (FPIC)}

Participation should be aimed at ensuring that a diversity of knowledge, skills and ideas inform the implementation and evolution of the intervention, wherebystakeholders have ownership of NbS and can even self-mobilise collective and continued actions post intervention. Full participation is important to the success of the intervention. Passive participation where certain stakeholder groups may simply be informed of what will or has happened will detract from the robustness of the process. Similarly, participation cannot be an information extraction exercise by one or more stakeholder groups, nor can it be based on coercion or incentivised by material gains. Where Indigenous peoples are affected, the principle of Free, Prior and Informed consent (FPIC) particularly needs to be followed in NbS design and implementation, but other stakeholder groups can also benefit from FPIC approaches.

\section{C-5.3 Stakeholders who are directly and indirectly affected by the NbS have been identified and involved in all processes of the NbS intervention}

NbS should allow for the active participation of all people who may be directly or indirectly affected from the start to end of the intervention. Using a robust stakeholder-mapping tool, a stakeholder analysis needs to be carried out in order to identify and engage the full range of people that may be affected by the NbS. The process also needs to identify stakeholders who may be negatively affected and afford opportunities for their empowerment, along with redress, to 
prevent them being further marginalised due to the NbS. Mechanisms for decision-making and implementation of the NbS intervention must reflect the diversity and input of the affected stakeholder groups.

\section{C-5.4 Decision-making processes document and respond to the rights and interests of all participating and affected stakeholders}

Where stakeholders are subject to inequality, inequity and marginalisation, in terms of their power, social position, culture or financial status, the underlying causes should be understood and all efforts made to reduce or avoid such inequities as much as possible. Doing so will reduce the probability of conflicts. In the case of potential conflicts, they are resolved in respectful negotiation, which recognises the rights of stakeholders according to cultural and societal contexts, and the need for agreement to reduce the risk of failure. Doing so will also inform adaptive management of the NbS intervention as it is impossible to foresee and reduce all impacts and implications of the intervention through the planning process only. Furthermore, if conflicts cannot be resolved amongst the stakeholders, the grievance and redress mechanism will need to be used.

\section{C-5.5 Where the scale of the NbS extends beyond jurisdictional boundaries, mechanisms are established to enable joint decision- making of the stakeholders in the affected jurisdictions}

Ecosystems often transcend political or administrative boundaries. Therefore, it is important to ensure holistic approaches that involve stakeholders and institutions beyond the boundaries of the geographic scale of an NbS being implemented. Establishing collaborative organisations and rules, or building on existing ones, is important for interventions that involve trans-jurisdictional interventions such as rivers and migratory species. Such bodies can avoid conflicting management objectives in adjacent jurisdictions that are part of the same ecological system. A mismatch of social and ecological scales increases the risk of failure, therefore participatory governance approaches need to explicitly acknowledge these connections (see also Criterion 2 on ecological scales).

Where appropriate, effective NbS sometimes require coordination on transboundary, crossborder or regional cooperation. In such cases, it will be necessary to obtain cooperation agreements from relevant national authorities that frame a shared vision and consistent approach to NbS planning, monitoring, shared decision-making and implementation. Agreement should be accompanied by a legal review to ensure compliance with respective international cooperation arrangements (i.e. that the implementing national authorities have the necessary mandate and there is an established recourse procedure that can be used in the case of any disputes or unforeseen consequences) and the laws and regulations of the various involved jurisdictions. Often an intergovernmental organisation (IGO) can be asked to facilitate the process. 


\section{Criterion 6: NbS equitably balance trade-offs between achievement of their primary goal(s) and the continued provision of multiple benefits}

Even though an individual NbS is expected to explicitly prioritise one of more specific societal challenges (Criterion 1), the supporting ecosystems will continue to deliver a range of benefits that are important to society as a whole (Criterion 3). Indeed, the ability to deliver multiple benefits simultaneously is a major attribute of NbS. In some cases, the 'stacking' of key benefits (e.g. water protection, carbon sequestration and public health through recreation) is an important determinant as to whether an NbS is economically viable (Criterion 4).

However, this fundamental attribute of ecosystems can also provide a challenge to the NbS practitioner. Maximising the provision of multiple benefits from any NbS risks a commensurate reduction in the key ecosystem benefit that is instrumental for addressing the societal challenge at hand. Conversely maximising the provision of the key ecosystem benefit will almost certainly result in a reduction of the quality and quantity of other ecosystem benefits. Such trade-offs are very often an inherent feature of natural resource management and arise when a particular ecosystem service or stakeholder preference (e.g. clean drinking water) is favoured at the expense of another (e.g. agricultural output). Also, not all stakeholders are equally affected and the NbS needs to be explicit about whose benefits and whose costs will be addressed. Some trade-offs result from deliberate decisions, while others occur without planning or awareness of the impacts. Tradeoffs become a major problem when the same choice is replicated multiple times, so that suites of important ecosystem benefits disappear or otherwise occur at sub-optimal levels across the entire landscape/seascape.
However, trade-offs can be successfully managed if the likely consequences are properly assessed, fully disclosed and agreed upon by the most affected stakeholders (see the case study for Criterion 6 in Part I). Fair and transparent negotiation of trade-offs and compensation among potentially affected parties for any loss as a result of the NbS, including livelihoods, provides the basis for successful long-term NbS outcomes. Critically, it is important to recognise that trade-offs have limits, which means that safeguards will be necessary to ensure that the long-term stabilising properties of ecosystem regulating and supporting services are not exceeded, as is the case with intensive industrial land use practices. More recently, tools such as the Integrated Valuation of Ecosystem Services and Tradeoffs - InVEST (Sharp et al., 2020) and case studies on lessons from managing tradeoffs are also available. A compilation of useful case studies and suggested tools will be available, complementing this guidance.

\section{C-6.1 The potential costs and benefits of associated trade- offs of the $\mathrm{NbS}$ intervention are explicitly acknowledged and inform safeguards and any appropriate corrective actions}

NbS practitioners identify and document the benefits and costs of the NbS, and who receives and who pays them (Criterion 4), the results of which then inform actions, and the equitable sharing of benefits and costs among stakeholders. Such analysis should not be restricted to the planning phase but also be built into the entire NbS life cycle, including initiation, planning, execution and closure, acknowledging 
that NbS interventions can be implemented in perpetuity.

Trade-offs have a spatial, temporal and reversibility dimension. The spatial dimension refers to whether the effects of the trade-offs are felt locally or at a distant location. The temporal dimension refers to whether the effects take place relatively rapidly or slowly. Reversibility expresses the likelihood that a disrupted ecosystem service may return to its original state if the disturbance event ceases. Furthermore, benefit-sharing arrangements that have been mutually agreed must be established to ensure equitable balancing of benefits and trade-offs from policies and investments.

\section{C-6.2 The rights, usage of and access to land and resources, along with the responsibilities of different stakeholders, are acknowledged and respected}

The legal and usage rights of vulnerable and marginalised groups need to be upheld. Rights, use, responsibilities and accountability of stakeholder groups must be analysed and assessed using appropriate tools, building on the outcomes of stakeholder analysis or mapping.
Particularly, when dealing with Indigenous peoples and local communities, free, prior and informed consent (FPIC) must be used (aligned to Criterion 5). Additionally, not all stakeholders are equally affected and the NbS needs to have mechanisms to balance trade-offs among groups through using approaches such as transparency, incentives and sustainable alternatives.

\section{C-6.3 The established safeguards are periodically reviewed to ensure that mutually-agreed trade-off limits are respected and do not destabilise the entire NbS}

Many relevant policies in the field of conservation have explicit safeguard policies (see for example the UNFCCC Cancun Agreement Appendix 1). Voluntary carbon projects have often followed the Climate, Community and Biodiversity Standards. Other safeguards have been established for World Bank investments. These safeguard systems are in place to anticipate and avoid adverse consequences of interventions and can be used as a basis for an NbS safeguard appropriate to local contexts. 


\section{Criterion 7: NbS are managed adaptively, based on evidence}

This Criterion is strongly linked to Indicators 2.3 and 3.3.

NbS harness services of ecosystems, which are complex, dynamic and self-organising systems. Ecosystems may respond in desirable ways to an NbS intervention. However, the intervention could also create unintended, unforeseen and undesirable consequences. Therefore, NbS are attempts to influence an ecosystem to change in ways that meet societal needs in the long term and cannot be regarded as interventions that can fully predict outcomes in an absolute problem-solving sense. As a result, the NbS should be based on a theory of change, which is tested and adapted based upon evidence. The theory of change should recognise the selforganising properties of ecosystems and be based on an assessment of process and function as these relate to societal challenges. Critical assumptions with regards to the risk of systemic failure must be clearly stated in the theory of change and tested against evidence or through experimentation. The theory of change should also identify enabling conditions for the NbS.

Adaptive management, therefore, needs to be incorporated into the NbS implementation process. Adaptive management is defined as: "A structured, iterative process of ... decisionmaking in the face of uncertainty, with an aim to reducing uncertainty over time." Furthermore, in responding to such a management approach, continuous learning about system-wide processes and adapting the NbS according to systemic changes is needed from all stakeholders involved. This may also include considerations of long-term sustainability impacts of the immediate NbS site, changes that may be triggered in adjacent and downstream landscapes/seascapes and impacts that may occur at larger scales, both over time and geographical space.
On the other hand, undesirable impacts from adjacent,downstream landscapes/seascapes and larger scale systems may be beyond the control of the stakeholders. This underlines the need for adaptive management, flexibility and iterative learning processes when implementing $\mathrm{NbS}$. Underpinning such learning and management approaches would be the recognition of interactions between the social and ecological components of the entire system within a landscape/seascape as well as the interactions that occur across the different levels of social and ecological scales. The success of this is strongly dependent on Criterion 5, inclusive, transparent and empowering governance processes. Adaptive management can also contribute to measuring the amount of carbon stored in soils, vegetation and its permanence through time, as well as the changes in biodiversity composition.

\section{C-7.1 An NbS strategy is established and used as a basis for regular monitoring and evaluation of the intervention}

In an NbS, the theory of change is not static; it is dynamic and acknowledges the uncertainty of bio-economic systems and changing conditions. Assumptions and enablers identified in the theory of change must be regularly reviewed against the established baseline. Other relevant and new social, economic and ecological evidence that could enhance the impacts of the NbS as well as reduce the risks of negative unintended outcomes should also be considered alongside the baseline. A monitoring and evaluation plan will also enable systematic review of the NbS intervention against the baseline and other new evidence. 


\section{C-7.2 A monitoring and evaluation plan is developed and implemented throughout the intervention lifecycle}

A monitoring and evaluation (M\&E) plan, preferably a participatory M\&E plan that involves stakeholders in the verification of outcomes and learning, will ensure that the NbS intervention is on track for implementation and delivery and will help manage positive and negative long-term impacts. While it can sometimes be perceived as an administrative burden, it is a powerful approach to understand whether the NbS intervention effectively addresses the societal challenge(s). In ensuring that monitoring considerations are not compromised due to cost cutting measures, all monitoring plans should be established in advance of implementation. Where required, M\&E may need to be independent and conducted by a third party. In the case of self-verification or second party verification, it is highly recommended that an external review or evaluation of the initiative be carried out, ideally at mid-term and at the end.

When done well, not only can M\&E help assess the changes throughout the intervention, but also capture immediate and short-term impacts on nature and people's lives. It will support NbS interventions in upholding accountability and compliance.

Such an M\&E plan is also important when identifying responses under changing conditions described in Indicator 7.1 and managing the resulting deviations. These responses will serve as adaptive management actions to be undertaken by the stakeholder community. The actions must be developed and executed in an inclusive and participatory way, thereby upholding Criterion 5. Information on the processes to identify the actions as well as the execution of the actions must be available for inspection, with appropriate attributions, while respecting the privacy and security of informants. The appropriate ecological and social scales must be reflected in M\&E since NbS can have influences across varying scales and the actions may require engaging at scales different to the original NbS. Without such an adaptive approach, the actions may have marginal or no impact.

\section{C-7.3 A framework for iterative learning that enables adaptive management is applied throughout the intervention lifecycle}

Learning is the process of developing an understanding based upon the evidence, and adaptation is the adjustment of management according to new information. Learning based on evidence should drive NbS management. Furthermore, iterative learning-applicationlearning is essential in informing adaptive management actions, in order to respond to the factors influencing NbS interventions. For this Criterion, Indicators 7.1 and 7.2 provide a continuous feedback loop in order to learn and adapt the NbS intervention. Such feedback processes can be embedded as part of the monitoring and evaluation plan of the intervention, enabling a consistent timeframe for repeated analyses. Further evidence, produced from both traditional and scientific knowledge sources, can also be brought into the iterative learning process. This is especially important given the climate change impacts experienced by ecosystems. Ideally, iterative learning is institutionalised so that it carries on even after the NbS intervention ceases. 


\section{Criterion 8: NbS are sustainable and mainstreamed within an appropriate jurisdictional context}

Given that NbS is a relatively new and emerging concept, information about NbS must circulate freely and openly increasing the demand and supply of NbS. This allows people to extract lessons learned and determine whether and how the NbS processes need to be adjusted. Once better known, it should be possible to scale up and/or replicate individual NbS. Both scaling up and replicating will add evidence for and understanding of the NbS approach, further enabling the design of even more effective, affordable and sustainable NbS.

NbS are designed and managed to be complementary to institutional structures, policies, plans, laws, regulations and nearby interventions (see Design at Scale Criterion 2 and Adaptive Management Criterion 7 respectively). However, while an NbS intervention may be time bound (for example, where specific actions such as planting mangroves is limited to five years), the NbS overall, including the resulting framework and impact, continues outside these boundaries. The purpose of this Criterion is to ensure that NbS enable their own mainstreaming for solutions to persist through time.

In supporting the uptake and scaling of NbS across time and well beyond the timeline of the intervention, NbS practitioners should ensure that NbS have a long-term trajectory that spans several decades. There are varied approaches to mainstreaming NbS, however all rely on strategic communications and outreach. Audiences to consider include individuals (the public, academics), institutions (national government, start-ups, non-government organisations) and global networks (Sustainable Development Goals, Paris Agreement).

\section{C-8.1 The NbS design, implementation and lessons learnt are shared to trigger transformative change}

For an NbS approach to be scaled up (mainstreamed), scaled out (expanded at geographical, sectoral or target size) or replicated, it is important that the process of design and implementation, along with lessons learnt, are made available and accessible to relevant individuals or upon demand by any stakeholder directly impacted or also highly interested in replicating the process. Audiences for this communication include individuals such as decision makers in sectors where NbS can be a solution, investors, NbS users from public and private sectors and the general public. Examples include newsletters on lessons learnt, press releases on partnerships formed, capacity trainings on design or implementation, policy briefs and lobbying. Lessons learnt must include both positive and negative (including unintended) consequences and possible ways to overcome them in future.

For these communications to be accessible, audiences that may encounter barriers in terms of technology, culture or socioeconomic background must be considered. NbS practitioners may consider it appropriate to publish results in an open-access publisher. Additionally, site-specific visibility and awareness raising can be considered, such as through billboards and signs. 


\section{C-8.2 The NbS informs and enhances facilitating policy and regulation frameworks to support its uptake and mainstreaming}

$\mathrm{NbS}$ are already subject to a range of pre-existing policies, plans, laws and regulations, in some cases constraining and in others supporting. $\mathrm{NbS}$ need to address and be compatible with the context provided by current policies, plans, laws and regulations so that they are fully enabled to deliver their intended outcomes (Design at Scale Criterion 2), or suggest new policies and regulations needed to guarantee their successful implementation. Failure to do so may threaten the durability and viability of the NbS over the long term if, for example, it requires actions or interventions that contravene or are otherwise incompatible with established land-use strategy policies and practices. There may also be situations where existing land-use policies undermine one another and therefore present additional challenges to NbS implementation. Under these circumstances, NbS can provide the opportunity to highlight these incompatibilities to policy makers and act as a trigger to amend regulations in order to ensure sustainability and durability.

On occasions, contradictions between the objectives or requirements of different land-use or sectoral policies may be encountered which have the potential to reduce the effectiveness and/ or efficiency of NbS implementation. These should be fully documented along with options to resolve or work around any such obstacles both for monitoring purposes and for the consideration of policy makers. In order to improve the design and facilitate effective policy alignment of future $\mathrm{NbS}$, monitoring and evaluation outcomes as well as other forms of lesson learning should be maintained and remain easily accessible within the public domain.

\section{C-8.3 Where relevant, the NbS contributes to national and global targets for human well-being, climate change, biodiversity and human rights, including the United Nations Declaration on the Rights of Indigenous Peoples (UNDRIP)}

NbS aim to address global societal challenges. Individual NbS build on this momentum, by recording their progress towards increasing human well-being (including health, wealth, etc.) and tackling the climate and biodiversity crisis. Where NbS impacts contribute to relevant national and global targets (mapped in Design at Scale Criterion 2), the bodies responsible for these targets should be informed so that this impact is documented. Targets to consider include:

- National and sub-national policies, regulations and laws;

- UN Sustainable Development Goals (SDGs);

- UN Decade on Ecosystem Restoration;

- UN Convention to Combat Desertification (UNCCD) goals such as Land Degradation Neutrality (LDN);

- Those specific to a societal challenge (Paris Agreement, Wold Health Organisation (WHO) Global Nutrition Targets, Sendai Framework for Disaster Risk Reduction - SFDRR);

- Those specific to the biodiversity crisis (Aichi Targets or their successor, Nagoya Protocol for Access and Benefit Sharing or its successor, National Biodiversity Strategies and Action Plans - NBSAPs)

Informing those responsible for the targets can be achieved through knowledge transfer, policy briefs, meetings with policy makers or reporting to the different policy mechanisms. 


\section{How to use the Standard}

The Standard has been developed to be used in design, scaling up and verification applications as a simple yet robust hands-on tool that reinforces best practice, addressing and correcting shortfalls and enabling interventions to align with internationally accepted NbS principles (WCC2016-Res-069). Users can apply the Standard to both ongoing and proposed interventions using the self-assessment tool which has been designed so it can be used alongside existing project management tools and technical approaches. The Indicators, their guidance and scoring scales can easily be aligned with existing reporting and operational management systems in order to minimise the additional work needed.

For the initial rollout phase of the NbS Standard, a self-assessment tool (downloadable here) has been developed to enable Standard users to calculate the percentage match of their intervention against the eight Criteria and identify whether their intervention adheres to the IUCN Global Standard for NbS. The self-assessment sheet, in the form of an Excel spreadsheet, enables users to identify the extent to which their intervention adheres to individual Indicators; strong, adequate, partial or insufficient. Users are then provided with a traffic light system for each Criteria which allows them to identify areas of improvement and gives an overall match, to be able to state whether the intervention adheres to the IUCN Global Standard for NbS.

For each Indicator, a score out of four is recorded, depending on whether the intervention addresses the Indicator to a strong, adequate, partial or insufficient extent. The result is used to calculate the level of adherence to each individual Criterion, also giving a strong, adequate, partial and insufficient result for scores greater than 75, between 50 and 75, between 25 and 50 and lower than 25 per cent respectively (Table 1). These Indicator scores are then normalised so that each Criterion has equal weight. After normalisation, the Criterion scores are combined to give the overall percentage match. Regardless of the overall percentage match, if an intervention scores an 'insufficient' rating against any Criterion, then it does not adhere to the IUCN Global Standard for NbS. The percentage match can then be used to describe if this adherence is strong, adequate or partial.

While the Standard assesses whether the design of an intervention meets the qualifying requirements of an NbS, its execution will require other operationalising standards, tools and approaches. As an example, if a watershed were to be managed for flood risk reduction, tools such as the guidelines for Integrated

Table 1: Output of self-assessment sheet.

\begin{tabular}{ccc}
\hline \multicolumn{1}{c}{ Key (\%) } & Output \\
\cline { 1 - 2 }$\geq 75$ & Strong & \\
\cline { 1 - 2 }$\geq 50 \&<75$ & Adequate & Intervention adheres to the IUCN Global Standard for NbS. \\
\cline { 1 - 2 }$\geq 25 \&<50$ & Partial & \\
\hline$<25$ & Insufficient & Intervention does not adhere to the IUCN Global Standard for NbS. \\
\hline
\end{tabular}


Water Resource Management would be required to operationalise the NbS, once it is designed according to the eight Criteria (Figure
7). In this sense, the Global Standard for NbS supplements rather than replaces the use of other standards.

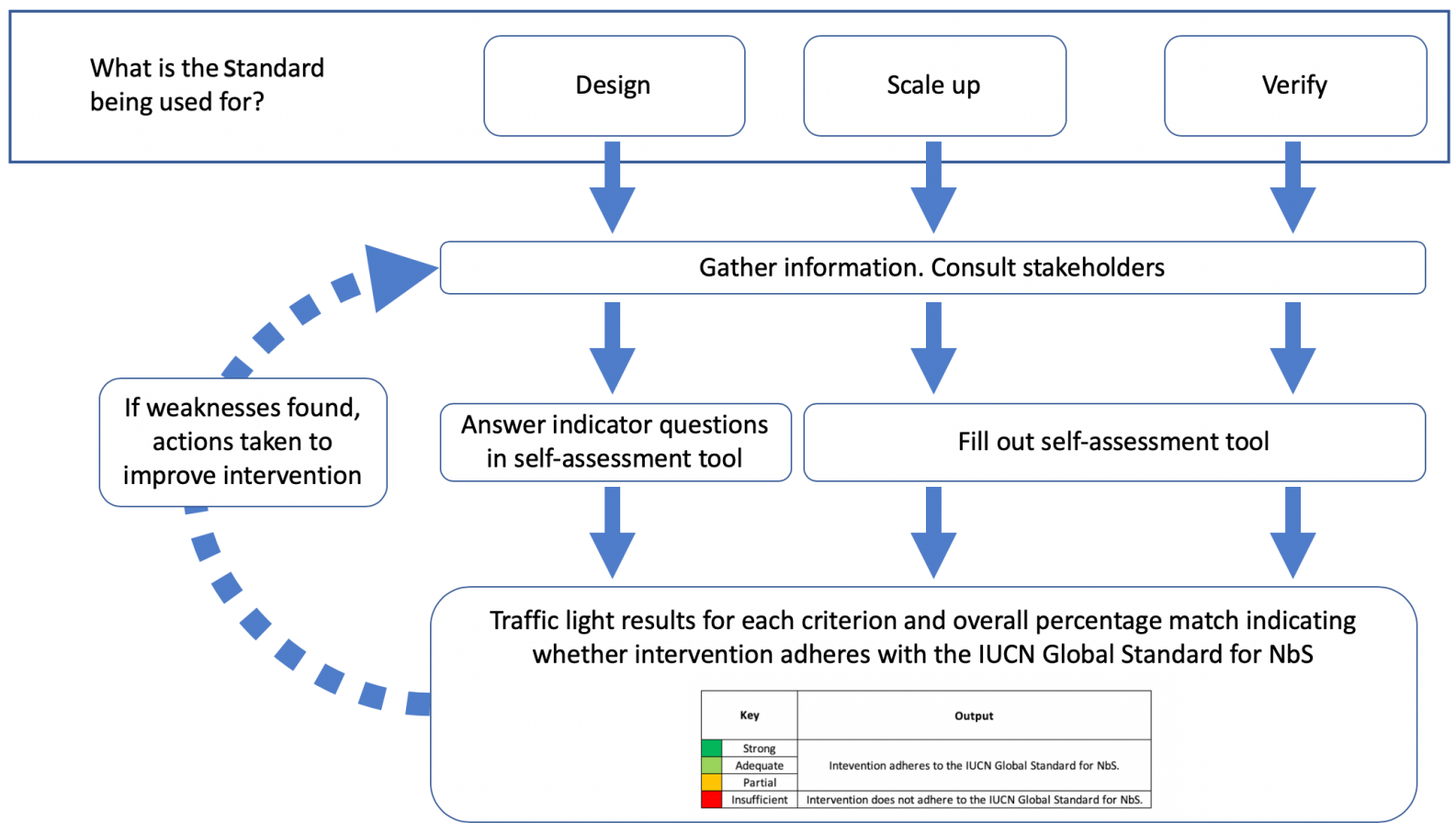

Figure 7: How to use the Standard and how it is linked to the self-assessment. (৫ IUCN)

\subsection{How to self-assess}

The self-assessment against the NbS Standard should be carried out at different stages of the project cycle, to help identify non-anticipated outputs, weaknesses and strengths in order to improve or alleviate them. Therefore, the selfassessment should not be seen as a judgement of an NbS project. Rather, it aims to ensure the delivery of the anticipated societal benefits without compromising nature and vice versa. The self-assessment will make use of a traffic light system for indicating the status of the different listed Indicators where green expresses that an Indicator is fully met, orange illustrates partially reached and red, no accomplishment.
The self-assessment should be conducted as follows:

- Reviewthe Indicators, guidance and examples in Part II, and consider the suggested means of verification;

- Identify the means of verification that are most suitable for demonstrating to what degree your NbS meets a respective Indicator using the scale guidance for strong, adequate, partial and insufficient provided in the self-assessment tool;

- Describe how and to what extent your NbS meets the Indicator in the provided cells of the self-assessment tool; 
- Provide links to the means of verification used (if available online) or attach them to your self-assessment to substantiate your findings;

- Check the overview sheet for the traffic light results, overall match percentage and whether the intervention adheres to the IUCN Global Standard for NbS;

- Share, report and discuss the findings as needed to improve or implement solutions;
- Be flexible and reiterate the process as needed when some aspects change.

Parts | and II of the Standard will later be supplemented by a user-guide (Part III) and platform sharing approaches and tools. In the meantime, users of the Standard can join the global community of practice here, where they can also find assistance and FAQs. Questions can also be directed to NbSStandard@iucn.org to reach the NbS Group at IUCN. 


\section{Glossary of definitions}

\begin{tabular}{|c|c|c|c|}
\hline Term & Definition & Source & Link \\
\hline Action & $\begin{array}{l}\text { Actions are viewed not as reactive behaviour or } \\
\text { lifestyle changes but rather as an active exercise } \\
\text { of democratic participation in society. The action } \\
\text { should be undertaken consciously, intentionally and } \\
\text { voluntarily }\end{array}$ & $\begin{array}{l}\text { CBD Toolkit } \\
\text { Glossary }\end{array}$ & $\begin{array}{l}\frac{\text { https://www.cbd.int/cepa/ }}{\text { toolkit/2008/doc/CBD-Toolkit- }} \\
\text { Glossaries.pdf }\end{array}$ \\
\hline Action plan & $\begin{array}{l}\text { A written plan of implementation often detailing the } \\
\text { timelines, stages, roles and/or responsibilities of } \\
\text { projects related to the strategy's objectives. }\end{array}$ & $\begin{array}{l}\text { CBD Toolkit } \\
\text { Glossary }\end{array}$ & $\begin{array}{l}\text { https://www.cbd.int/cepa/ } \\
\text { toolkit/2008/doc/CBD-Toolkit- } \\
\text { Glossaries.pdf }\end{array}$ \\
\hline Adaptation & $\begin{array}{l}\text { Initiatives and measures to reduce the vulnerability } \\
\text { of natural and human systems against actual or } \\
\text { expected climate change effects. Various types } \\
\text { of adaptation exist, e.g. anticipatory and reactive, } \\
\text { private and public, and autonomous and planned. }\end{array}$ & IUCN Glossary & $\begin{array}{l}\frac{\text { https://www.iucn.org/sites/ }}{\text { dev/files/iucn-glossary-of- }} \\
\underline{\text { definitions en.pdf }}\end{array}$ \\
\hline $\begin{array}{l}\text { Adaptive } \\
\text { management }\end{array}$ & $\begin{array}{l}\text { A systematic process of continually improving } \\
\text { management policies and practices by learning from } \\
\text { the outcomes of existing programmes. }\end{array}$ & IUCN Glossary & $\begin{array}{l}\text { https://www.iucn.org/sites/ } \\
\text { dev/files/iucn-glossary-of- } \\
\text { definitions en.pdf }\end{array}$ \\
\hline Assessment & $\begin{array}{l}\text { The analysis and review of information derived } \\
\text { from research for the purpose of helping someone } \\
\text { in a position of responsibility to evaluate possible } \\
\text { actions or think about a problem. Assessment means } \\
\text { assembling, summarising, organising, interpreting, } \\
\text { and possibly reconciling pieces of existing knowledge } \\
\text { and communicating them so that they are relevant } \\
\text { and helpful to an intelligent but inexpert decision- } \\
\text { maker. }\end{array}$ & $\begin{array}{l}\text { Glossary of } \\
\text { ecosystem } \\
\text { services mapping } \\
\text { and assessment } \\
\text { terminology }\end{array}$ & $\begin{array}{l}\text { https://oneecosystem.pensoft. } \\
\underline{\text { net/articles.php?id=27110 }}\end{array}$ \\
\hline Baseline & $\begin{array}{l}\text { Reference for measurable quantities from which an } \\
\text { alternative outcome can be measured, e.g. a non- } \\
\text { intervention scenario used as a reference in the } \\
\text { analysis of intervention scenarios. }\end{array}$ & IPCC & $\begin{array}{l}\text { https://www.ipcc.ch/pdf/ } \\
\text { assessment-report/ar4/syr/ } \\
\underline{\text { ar4 syr appendix.pdf }}\end{array}$ \\
\hline
\end{tabular}

Any person, group of persons, or entity that uses or is likely to use the benefits obtained from nature

Beneficiaries of provided by the management unit. Examples include, the ecosystem but are not restricted to, persons, groups of persons, service or entities located in the neighbourhood of the management unit. End-users such as consumers or indirect beneficiaries of carbon mitigation are not considered to be beneficiaries.
Ecosystem Services Procedure: Impact Demonstration and Market Tools https://ic.fsc.org/filedownload.ecosystem-servicesprocedure.a-7433.pdf
Benefits: Positive change in 'well-being' from the fulfilment of needs and wants. In terms of

Benefits/Impact impact: Positive effect on individuals, society and environmental resources resulting from environmental change.
Glossary of

ecosystem

services mapping

and assessment

https://oneecosystem.pensoft. net/articles.php?id $=27110$ terminology
Biodiversity—short for biological diversity—-means the diversity of life in all its forms - the diversity of species, of genetic variations within one species, and of ecosystems. The importance of biological diversity

Biodiversity to human society is hard to overstate. An estimated 40 per cent of the global economy is based on biological products and processes. Poor people, especially those living in areas of low agricultural productivity, depend especially heavily on the genetic diversity of the environment.

$\begin{array}{ll}\text { CBD Toolkit } & \underline{\text { https://www.cbd.int/cepa/ }} \\ \text { Glossary } & \underline{\text { toolkit/2008/doc/CBD-Toolkit- }} \\ \text { Glossaries.pdf }\end{array}$



Definition

Source

From the time when humans first occupied Earth and began to hunt animals, gather food and chop wood, they have had an impact on biodiversity. Over the last two centuries, human population growth, overexploitation of natural resources and environmental degradation have resulted in an ever accelerating decline in global biodiversity.

Biodiversity loss Species are diminishing in numbers and becoming extinct, and ecosystems are suffering damage and disappearing. An estimated $80 \%$ of the original forest that covered the Earth 8,000 years ago has been cleared, damaged or fragmented. Some experts assess the rate at which species are becoming extinct at 1,000 to 10,000 times higher than the natural rate would be.

\begin{tabular}{|c|c|c|c|}
\hline Catchment & $\begin{array}{l}\text { The area drained by a river or body of water. The } \\
\text { term is often used interchangeably with Watershed. } \\
\text { See definition for Watershed. }\end{array}$ & IUCN Glossary & $\begin{array}{l}\frac{\text { https://www.lucn.org/sites/ }}{\text { dev/files/iucn-glossary-of- }} \\
\text { definitions en.pdf }\end{array}$ \\
\hline $\begin{array}{l}\text { Climate } \\
\text { adaptation } \\
\text { services }\end{array}$ & $\begin{array}{l}\text { Benefits to people from increased social ability } \\
\text { to respond to change, provided by the capacity } \\
\text { of ecosystems to moderate and adapt to climate } \\
\text { change and variability. }\end{array}$ & $\begin{array}{l}\text { IUCN } 2016 \\
\text { Publication on } \\
\text { Nature-based } \\
\text { Solutions - (Lavorel } \\
\text { et al., 2015) }\end{array}$ & $\begin{array}{l}\frac{\text { https://portals.iucn.org/ }}{\text { library/sites/library/files/ }} \\
\underline{\text { documents/2016-036.pdf }}\end{array}$ \\
\hline
\end{tabular}

Climate change. Climate change refers to any change in climate over time, whether due to natural variability or as a result of human activity. This usage differs from that in the United Nations Framework

Climate change Convention on Climate Change, which defines 'climate change' as: "a change of climate which is attributed directly or indirectly to human activity that

CBD Toolkit

https://www.cbd.int/cepa/ Glossary toolkit/2008/doc/CBD-Toolkit Glossaries.pdf alters the composition of the global atmosphere and which is in addition to natural climate variability observed over comparable time period".

Closing Project Closure aims to capture lessons from the project for future use.

https://www.iucn.org/ resources/projectmanagement-tools/projectguidelines

International standards for the practice of ecological restoration http://seraustralasia. a restoration or monitoring plan usually listed to species or genus (for plants and vertebrate fauna) or at least to order (for invertebrates and microorganisms).
com/wheel/image/SER International_Standards.pdf

and key concepts

A unit of knowledge created by a unique combination of characteristics. Concepts are abstract summaries, general notions, knowledge, etc., of a whole set of behaviours, attitudes or characteristics which are seen as having something in common. Concepts are used to assist in presenting/conveying precise meaning, categorising, interpreting, structuring and making sense of phenomena.

\section{United Nations}

Glossary of

Classification

Terms, prepared by the Expert Group on International

http://data.un.org/Glossary.

Economic

and Social

Classifications 
An incompatibility between opinions, principles, etc. Conflict is not necessarily bad, abnormal or dysfunctional, but rather an inherent element of human interaction. When thinking about the

Conflict directions taken by society, the governance processes by which we deal with conflict are what really matter. Where there is conflict, parties may be less inclined or able to participate fully or constructively in negotiations until the conflict is adequately acknowledged.

External exchanges - the 2-way flows that occur between ecological units within the landscape or aquatic environment including flows of energy, water, fire, genetic material, animals and seeds. Exchanges are facilitated by habitat linkages. https://www.iucn.org/

IUCN

Environmental Law Glossary theme/environmental-law/ our-work/water/water-lawand-governance-supportplatform/learning-resources/ glossary\#PStext

\begin{tabular}{lll}
\hline $\begin{array}{l}\text { External exchanges - the 2-way flows that occur } \\
\text { between ecological units within the landscape or } \\
\text { aquatic environment including flows of energy, water, } \\
\text { fire, genetic material, animals and seeds. Exchanges } \\
\text { are facilitated by habitat linkages. }\end{array}$ & $\begin{array}{l}\text { International } \\
\text { standards for } \\
\text { the practice } \\
\text { of ecological } \\
\text { restoration }- \\
\text { including principles } \\
\text { and key concepts }\end{array}$ & $\begin{array}{ll}\frac{\text { http://seraustralasia. }}{\text { com/wheel/image/SER }} \\
\text { International Standards.pdf }\end{array}$ \\
\hline
\end{tabular}

The protection, care, management and maintenance of ecosystems, habitats, wildlife species and populations, within or outside of their natural environments, in order to safeguard the natural conditions for their long-term permanence. Conservation ex situ. The conservation of the

Conservation components of the biological diversity outside of their natural habitats. Conservation in situ. The conservation of the ecosystems and natural habitats and maintenance and recovery of viable populations of species in their natural environments and, in the case of tame and cultivated species, in the environments where they have developed their specific characteristics. https://www.iucn.org/sites/

IUCN Glossary dev/files/iucn-glossary-ofdefinitions en.pdf

Consultation is a two-way process of dialogue between the project company and its stakeholders. Stakeholder consultation is really about initiating and sustaining constructive external relationships over time. Companies that start the process early and take a long-term, strategic view are, in essence, developing their local "social license to operate."

International

Finance

Corporation https://www.ifc.org/wps/wcm/ connect/5a4e740048855591 b724f76a6515bb18/PartOne StakeholderConsultation. pdf?MOD=AJPERES

Gareis, R.,

Huemann, M., \&

Project costs contain all costs arising during the course of a project. They can be calculated for

Cost individual work packages, for individual objects of consideration, for internal assignments, and for the whole project.

Martinuzzi, A., 2010

Relating sustainable development

and project

management: a

conceptual model. https://www.pmi.org/learning/ library/relating-sustainabledevelopment-projectmanagement-6497

\section{IUCN Glossary} https://www.iucn.org/sites/ dev/files/iucn-glossary-ofdefinitions en.pdf

analysis projects by comparing their costs and benefits.

"Cultural" refers to spiritual, material, intellectual and emotional features of society or a social group in addition to art and literature, lifestyles, ways of living together, value systems, tradition and beliefs.

UNESCO

https://unesdoc.unesco.org/ ark:/48223/pf0000127162

Cultural

Variety or multiformity of human social structures, belief systems, and strategies for adapting to

Cultural situations in different parts of the world. Language is a good indicator of cultural diversity, with over 6,000 languages currently being spoken.

https://www.cbd.int/cepa/ toolkit/2008/doc/CBD-ToolkitGlossaries.pdf 


\begin{tabular}{|c|c|c|c|}
\hline Term & Definition & Source & Link \\
\hline $\begin{array}{l}\text { Cultural } \\
\text { ecosystem } \\
\text { services }\end{array}$ & $\begin{array}{l}\text { The nonmaterial benefits people obtain from } \\
\text { ecosystems through spiritual enrichment, cognitive } \\
\text { development, reflection, recreation, and aesthetic } \\
\text { experience, including, e.g. knowledge systems, social } \\
\text { relations, and aesthetic values. }\end{array}$ & $\begin{array}{l}\text { Millennium } \\
\text { Ecosystem Services } \\
\text { - MEA }\end{array}$ & $\begin{array}{l}\text { https://www. } \\
\text { millenniumassessment.org/ } \\
\text { documents/document.776. } \\
\text { aspx.pdf }\end{array}$ \\
\hline Decision maker & $\begin{array}{l}\text { A person whose decisions, and the actions that } \\
\text { follow from them, can influence a condition, process, } \\
\text { or issue under consideration. }\end{array}$ & $\begin{array}{l}\text { Millennium } \\
\text { Ecosystem Services } \\
\text { - MEA }\end{array}$ & $\begin{array}{l}\frac{\text { https://www. }}{\text { millenniumassessment.org/ }} \\
\text { documents/document.776. } \\
\text { aspx.pdf }\end{array}$ \\
\hline
\end{tabular}

A serious disruption of the functioning of a community or a society causing widespread human, material, economic or environmental losses which exceed the ability of the affected community or society to cope using its own resources (ISDR 2004). Disaster Risk Reduction. People and institutions

Disaster involved in preparedness, mitigation (e.g. reinforcing building structures, improving public awareness about disaster risks), and prevention activities (e.g. planting trees to stabilize riverbanks) associated with extreme events. These include hazard forecasting and immediate relief efforts for major disasters resulting from floods, cyclones and, in some cases, pollution events (adapted from IISD/IUCN/SEI 2003).

\begin{tabular}{|c|c|c|c|}
\hline Disaster risk & $\begin{array}{l}\text { The potential loss of life, injury, destroyed or } \\
\text { damaged assets which could occur to a system, } \\
\text { society or a community in a specific period of time, } \\
\text { determined probabilistically as a function of hazards, } \\
\text { exposure, vulnerability and capacity. }\end{array}$ & $\begin{array}{l}\text { Monty, F., Murti, } \\
\text { R., Miththapala, } \\
\text { S. and Buyck, C., } \\
\text { 2017. Ecosystems } \\
\text { protecting } \\
\text { infrastructure } \\
\text { and communities: } \\
\text { lessons learned } \\
\text { and guidelines for } \\
\text { implementation. }\end{array}$ & $\begin{array}{l}\frac{\text { https://portals.iucn.org/ }}{\text { library/sites/library/files// }} \\
\text { documents/2017-045.pdf }\end{array}$ \\
\hline $\begin{array}{l}\text { Ecological } \\
\text { engineering }\end{array}$ & $\begin{array}{l}\text { Management of systems of human and } \\
\text { environmental self-design or light management that } \\
\text { joins human design and environmental self-design, } \\
\text { so that they are mutually symbiotic. The design of } \\
\text { sustainable ecosystems that integrate human society } \\
\text { with its natural environment for the benefit of both. }\end{array}$ & $\begin{array}{l}\text { IUCN } 2016 \\
\text { Publication on } \\
\text { Nature-based } \\
\text { Solutions (Odum, } \\
\text { 1996) \& (Mitsch, } \\
\text { 2012) }\end{array}$ & $\frac{\frac{\text { https://portals.iucn.org/ }}{\text { library/sites/library/files// }}}{\underline{\text { documents/2016-036.pdf }}}$ \\
\hline $\begin{array}{l}\text { Ecological } \\
\text { subsidies }\end{array}$ & $\begin{array}{l}\text { A donor-controlled resource (prey, detritus, } \\
\text { nutrients) from one habitat to a recipient (plant or } \\
\text { consumer) from a second habitat, which increases } \\
\text { population productivity of the recipient, potentially } \\
\text { altering consumer-resource dynamics in the } \\
\text { recipient system. }\end{array}$ & Polis et al., 1997 & $\begin{array}{l}\text { https://www.annualreviews. } \\
\text { org/doi/pdf/10.1146/annurev. } \\
\text { ecolsys.28.1.289 }\end{array}$ \\
\hline Ecosystem & $\begin{array}{l}\text { Ecosystem. According to the Agreement on Biological } \\
\text { Diversity, an ecosystem is understood as a dynamic } \\
\text { complex of vegetable, animal and microorganism } \\
\text { communities and their nonliving environment that } \\
\text { interact as a functional unit. Ecosystems may be } \\
\text { small and simple, like an isolated pond, or large and } \\
\text { complex, like a specific tropical rainforest or a coral } \\
\text { reef in tropical seas. }\end{array}$ & IUCN Glossary & $\frac{\frac{\text { https://www.iucn.org/sites/ }}{\text { dev/files/iucn-glossary-of- }}}{\underline{\text { definitions en.pdf }}}$ \\
\hline
\end{tabular}




\begin{tabular}{|c|c|c|c|}
\hline $\begin{array}{l}\text { Ecosystem } \\
\text { Approach }\end{array}$ & $\begin{array}{l}\text { The Ecosystem Approach is a strategy for the } \\
\text { integrated management of land, water and living } \\
\text { resources that promotes conservation and } \\
\text { sustainable use in an equitable way. The Ecosystem } \\
\text { Approach places human needs at the centre of } \\
\text { biodiversity management. It aims to manage the } \\
\text { ecosystem, based on the multiple functions that } \\
\text { ecosystems perform and the multiple uses that are } \\
\text { made of these functions. The ecosystem approach } \\
\text { does not aim for short-term economic gains, but } \\
\text { aims to optimize the use of an ecosystem without } \\
\text { damaging it. }\end{array}$ & $\begin{array}{l}\text { CBD Toolkit } \\
\text { Glossary }\end{array}$ & $\begin{array}{l}\text { https://www.cbd.int/cepa/ } \\
\text { toolkit/2008/doc/CBD-Toolkit- } \\
\text { Glossaries.pdf }\end{array}$ \\
\hline $\begin{array}{l}\text { Ecosystem } \\
\text { function }\end{array}$ & $\begin{array}{l}\text { The size, biodiversity, stability, degree of organization, } \\
\text { internal exchanges of materials, energy, and } \\
\text { information among different pools, and other } \\
\text { properties that characterize an ecosystem. Includes } \\
\text { ecosystem functions and processes. }\end{array}$ & $\begin{array}{l}\text { Millennium } \\
\text { Ecosystem Services } \\
\text { - MEA }\end{array}$ & $\begin{array}{l}\frac{\text { https://www. }}{\text { millenniumassessment.org/ }} \\
\text { documents/document.776. } \\
\underline{\text { aspx.pdf }}\end{array}$ \\
\hline $\begin{array}{l}\text { Ecosystem } \\
\text { health }\end{array}$ & $\begin{array}{l}\text { Condition of an ecosystem: The capacity of an } \\
\text { ecosystem to yield services, relative to its potential } \\
\text { capacity. Condition of an ecosystem service: The } \\
\text { capacity of an ecosystem service to yield benefits to } \\
\text { people, relative to its potential capacity. }\end{array}$ & $\begin{array}{l}\text { Millennium } \\
\text { Ecosystem Services } \\
\text { - MEA }\end{array}$ & $\begin{array}{l}\frac{\text { https://www. }}{\text { millenniumassessment.org/ }} \\
\text { documents/document.776. } \\
\text { aspx.pdf }\end{array}$ \\
\hline $\begin{array}{l}\text { Ecosystem } \\
\text { management }\end{array}$ & $\begin{array}{l}\text { Management (of an ecosystem) - a broad } \\
\text { categorization that can include maintenance and } \\
\text { repair of ecosystems (including restoration). }\end{array}$ & $\begin{array}{l}\text { International } \\
\text { standards for } \\
\text { the practice } \\
\text { of ecological } \\
\text { restoration - } \\
\text { including principles } \\
\text { and key concepts }\end{array}$ & $\begin{array}{l}\text { http://seraustralasia. } \\
\underline{\text { com/wheel/image/SER }} \\
\underline{\text { International Standards.pdf }}\end{array}$ \\
\hline $\begin{array}{l}\text { Ecosystem } \\
\text { process }\end{array}$ & $\begin{array}{l}\text { Any change or reaction, which occurs within } \\
\text { ecosystems, physical, chemical or biological. } \\
\text { Ecosystem processes include decomposition, } \\
\text { production, nutrient cycling, and fluxes of nutrients } \\
\text { and energy. }\end{array}$ & $\begin{array}{l}\text { Glossary of } \\
\text { ecosystem } \\
\text { services mapping } \\
\text { and assessment } \\
\text { terminology }\end{array}$ & $\begin{array}{l}\text { https://oneecosystem.pensoft. } \\
\underline{\text { net/articles.php?id=27110 }}\end{array}$ \\
\hline $\begin{array}{l}\text { Ecosystem } \\
\text { properties }\end{array}$ & $\begin{array}{l}\text { Attributes which characterize an ecosystem, } \\
\text { such as its size, biodiversity, stability, degree of } \\
\text { organization, as well as its functions and processes } \\
\text { (i.e., the internal exchanges of materials, energy and } \\
\text { information among different pools). }\end{array}$ & $\begin{array}{l}\text { Glossary of } \\
\text { ecosystem } \\
\text { services mapping } \\
\text { and assessment } \\
\text { terminology }\end{array}$ & $\begin{array}{l}\text { https://oneecosystem.pensoft. } \\
\text { net/articles.php?id=27110 }\end{array}$ \\
\hline $\begin{array}{l}\text { Ecosystem } \\
\text { services }\end{array}$ & $\begin{array}{l}\text { The benefits people obtain from ecosystems. These } \\
\text { include provisioning services such as food and water; } \\
\text { regulating services such as flood and disease control; } \\
\text { cultural services such as spiritual, recreational, and } \\
\text { cultural benefits; and supporting services such as } \\
\text { nutrient cycling that maintain the conditions for } \\
\text { life on Earth. The concept "ecosystem goods and } \\
\text { services" is synonymous with ecosystem services. }\end{array}$ & $\begin{array}{l}\text { Millennium } \\
\text { Ecosystem Services } \\
\text { - MEA }\end{array}$ & $\begin{array}{l}\frac{\text { https://www. }}{\text { millenniumassessment.org/ }} \\
\text { documents/document.776. } \\
\underline{\text { aspx.pdf }}\end{array}$ \\
\hline
\end{tabular}

\section{Ecosystem stewardship is an action-oriented} framework intended to foster the social-ecological sustainability of a rapidly changing planet. Its central goal is to sustain the capacity to provide ecosystem services that support human well-being under conditions of uncertainty and change.

Ecosystem Ecosystem stewardship integrates three broadly stewardship overlapping sustainability approaches: (i) reducing vulnerability to expected changes; (ii) fostering resilience to sustain desirable conditions in the face of perturbations and uncertainty; and (iii) transforming from undesirable trajectories when opportunities [for change] emerge. 


\begin{tabular}{|c|c|c|c|}
\hline Term & Definition & Source & Link \\
\hline $\begin{array}{l}\text { Ecosystem } \\
\text { structure }\end{array}$ & $\begin{array}{l}\text { A static characteristic of an 'Ecosystem' that is } \\
\text { measured as a stock or volume of material or energy, } \\
\text { or the composition and distribution of biophysical } \\
\text { elements. }\end{array}$ & $\begin{array}{l}\text { Glossary of } \\
\text { ecosystem } \\
\text { services mapping } \\
\text { and assessment } \\
\text { terminology }\end{array}$ & $\begin{array}{l}\text { https://oneecosystem.pensoft. } \\
\underline{\text { net/articles.php?id=27110 }}\end{array}$ \\
\hline $\begin{array}{l}\text { Ecosystem- } \\
\text { based } \\
\text { Adaptation }\end{array}$ & $\begin{array}{l}\text { The use of biodiversity and ecosystem services as } \\
\text { part of an overall adaptation strategy to help people } \\
\text { to adapt to the adverse effects of climate change. }\end{array}$ & $\begin{array}{l}\text { IUCN } 2016 \\
\text { Publication on } \\
\text { Nature-based } \\
\text { Solutions - (CBD, } \\
\text { 2009) }\end{array}$ & $\frac{\frac{\text { https://portals.iucn.org/ }}{\text { library/sites/library/files/ }}}{\underline{\text { documents/2016-036.pdf }}}$ \\
\hline $\begin{array}{l}\text { Ecosystem- } \\
\text { based disaster } \\
\text { risk reduction }\end{array}$ & $\begin{array}{l}\text { The sustainable management, conservation and } \\
\text { restoration of ecosystems to provide services that } \\
\text { reduce disaster risk by mitigating hazards and by } \\
\text { increasing livelihood resilience. }\end{array}$ & $\begin{array}{l}\text { IUCN } 2016 \\
\text { Publication on } \\
\text { Nature-based } \\
\text { Solutions - (PEDRR, } \\
\text { 2010) }\end{array}$ & $\begin{array}{l}\frac{\text { https://portals.iucn.org/ }}{\text { library/sites/library/files/ }} \\
\underline{\text { documents/2016-036.pdf }}\end{array}$ \\
\hline $\begin{array}{l}\text { Ecosystem- } \\
\text { based } \\
\text { management }\end{array}$ & $\begin{array}{l}\text { Integrated, science-based approach to the } \\
\text { management of natural resources that aims to } \\
\text { sustain the health, resilience and diversity of } \\
\text { ecosystems while allowing for sustainable use by } \\
\text { humans of the goods and services they provide. }\end{array}$ & $\begin{array}{l}\text { IUCN } 2016 \\
\text { Publication on } \\
\text { Nature-based } \\
\text { Solutions - (Kappel } \\
\text { et al., 2006) \& } \\
\text { (Garcia et al., 2003) }\end{array}$ & $\begin{array}{l}\frac{\text { https://portals.iucn.org/ }}{\text { library/sites/library/files/ }} \\
\underline{\text { documents/2016-036.pdf }}\end{array}$ \\
\hline
\end{tabular}

\begin{tabular}{|c|c|c|c|}
\hline $\begin{array}{l}\text { Ecosystem- } \\
\text { based } \\
\text { mitigation }\end{array}$ & $\begin{array}{l}\text { Enhance the benefits for, and avoid negative impacts } \\
\text { on biodiversity from reducing emissions, taking into } \\
\text { account the need to ensure the full and effective } \\
\text { participation of indigenous and local communities } \\
\text { in relevant policy-making and implementation } \\
\text { processes, where appropriate. Enhance the } \\
\text { conservation, sustainable use and restoration of } \\
\text { marine and coastal habitats that are vulnerable to } \\
\text { the effects of climate change or which contribute to } \\
\text { climate-change mitigation. }\end{array}$ & $\begin{array}{l}\text { IUCN } 2016 \\
\text { Publication on } \\
\text { Nature-based } \\
\text { Solutions - (CBD, } \\
\text { 2010) }\end{array}$ & $\begin{array}{l}\text { https://portals.iucn.org/ } \\
\frac{\text { library/sites/library/files/ }}{\text { documents/2016-036.pdf }}\end{array}$ \\
\hline Engage & $\begin{array}{l}\text { Attract or involve someone's interest or attention. } \\
\text { Engage in/with: participate or become involved in. }\end{array}$ & $\begin{array}{l}\text { IUCN } \\
\text { Environmental Law } \\
\text { Glossary }\end{array}$ & $\begin{array}{l}\text { https://www.iucn.org/ } \\
\text { theme/environmental-law/ } \\
\text { our-work/water/water-law- } \\
\text { and-governance-support- } \\
\text { platform/learning-resources/ } \\
\text { glossary\#PStext }\end{array}$ \\
\hline Environment & $\begin{array}{l}\text { It refers to all living and non-living components } \\
\text { and all the factors, like the climate, that surround } \\
\text { an organism. It is frequently confused with the } \\
\text { word ecology, which is the science that studies the } \\
\text { relations of living beings with each other as well as } \\
\text { with all the non-living parts of an environment. The } \\
\text { environment could be conceived as a row of domino } \\
\text { tiles. In this sense, ecology would be the study of } \\
\text { the effect on each other of all the domino tiles while } \\
\text { falling. }\end{array}$ & IUCN Glossary & $\begin{array}{l}\text { https://www.iucn.org/sites/ } \\
\text { dev/files/iucn-glossary-of- } \\
\text { definitions en.pdf }\end{array}$ \\
\hline $\begin{array}{l}\text { Equitable } \\
\text { benefits }\end{array}$ & $\begin{array}{l}\text { It refers to the ultimate impact of development } \\
\text { efforts on both genders. It implies that the results } \\
\text { should be equally accessed and utilized by men } \\
\text { and women. Equality of opportunities does not, } \\
\text { necessarily, imply that both genders enjoy the same } \\
\text { benefits. }\end{array}$ & IUCN Glossary & $\begin{array}{l}\text { https://www.iucn.org/sites/ } \\
\text { dev/files/iucn-glossary-of- } \\
\underline{\text { definitions en.pdf }}\end{array}$ \\
\hline
\end{tabular}




\begin{tabular}{|c|c|c|c|}
\hline Term & Definition & Source & Link \\
\hline Equity & $\begin{array}{l}\text { It seeks people's access to equal opportunities and } \\
\text { the development of basic capacities; this means } \\
\text { that the barriers hindering economic and political } \\
\text { opportunities, as well as the access to education } \\
\text { and basic services, should be eliminated, so that the } \\
\text { people (women and men of all ages, conditions and } \\
\text { positions) may be able to enjoy such opportunities } \\
\text { and benefit from them. It means justice; that is, giving } \\
\text { each one what is rightfully theirs, recognizing the } \\
\text { specific conditions or characteristics of each person } \\
\text { or human group (sex, gender, class, religion, age); it is } \\
\text { the recognition of diversity, without giving reason to } \\
\text { discrimination. }\end{array}$ & IUCN Glossary & $\begin{array}{l}\text { https://www.iucn.org/sites/ } \\
\text { dev/files/iucn-glossary-of- } \\
\text { definitions en.pdf }\end{array}$ \\
\hline Equity & $\begin{array}{l}\text { The quality of being fair and impartial. Principle } \\
\text { under which all individuals that are in the same } \\
\text { situation must abide by the same laws, without any } \\
\text { type of distinction or discrimination. }\end{array}$ & $\begin{array}{l}\text { IUCN } \\
\text { Environmental Law } \\
\text { Glossary }\end{array}$ & $\begin{array}{l}\text { https://www.iucn.org/ } \\
\text { theme/environmental-law/ } \\
\text { our-work/water/water-law- } \\
\text { and-governance-support- } \\
\text { platform/learning-resources/ } \\
\text { glossary\#PStext }\end{array}$ \\
\hline $\begin{array}{l}\text { Evolutionary } \\
\text { process }\end{array}$ & $\begin{array}{l}\text { A series of events that produce changes in gene } \\
\text { frequencies within a population. Such changes can } \\
\text { result in the appearance of new species (speciation) } \\
\text { or new intraspecific taxa. }\end{array}$ & $\begin{array}{l}\text { Glossary of } \\
\text { ecosystem } \\
\text { services mapping } \\
\text { and assessment } \\
\text { terminology }\end{array}$ & $\begin{array}{l}\text { https://oneecosystem.pensoft. } \\
\underline{\text { net/articles.php?id=27110 }}\end{array}$ \\
\hline $\begin{array}{l}\text { Flow (ecosystem } \\
\text { service) }\end{array}$ & $\begin{array}{l}\text { The amount of an ecosystem service that is actually } \\
\text { mobilized in a specific area and time }\end{array}$ & $\begin{array}{l}\text { Glossary of } \\
\text { ecosystem } \\
\text { services mapping } \\
\text { and assessment } \\
\text { terminology }\end{array}$ & $\begin{array}{l}\text { https://oneecosystem.pensoft. } \\
\underline{\text { net/articles.php?id=27110 }}\end{array}$ \\
\hline Food security & $\begin{array}{l}\text { Food security - the availability of food that is } \\
\text { accessible to all, safe and locally appropriate, and } \\
\text { reliable through time and across space - is one of } \\
\text { the major issues facing the world today. }\end{array}$ & $\begin{array}{l}\text { IUCN } 2016 \\
\text { Publication on } \\
\text { Nature-based } \\
\text { Solutions }\end{array}$ & $\begin{array}{l}\frac{\text { https://portals.iucn.org/ }}{\text { library/sites/library/files/ }} \\
\underline{\text { documents/2016-036.pdf }}\end{array}$ \\
\hline $\begin{array}{l}\text { Forest } \\
\text { landscape } \\
\text { restoration }\end{array}$ & $\begin{array}{l}\text { A planned process that aims to regain ecological } \\
\text { integrity and enhance human well-being in } \\
\text { deforested or degraded landscapes. Forest } \\
\text { landscape restoration is the long-term process of } \\
\text { regaining ecological functionality and enhancing } \\
\text { human well-being across deforested or degraded } \\
\text { forest landscapes. }\end{array}$ & $\begin{array}{l}\text { IUCN } 2016 \\
\text { Publication on } \\
\text { Nature-based } \\
\text { Solutions- } \\
\text { (Mansourian et al., } \\
\text { 2005) \& (Maginnis } \\
\text { et al., 2014) }\end{array}$ & $\begin{array}{l}\frac{\text { https://portals.iucn.org/ }}{\text { library/sites/library/files/ }} \\
\underline{\text { documents/2016-036.pdf }}\end{array}$ \\
\hline Framework & $\begin{array}{l}\text { Framework. A high-level structure which lays down } \\
\text { a common purpose and direction for plans and } \\
\text { programmes. }\end{array}$ & IUCN Glossary & $\begin{array}{l}\frac{\text { https://www.iucn.org/sites/ }}{\text { dev/files/iucn-glossary-of- }} \\
\text { definitions en.pdf }\end{array}$ \\
\hline
\end{tabular}

Genders are bio-socio-cultural groups, historically built from the identification of sexual characteristics that classify human beings. Once classified, they are assigned a differentiated set of functions, activities,

Gender social relations, forms and standards of behavior. It is a complex set of economic, social, legal, political and psychological determinations and characteristics, that is, cultural, creating that which in each period of time, society or culture constitutes the specific contents of being a man or a woman.

The estimated increase in GMST averaged over a 30-year period, or the 30-year period centred on a particular year or decade, expressed relative to

Global warming pre-industrial levels unless otherwise specified. For 30-year periods that span past and future years, the current multi-decadal warming trend is assumed to continue.

https://www.ipcc.ch/ site/assets/uploads/ sites/2/2019/05/SR15 SPM version report LR.pdf 
Term

\section{Definition}

The action or manner of governing; the system of controlling, directing, or regulating influence. It

Governance involves four aspects: social, political, economic and legal. More than government, governance refers to the complex of processes and institutions by which society contests, makes and manages decisions.
Source Link

Committee or board responsible for the strategic guidance of the organization, the effective monitoring of management, and the accountability of management to the broader organization and its stakeholders https://www.iucn.org/

IUCN

Environmental Law

Glossary theme/environmental-law/

our-work/water/water-law-

and-governance-supportplatform/learning-resources/ glossary\#PStext

\begin{tabular}{llll}
\hline & Committee or board responsible for the strategic & & \\
$\begin{array}{l}\text { Governance } \\
\text { body }\end{array}$ & $\begin{array}{l}\text { guidance of the organization, the effective } \\
\text { monitoring of management, and the accountability } \\
\text { of management to the broader organization and its } \\
\text { stakeholders }\end{array}$ & $\begin{array}{l}\text { Global Reporting } \\
\text { Institute Glossary }\end{array}$ & $\underline{\underline{\text { org/standards/media/1913/ }}}$ \\
& gri-standards-glossary.pdf & \\
\hline
\end{tabular}

Gl comprises of all natural, semi-natural and artificial networks of multifunctional ecological systems within, around and between urban areas, at all spatial scales. The green infrastructure concept emphasises on the quality as well as quantity of urban and periurban green spaces, their multifunctional role, and the importance of interconnections between

Green

Infrastructure habitats. Gl is a strategically planned network of natural and semi-natural areas with other environmental features designed and managed to deliver a wide range of ecosystem services. It incorporates green spaces (or blue if aquatic ecosystems are concerned) and other physical features in terrestrial (including coastal) and marine areas. On land, Gl is present in rural and urban settings.

\section{IUCN 2016}

Publication on

Nature-based

Solutions - (Tzoulas

et al., 2007)

\& (European

Commission, 2013) https://portals.iucn.org/

library/sites/library/files/ documents/2016-036.pdf

\section{Grievance mechanism system consisting of}

procedures, roles and rules for receiving complaints and providing remedy Note: Effective grievance mechanisms are expected to be legitimate,

Grievance mechanism accessible, predictable, equitable, transparent, rightscompatible, and a source of continuous learning. For operational-level mechanisms to be effective, they are expected to be based on engagement and dialogue. For a description of each of these criteria, see Guiding Principle 31 in the United Nations (UN).

\section{Global Reporting} Institute Glossary https://www.globalreporting. org/standards/media/1913/ gri-standards-glossary.pdf

A state of complete physical, mental, and social wellbeing and not merely the absence of disease or infirmity. The health of a whole community or population is reflected in measurements of disease incidence and prevalence, age-specific death rates, Human health and life expectancy. Constituents of well-being: The experiential aspects of well-being, such as health, happiness, and freedom to be and do, and, more broadly, basic liberties. Determinants of well-being: Inputs into the production of wellbeing, such as food, clothing, potable water, and access to knowledge and information.

\section{Millennium \\ Ecosystem Services - MEA}

https://www. millenniumassessment.org/ documents/document.776. aspx.pdf

"Human well-being is assumed to have multiple constituents, including the basic material for a good life, such as secure and adequate livelihoods, enough food at all times, shelter, clothing, and access to goods; health, including feeling well and having a healthy physical environment, such as clean air Human well- $\quad$ and access to clean water; good social relations, being including social cohesion, mutual respect, and the ability to help others and provide for children; security, including secure access to natural and other

Millennium Ecosystem Services - MEA https://www. millenniumassessment.org/ documents/document.776. aspx.pdf resources, personal safety, and security from natural and human-made disasters; and freedom of choice and action, including the opportunity to achieve what an individual values doing and being." 


\begin{tabular}{|c|c|c|c|}
\hline Term & Definition & Source & Link \\
\hline Impact & $\begin{array}{l}\text { Negative or positive effect on individuals, society } \\
\text { and environmental resources resulting from } \\
\text { environmental change. }\end{array}$ & $\begin{array}{l}\text { Glossary of } \\
\text { ecosystem } \\
\text { services mapping } \\
\text { and assessment } \\
\text { terminology }\end{array}$ & $\begin{array}{l}\text { https://oneecosystem.pensoft. } \\
\text { net/articles.php?id=27110 }\end{array}$ \\
\hline $\begin{array}{l}\text { Impact } \\
\text { (environmental) }\end{array}$ & $\begin{array}{l}\text { The measurable effect of human action over a } \\
\text { certain ecosystem. A measuring instrument is the } \\
\text { manifestation of environmental impact, through } \\
\text { which document is revealed the significant and } \\
\text { potential environmental impact generated by an } \\
\text { activity or work, as well as how it could be avoided or } \\
\text { mitigated in the case of a negative impact. }\end{array}$ & IUCN Glossary & $\begin{array}{l}\frac{\text { https://www.iucn.org/sites/ }}{\text { dev/files/iucn-glossary-of- }} \\
\text { definitions en.pdf }\end{array}$ \\
\hline
\end{tabular}

Implementation describes the actions taken to meet commitments under a treaty and encompasses legal and effective phases. Legal implementation refers to legislation, regulations, judicial decrees, including other actions such as efforts to administer progress Implementation which governments take to translate international accords into domestic law and policy. Effective implementation needs policies and programmes that induce changes in the behaviour and decisions of target groups. Target groups then take effective measures of mitigation and adaptation. See also Compliance.

\begin{tabular}{|c|c|c|c|}
\hline Indicator & $\begin{array}{l}\text { Quantitative or qualitative factor or variable that } \\
\text { provides a simple and reliable means to measure } \\
\text { achievement of outcomes, to reflect the changes } \\
\text { connected to a standards system, or to help assess } \\
\text { the performance of an organisation. }\end{array}$ & $\begin{array}{l}\text { ISEAL Glossary of } \\
\text { terms - adapted } \\
\text { from OECD } \\
\text { Glossary, } 2002 .\end{array}$ & 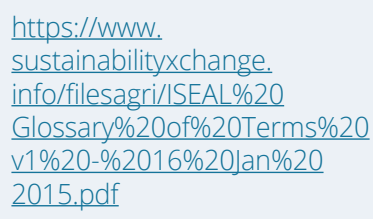 \\
\hline $\begin{array}{l}\text { Indigenous } \\
\text { knowledge }\end{array}$ & $\begin{array}{l}\text { The knowledge that is unique to a given culture or } \\
\text { society. See traditional knowledge. }\end{array}$ & $\begin{array}{l}\text { Millennium } \\
\text { Ecosystem Services } \\
\text { - MEA }\end{array}$ & $\begin{array}{l}\frac{\text { https://www. }}{\text { millenniumassessment.org/ }} \\
\text { documents/document.776. } \\
\text { aspx.pdf }\end{array}$ \\
\hline $\begin{array}{l}\text { Indigenous } \\
\text { peoples }\end{array}$ & $\begin{array}{l}\text { The existing descendants of the peoples who } \\
\text { inhabited the present territory of a country wholly } \\
\text { or partially at the time when persons of a different } \\
\text { culture or ethnic origin arrived there from other } \\
\text { parts of the world, overcame them and, by conquest, } \\
\text { settlement, or other means reduced them to a non- } \\
\text { dominant or colonial situation; who today live more } \\
\text { in conformity with their particular social, economic } \\
\text { and cultural customs and traditions than with the } \\
\text { institutions of the country of which they now form } \\
\text { a part, under State structure which incorporates } \\
\text { mainly the national, social and cultural characteristics } \\
\text { of other segments of the population which are } \\
\text { predominant. (Working definition adopted by the } \\
\text { UN Working Group on Indigenous Peoples). }\end{array}$ & IUCN Glossary & $\frac{\frac{\text { https://www.lucn.org/sites/ }}{\text { dev/files/iucn-glossary-of- }}}{\text { definitions en.pdf }}$ \\
\hline Infrastructure & $\begin{array}{l}\text { The basic equipment, utilities, productive } \\
\text { enterprises, installations, and services essential } \\
\text { for the development, operation, and growth of an } \\
\text { organization, city, or nation. }\end{array}$ & IPCC & $\begin{array}{l}\frac{\text { https://www.ipcc.ch/pdf/ }}{\text { assessment-report/ar4/syr/ }} \\
\underline{\text { ar4_syr appendix.pdf }}\end{array}$ \\
\hline Institutions & $\begin{array}{l}\text { Institutions are persistent, predictable arrangements, } \\
\text { laws, processes or customs serving to structure } \\
\text { political, social, cultural or economic transactions and } \\
\text { relationships in a society. They may be informal or } \\
\text { formal, and allow organized, collective efforts around } \\
\text { common concerns. Although persistent, institutions } \\
\text { constantly evolve. }\end{array}$ & $\begin{array}{l}\text { IUCN } \\
\text { Environmental Law } \\
\text { Glossary }\end{array}$ & $\begin{array}{l}\text { https://www.iucn.org/ } \\
\text { theme/environmental-law/ } \\
\text { our-work/water/water-law- } \\
\text { and-governance-support- } \\
\text { platform/learning-resources/ } \\
\text { glossary\#PStext }\end{array}$ \\
\hline
\end{tabular}


A method of analysis that combines results and models from the physical, biological, economic and social sciences, and the interactions between these

Integrated assessment components in a consistent framework to evaluate the status and the consequences of environmental change and the policy responses to it. Models used to carry out such analysis are called Integrated Assessment Models.
IPCC $\quad \frac{\text { https://www.ipcc.ch/pdf/ }}{\text { assessment-report/ar4/syr/ }}$ ar4_syr_appendix.pdf

\begin{tabular}{|c|c|c|c|}
\hline Integration & $\begin{array}{l}\text { The level of integration within existing 'Ecosystem } \\
\text { assessments' varies; but usually falls within i) } \\
\text { combining, ii) interpreting and iii) communicating } \\
\text { knowledge from diverse disciplines. }\end{array}$ & $\begin{array}{l}\text { Glossary of } \\
\text { ecosystem } \\
\text { services mapping } \\
\text { and assessment } \\
\text { terminology }\end{array}$ & $\begin{array}{l}\text { https://oneecosystem.pensoft. } \\
\text { net/articles.php?id=27110 }\end{array}$ \\
\hline $\begin{array}{l}\text { Introduced } \\
\text { species }\end{array}$ & $\begin{array}{l}\text { Introduced species are those occurring outside } \\
\text { their natural range (past or present) and dispersal } \\
\text { potential (i.e. outside the range they occupy naturally } \\
\text { or could not occupy without direct or indirect } \\
\text { introduction or care by humans). }\end{array}$ & RLTS Glossary & $\begin{array}{l}\frac{\text { http://www.iucnredlist. }}{\text { org/initiatives/mammals/ }} \\
\text { description/glossary }\end{array}$ \\
\hline Invasive species & $\begin{array}{l}\text { An alien species is a species introduced by humans } \\
\text { - either intentionally or accidentally - outside of } \\
\text { its natural past or present distribution, however } \\
\text { not all alien species have negative impacts, and it } \\
\text { is estimated that between } 5 \% \text { and } 20 \% \text { of all alien } \\
\text { species become problematic. It is these species } \\
\text { that are termed 'invasive alien species' (IAS). "An } \\
\text { invasive alien species (IAS) is a species that is } \\
\text { established outside of its natural past or present } \\
\text { distribution, whose introduction and/or spread } \\
\text { threaten biological diversity" Convention on Biological } \\
\text { Diversity. }\end{array}$ & RLTS Glossary & $\begin{array}{l}\frac{\text { http://www.lucnredlist. }}{\text { org/initiatives/mammals/ }} \\
\underline{\text { description/glossary }}\end{array}$ \\
\hline Land use & $\begin{array}{l}\text { Land use refers to how a specific piece of land is } \\
\text { allocated: its purpose, need or use (e.g. agriculture, } \\
\text { industry, residential or nature). }\end{array}$ & $\begin{array}{l}\text { CBD Toolkit } \\
\text { Glossary }\end{array}$ & $\begin{array}{l}\frac{\text { https://www.cbd.int/cepa/ }}{\text { toolkit/2008/doc/CBD-Toolkit- }} \\
\text { Glossaries.pdf }\end{array}$ \\
\hline $\begin{array}{l}\text { Landscape } \\
\text { (cultural) }\end{array}$ & $\begin{array}{l}\text { Cultural properties that represent the combined } \\
\text { works of nature and of people. }\end{array}$ & $\begin{array}{l}\text { Glossary of } \\
\text { ecosystem } \\
\text { services mapping } \\
\text { and assessment } \\
\text { terminology }\end{array}$ & $\begin{array}{l}\text { https://oneecosystem.pensoft. } \\
\text { net/articles.php?id=27110 }\end{array}$ \\
\hline
\end{tabular}

An area, as perceived by people, whose character is the result of the action and interaction of natural and/or human factors. The term "landscape" is thus defined as a zone or area as perceived by local people or visitors, whose visual features and Landscape character are the result of the action of natural and (geographical) or cultural factors. Recognition is given to the fact that landscapes evolve through time and are the result of natural and human activities. Landscape should be considered as a whole - natural and cultural components are taken together, not separately.

\section{Glossary of} ecosystem services mapping and assessment terminology https://oneecosystem.pensoft. net/articles.php?id=27110

The landscape approach is based on an emerging set of principles that emphasize adaptive management,

Landscape approach stakeholder involvement, and multiple objectives to address societal concerns about environment and development trade-offs.
Sayer et al., 2013.

https://www.pnas.org/ content/110/21/8349

The extent, to which a landscape facilitates the movements of organisms and their genes, faces
critical threats from both fragmentation and habitat

Landscape loss.

https://www.fs.fed.us/rm/

Rudnick et al., 2012 pubs other/rmrs 2012 rudnick d001.pdf 


$\begin{array}{llll}\text { Term } & \text { Definition } & \text { Source } & \text { Link } \\ & & \text { International } & \\ & \text { Landscape flows - exchanges that occur at a level } & \text { standards for } & \text { http://seraustralasia. } \\ \text { Landscape } & \text { larger than the site (including aquatic environments) } & \text { the practice } & \underline{\text { com/wheel/image/SER }} \\ \text { flows } & \text { and including flows of energy, water, fire and genetic } & \text { of ecological } & \underline{\text { International Standards.pdf }} \\ & \text { material. Exchanges are facilitated by habitat linkages } & \text { restoration - } & \text { including principles } \\ & \text { (Wiens 1992). } & \text { and key concepts } & \\ \end{array}$

There is no single accepted definition of 'landscape scale'; rather, it is a term commonly used to refer to action that covers a large spatial scale, usually addressing a range of ecosystem processes, conservation objectives and land uses. The 'right scale' might need to take account of the particular interest of those involved locally, aesthetic or cultural characteristics, natural features such as river catchment areas or particular habitats, or recognised areas such as the 159 National Character Areas. Landscape scale conservation is characterised by

Landscape scale the pursuit of multiple benefits across a defined area (e.g. water quality, biodiversity and access). The best examples also make links to wider economic and social priorities, where enhancing nature can provide benefits to the local economy and quality of life. There are strong links between the landscape scale approach and an 'ecosystems approach', which encourages an integrated approach to land management, considering the costs and benefits of land use decisions, and pursuing those that minimise risks and maximise opportunities for people, for nature and for the economy.

Landscape scale - towards an integrated approach; The Natural Choice, Natural Environment White Paper, 2011 https://www banc org.uk/wpcontent/uploads/2015/05/ ECOS-33-3-4-6-Landscapescale-integrated-approach.pdf
Consecutive and interlinked stages of a product (good or service), from the extraction of natural resources to the final disposal.
UNDP Glossary adapted from ISO 14040:2006 https://www.unenvironment. org/explore-topics/resourceefficiency/why-does-resourceefficiency-matter/glossary

Lobbying or public affairs are a specialised form of public relations. It refers to those activities aimed at building up and maintaining informal relations

Lobbying with formal decision makers. The informal relations are used to influence decision-making processes in the interest of the organisation, its program and/or

CBD Toolkit Glossary https://www.cbd.int/cepa/ toolkit/2008/doc/CBD-ToolkitGlossaries.pdf objectives.

\begin{tabular}{|c|c|c|c|}
\hline $\begin{array}{l}\text { Local } \\
\text { knowledge }\end{array}$ & See indigenous or traditional knowledge. & - & - \\
\hline Mainstreaming & $\begin{array}{l}\text { Incorporating a specific concern, e.g. sustainable use } \\
\text { of ecosystems, into policies and actions }\end{array}$ & $\begin{array}{l}\text { Millennium } \\
\text { Ecosystem Services } \\
\text { - MEA }\end{array}$ & $\begin{array}{l}\frac{\text { https://www. }}{\text { millenniumassessment.org/ }} \\
\text { documents/document.776. } \\
\text { aspx.pdf }\end{array}$ \\
\hline Maintenance & $\begin{array}{l}\text { Ecosystem maintenance - ongoing activities - applied } \\
\text { after full recovery - intended to counteract processes } \\
\text { of ecological degradation to sustain the attributes of } \\
\text { an ecosystem. Higher ongoing maintenance is likely } \\
\text { to be required at restored sites where higher levels } \\
\text { of threats continue, compared to sites where threats } \\
\text { have been controlled (McDonald et al. 2016). }\end{array}$ & $\begin{array}{l}\text { International } \\
\text { standards for } \\
\text { the practice } \\
\text { of ecological } \\
\text { restoration - } \\
\text { including principles } \\
\text { and key concepts }\end{array}$ & $\begin{array}{l}\text { http://seraustralasia. } \\
\text { com/wheel/image/SER } \\
\text { International Standards.pdf }\end{array}$ \\
\hline
\end{tabular}


Measures that allow an activity with a negative impact on biodiversity, but reduce the impact on site by considering changes to the scale, design, location, process, sequencing, management and/ or monitoring of the proposed activity. It requires a Mitigation joint effort of planners, engineers, ecologists, other experts and often local stakeholders to arrive at the best practical environmental option. An example is the unacceptable impact on biodiversity of the construction of a certain road, that is mitigated by the construction of a wildlife viaduct.

$\begin{array}{ll}\text { CBD Toolkit } & \underline{\text { https://www.cbd.int/cepa/ }} \\ \text { Glossary } & \underline{\text { toolkit/2008/doc/CBD-Toolkit- }}\end{array}$

CBD Toolkit Glossaries.pdf

\begin{tabular}{|c|c|c|c|}
\hline Monitoring & $\begin{array}{l}\text { Regular, statistically designed counts of a population } \\
\text { in order to watch its numbers, composition and } \\
\text { distribution }\end{array}$ & IUCN Glossary & $\begin{array}{l}\frac{\text { https://www.lucn.org/sites/ }}{\text { dev/files/iucn-glossary-of- }} \\
\text { definitions en.pdf }\end{array}$ \\
\hline $\begin{array}{l}\text { Monitoring \& } \\
\text { Evaluation }\end{array}$ & $\begin{array}{l}\text { An ongoing process through which an organisation } \\
\text { draws conclusions about its contribution to intended } \\
\text { outcomes and impacts. A monitoring and evaluation } \\
\text { system consists of a set of interconnected functions, } \\
\text { processes and activities, including systematic } \\
\text { collection of monitoring data on specified indicators } \\
\text { and the implementation of outcome and impact } \\
\text { evaluations. }\end{array}$ & ISEAL Glossary & $\begin{array}{l}\frac{\text { https://www. }}{\text { Sustainabilityxchange. }} \\
\text { info/filesagri//SEAL\%20 } \\
\text { Glossary\%200f\%20Terms\%20 } \\
\underline{\text { v1\%20-\%2016\%20Jan\%20 }} \\
\underline{\text { 2015.pdf }}\end{array}$ \\
\hline $\begin{array}{l}\text { National } \\
\text { commitments }\end{array}$ & $\begin{array}{l}\text { National Biodiversity Strategy and Action Plan The } \\
\text { Convention on Biological Diversity calls on each of } \\
\text { its Parties to prepare a National Biodiversity Strategy } \\
\text { and Action Plan (Article 6a) that establishes specific } \\
\text { activities and targets for achieving the objectives of } \\
\text { the Convention. These plans mostly are implemented } \\
\text { by a partnership of conservation organisations. } \\
\text { Species or habitats which are the subject of NBSAPs } \\
\text { are the governments stated priorities for action } \\
\text { and therefore raise greater concern where they are } \\
\text { threatened. NBSAPs do not carry legal status and } \\
\text { listed species and habitat types are not necessarily } \\
\text { protected (although some are covered by other } \\
\text { legislation). }\end{array}$ & $\begin{array}{l}\text { CBD Toolkit } \\
\text { Glossary }\end{array}$ & $\begin{array}{l}\text { https://www.cbd.int/cepa/ } \\
\text { toolkit/2008/doc/CBD-Toolkit- } \\
\text { Glossaries.pdf }\end{array}$ \\
\hline
\end{tabular}

Local native ecosystem - an ecosystem comprising species or subspecies (excluding invasive non-native species) that are either known to have evolved locally or have recently migrated from neighbouring localities due to changing climates. Where local evidence is lacking, regional and historical information can help inform the most probable local native ecosystems. These are distinguished from 'cultural ecosystems' (e.g., agroecosystems) if the ecosystems have been substantially modified in extent and configuration beyond natural analogues or fall outside the range of natural variation for that ecosystem.
International standards for the practice of ecological restoration including principles

http://seraustralasia. com/wheel/image/SER International Standards.pdf
The natural environment comprises all living and non-living things that occur naturally on Earth. In its purest sense, it is thus an environment that is

Natural not the result of human activity or intervention. The natural environment may be contrasted to "the built environment", and is also in contrast to the concept of cultural landscape.
Natural Infrastructure (NI) is defined as a

"strategically planned and managed network of

Natural natural lands, such as forests and wetlands, working

Infrastructure landscapes, and other open spaces that conserves or enhances ecosystem values and functions and provides associated benefits to human populations".
CBD Toolkit

https://www.cbd.int/cepa/ Glossary toolkit/2008/doc/CBD-ToolkitGlossaries.pdf
IUCN 2016

Publication on

Nature-based

Solutions- Benedict

\& McMahon, 2006) https://portals.iucn.org/ library/sites/library/files/ documents/2016-036.pdf 


\begin{tabular}{|c|c|c|c|}
\hline Term & Definition & Source & Link \\
\hline NbS lifecycle & $\begin{array}{l}\text { Concept } \\
\text { Development } \\
\text { Implementation \& Monitoring } \\
\text { Evaluation } \\
\text { Closing }\end{array}$ & IUCN PAAS & $\begin{array}{l}\text { https://www.iucn.org/ } \\
\text { resources/project- } \\
\text { management-tools/project- } \\
\text { guidelines }\end{array}$ \\
\hline Opportunities & $\begin{array}{l}\text { Are the possibilities to develop intellectual, physical } \\
\text { and emotional abilities, to pursue and achieve the } \\
\text { goals set in life. }\end{array}$ & IUCN Glossary & $\frac{\frac{\text { https://www.iucn.org/sites/ }}{\text { dev/files/iucn-glossary-of- }}}{\underline{\text { definitions en.pdf }}}$ \\
\hline Outcomes & $\begin{array}{l}\text { Ecological or social conditions on the ground } \\
\text { that are direct consequences of the outputs and } \\
\text { contribute to the proposed impact. For example, } \\
\text { water body protected from cattle, change in area } \\
\text { of forest sustainably managed (resulting from } \\
\text { improved knowledge through training), erosion and } \\
\text { sedimentation reduction (resulting from replanting } \\
\text { on slopes). }\end{array}$ & $\begin{array}{l}\text { Ecosystem Services } \\
\text { Procedure: Impact } \\
\text { Demonstration and } \\
\text { Market Tools }\end{array}$ & $\begin{array}{l}\text { https://ic.fsc.org/file- } \\
\text { download.ecosystem-services- } \\
\text { procedure.a-7433.pdf }\end{array}$ \\
\hline Outputs & $\begin{array}{l}\text { Immediate and direct consequences from } \\
\text { management activities implemented on the } \\
\text { management unit. For example, metres of fence } \\
\text { constructed, number of people trained, and number } \\
\text { of hectares of slopes replanted, proportion of } \\
\text { management unit where exotic species have been } \\
\text { removed. }\end{array}$ & $\begin{array}{l}\text { Ecosystem Services } \\
\text { Procedure: Impact } \\
\text { Demonstration and } \\
\text { Market Tools }\end{array}$ & $\begin{array}{l}\frac{\text { https://ic.fsc.org/file- }}{\text { download.ecosystem-services- }} \\
\text { procedure.a-7433.pdf }\end{array}$ \\
\hline $\begin{array}{l}\text { Participatory } \\
\text { Action Research }\end{array}$ & $\begin{array}{l}\text { Participatory Action Research (PAR) is an approach } \\
\text { to enquiry which has been used since the 1940s. } \\
\text { It involves researchers and participants working } \\
\text { together to understand a problematic situation } \\
\text { and change it for the better. There are many } \\
\text { definitions of the approach, which share some } \\
\text { common elements. PAR focuses on social change } \\
\text { that promotes democracy and challenges inequality; } \\
\text { is context-specific, often targeted on the needs of } \\
\text { a particular group; is an iterative cycle of research, } \\
\text { action and reflection; and often seeks to 'liberate' } \\
\text { participants to have a greater awareness of their } \\
\text { situation in order to take action. PAR uses a range of } \\
\text { different methods, both qualitative and quantitative. }\end{array}$ & $\begin{array}{l}\text { Institute of } \\
\text { Development } \\
\text { Studies }\end{array}$ & $\begin{array}{l}\frac{\text { https://www. }}{\text { participatorymethods.org/ }} \\
\text { glossary-terms }\end{array}$ \\
\hline $\begin{array}{l}\text { Participatory } \\
\text { Learning and } \\
\text { Action }\end{array}$ & $\begin{array}{l}\text { Participatory Learning and Action is a family of } \\
\text { approaches, methods, attitudes, behaviours and } \\
\text { relationships, which enable and empower people to } \\
\text { share, analyse and enhance their knowledge of their } \\
\text { life and conditions, and to plan, act, monitor, evaluate } \\
\text { and reflect. }\end{array}$ & $\begin{array}{l}\text { Institute of } \\
\text { Development } \\
\text { Studies }\end{array}$ & $\begin{array}{l}\text { https://www. } \\
\text { participatorymethods.org/ } \\
\text { glossary-terms }\end{array}$ \\
\hline Policy & $\begin{array}{l}\text { General principles that guide a government in its } \\
\text { management of public affairs. A course or principle } \\
\text { of action adopted or proposed by an organization or } \\
\text { individual. }\end{array}$ & $\begin{array}{l}\text { IUCN } \\
\text { Environmental Law } \\
\text { Glossary }\end{array}$ & $\begin{array}{l}\text { https://www.iucn.org/ } \\
\text { theme/environmental-law/ } \\
\text { our-work/water/water-law- } \\
\text { and-governance-support- } \\
\text { platform/learning-resources/ } \\
\text { glossary\#PStext }\end{array}$ \\
\hline Pre-industrial & $\begin{array}{l}\text { The multi-century period prior to the onset of large- } \\
\text { scale industrial activity around } 1750 \text {. The reference } \\
\text { period 1850-1900 is used to approximate pre- } \\
\text { industrial GMST. }\end{array}$ & IPCC report & $\begin{array}{l}\frac{\text { https://www.ipcc.ch/ }}{\text { site/assets/uploads/ }} \\
\text { sites/2/2019/05/SR15 SPM } \\
\text { version report LR.pdf }\end{array}$ \\
\hline Project & $\begin{array}{l}\text { A project is a time-bound set of activities designed to } \\
\text { achieve results and deliver impacts. }\end{array}$ & IUCN PAAS & $\begin{array}{l}\text { https://www.iucn.org/ } \\
\text { resources/project- } \\
\text { management-tools/project- } \\
\text { guidelines }\end{array}$ \\
\hline
\end{tabular}


Term Definition

Designing the adequate project organization for a particular project may be considered as a central project success factor. Projects require adequate organizational designs including roles such as project

Project design owner, project manager, project team members, project teams, and sub teams. Further, the project organization must be related to the project executing company or companies. Central project management methods are the project organization chart and project role descriptions.
Source Link

Relating sustainable development and project management: a https://www.pmi.org/learning/ conceptual model - management-6497 (Gareis, 2005)

\section{library/relating-sustainable-}

\begin{tabular}{|c|c|c|c|}
\hline Projection & $\begin{array}{l}\text { A potential future evolution of a quantity or set of } \\
\text { quantities, often computed with the aid of a model. } \\
\text { Projections are distinguished from predictions } \\
\text { in order to emphasise that projections involve } \\
\text { assumptions concerning, for example, future socio- } \\
\text { economic and technological developments that may } \\
\text { or may not be realised, and are therefore subject to } \\
\text { substantial uncertainty. }\end{array}$ & IPCC & $\begin{array}{l}\text { https://www.ipcc.ch/pdf/ } \\
\text { assessment-report/ar4/syr/ } \\
\text { ar4_syr_appendix.pdf }\end{array}$ \\
\hline Protected area & $\begin{array}{l}\text { IUCN defines a protected area as: "A clearly defined } \\
\text { geographical space, recognised, dedicated and } \\
\text { managed, through legal or other effective means, } \\
\text { to achieve the long-term conservation of nature } \\
\text { with associated ecosystem services and cultural } \\
\text { values" (Dudley, 2008). Effective protection can also } \\
\text { take place elsewhere and IUCN leads a process to } \\
\text { define "other effective area-based conservation } \\
\text { mechanisms" in recognition of this (Jonas et al., } \\
\text { 2014). }\end{array}$ & $\begin{array}{l}\text { IUCN Protected } \\
\text { Areas }\end{array}$ & $\begin{array}{l}\text { https://www.iucn.org/theme/ } \\
\text { protected-areas/about }\end{array}$ \\
\hline $\begin{array}{l}\text { Provisioning } \\
\text { services }\end{array}$ & $\begin{array}{l}\text { The products obtained from ecosystems, including, } \\
\text { for example, genetic resources, food and fibre, and } \\
\text { fresh water. }\end{array}$ & $\begin{array}{l}\text { Millennium } \\
\text { Ecosystem Services } \\
\text { - MEA }\end{array}$ & $\begin{array}{l}\frac{\text { https://www. }}{\text { millenniumassessment.org/ }} \\
\text { documents/document.776. } \\
\underline{\text { aspx.pdf }}\end{array}$ \\
\hline $\begin{array}{l}\text { Regulating } \\
\text { services }\end{array}$ & $\begin{array}{l}\text { The benefits obtained from the regulation of } \\
\text { ecosystem processes, including, for example, the } \\
\text { regulation of climate, water, and some human } \\
\text { diseases. }\end{array}$ & $\begin{array}{l}\text { Millennium } \\
\text { Ecosystem Services } \\
\text { - MEA }\end{array}$ & $\begin{array}{l}\frac{\text { https://www. }}{\text { millenniumassessment.org/ }} \\
\text { documents/document.776. } \\
\text { aspx.pdf }\end{array}$ \\
\hline $\begin{array}{l}\text { Resilience } \\
\text { (ecosystem) }\end{array}$ & $\begin{array}{l}\text { Ecosystem resilience - the capacity of a system } \\
\text { to absorb disturbance and reorganize while still } \\
\text { retaining similar function, structure, and feedbacks. } \\
\text { In plant and animal communities, this property } \\
\text { is highly dependent on adaptations by individual } \\
\text { species to disturbances or stresses experienced } \\
\text { during the species' evolution. }\end{array}$ & $\begin{array}{l}\text { International } \\
\text { standards for } \\
\text { the practice } \\
\text { of ecological } \\
\text { restoration - } \\
\text { including principles } \\
\text { and key concepts }\end{array}$ & $\begin{array}{l}\text { http://seraustralasia. } \\
\underline{\text { com/wheel/image/SER }} \\
\text { International_Standards.pdf }\end{array}$ \\
\hline $\begin{array}{l}\text { Resilience } \\
\text { (general) }\end{array}$ & $\begin{array}{l}\text { The ability of a social or ecological system to } \\
\text { absorb disturbances while retaining the same basic } \\
\text { structure and ways of functioning, the capacity for } \\
\text { self-organisation, and the capacity to adapt to stress } \\
\text { and change. }\end{array}$ & IPCC & $\begin{array}{l}\text { https://www.ipcc.ch/pdf/ } \\
\text { assessment-report/ar4/syr/ } \\
\text { ar4syr appendix.pdf }\end{array}$ \\
\hline $\begin{array}{l}\text { Resources } \\
\text { (biological) }\end{array}$ & $\begin{array}{l}\text { Biological resources. The genetic resources, } \\
\text { organisms or parts thereof, populations, or any } \\
\text { other biotic component of ecosystems with real } \\
\text { or potential value or usefulness to human beings. } \\
\text { Access: Defined as the possibility for participation, } \\
\text { utilization and benefit. }\end{array}$ & IUCN Glossary & $\begin{array}{l}\text { https://www.iucn.org/sites/ } \\
\text { dev/files/iucn-glossary-of- } \\
\text { definitions en.pdf }\end{array}$ \\
\hline
\end{tabular}


Natural resources Natural resources are often

classified into renewable and non-renewable resources. Renewable resources are generally living resources (fish, coffee, and forests, for example), which can restock (renew) themselves if they are not overharvested. Renewable resources can restock themselves and be used indefinitely if they are used sustainably. Once renewable resources are consumed at a rate that exceeds their natural rate of replacement, the standing stock will diminish and eventually run out. The rate of sustainable use of a renewable resource is determined by the replacement rate and amount of standing stock of that particular resource. Non-living renewable Resources natural resources include soil, as well as water, wind, (natural) tides and solar radiation - compare with renewable energy. Resources can also be classified on the basis of their. origin as biotic and abiotic. Biotic resources are derived from animals and plants (i.e-the living world). Abiotic resources are derived from the nonliving world e.g. land, water, and air. Mineral and power resources are also abiotic resources some are derived from nature. Both extraction of the basic resource and refining it into a purer, directly usable form, (e.g., metals, refined oils) are generally considered natural-resource activities, even though the latter may not necessarily occur near the former. Natural resources are natural capital converted to commodity inputs to infrastructural capital processes.

\begin{tabular}{|c|c|c|c|}
\hline Restoration & $\begin{array}{l}\text { Recovery of the structure, function and processes of } \\
\text { the original ecosystem. }\end{array}$ & IUCN Glossary & $\frac{\text { https://www.iucn.org/sites/ }}{\text { dev/files/iucn-glossary-of- }}$ \\
\hline Results & $\begin{array}{l}\text { The outputs, outcomes, and impacts resulting from } \\
\text { the implementation of a standards system (adapted } \\
\text { from OECD Glossary, 2002). }\end{array}$ & ISEAL Glossary & $\begin{array}{l}\frac{\text { https://www. }}{\text { sustainabilityxchange. }} \\
\text { info/filesagri/lSEAL\%20 } \\
\text { Glossary\%20of\%20Terms\%20 } \\
\text { v1\%20-\%2016\%20Jan\%20 } \\
\text { 2015.pdf }\end{array}$ \\
\hline Risk & $\begin{array}{l}\text { A project risk can be described as "possibility of } \\
\text { a negative or positive deviation from a project } \\
\text { objective". Therefore, risks can affect the success of a } \\
\text { project and have to be managed properly. }\end{array}$ & $\begin{array}{l}\text { Relating sustainable } \\
\text { development } \\
\text { and project } \\
\text { management: a } \\
\text { conceptual model - } \\
\text { (Gareis, 2005). }\end{array}$ & $\begin{array}{l}\frac{\text { https://www.pmi.org/learning/ }}{\text { library/relating-sustainable- }} \\
\text { development-project- } \\
\underline{\text { management-6497 }}\end{array}$ \\
\hline Scalability & $\begin{array}{l}\text { Through this process 'scalability' was defined as: the } \\
\text { ability of [an] intervention shown to be efficacious on } \\
\text { a small scale and or under controlled conditions to } \\
\text { be expanded under real world conditions to reach a } \\
\text { greater proportion of the eligible population, while } \\
\text { retaining effectiveness. }\end{array}$ & $\begin{array}{l}\text { The concept } \\
\text { of scalability: } \\
\text { increasing the } \\
\text { scale and potential } \\
\text { adoption of } \\
\text { health promotion } \\
\text { interventions into } \\
\text { policy and practice. }\end{array}$ & $\begin{array}{l}\text { https://www.ncbi.nlm.nih.gov/ } \\
\text { pubmed/22241853 }\end{array}$ \\
\hline Scale & $\begin{array}{l}\text { The measurable dimensions of phenomena or } \\
\text { observations. Expressed in physical units, such as } \\
\text { meters, years, population size, or quantities moved } \\
\text { or exchanged. In observation, scale determines the } \\
\text { relative fineness and coarseness of different detail } \\
\text { and the selectivity among patterns these data may } \\
\text { form. }\end{array}$ & $\begin{array}{l}\text { Millennium } \\
\text { Ecosystem Services } \\
\text { - MEA }\end{array}$ & $\begin{array}{l}\text { https://www. } \\
\frac{\text { millenniumassessment.org/ }}{\text { documents/document.776. }} \\
\text { aspx.pdf }\end{array}$ \\
\hline
\end{tabular}

https://www.cbd.int/cepal

\section{toolkit/2008/doc/CBD-Toolkit- Glossaries.pdf \\ CBD Toolkit Glossary}


Scaling up is defined as "expanding, replicating, adapting and sustaining successful policies, programs or projects in geographic space and over time to reach a greater number of people. "It is important to define up-front the ultimate scale to which an intervention should or could be taken,

Scaling up given the needs of the target population and the nature of the intervention. It is also important to consider realistically the time horizon over which the scaling process needs to extend in order to achieve the desired ultimate scale. Hartmann and Linn found that successful scaling up of programs to national scale can take ten to fifteen years, or longer.

Scaling-up is achieved by: participation in decisionmaking processes and action; learning what change is needed and feasible; relationship and networks

Scaling up that spread ideas and inspire action. Participation, learning and relationship generate workable interventions that meet local needs and ownership by stakeholders. This leads to sustainability and scaling of outcomes.
Taking Innovations to Scale: Methods, Applications and Lessons https://www.usaid.gov/sites/ default/files/documents/1865/ v5web R4D MSIBrookingsSynthPaper0914-3. pdf
Burns, D., and

Worsley, S. 2015. Navigating

Complexity in International

Development, Rugby, UK: Practical Action Publishing http:// dx.doi.org/ 10.3362/

9781780448510

The Programme for International Student

Assessment (PISA) defines scientific literacy as the capacity to use scientific knowledge, to identify

Scientific knowledge questions, and to draw evidence-based conclusions in order to understand and help make decisions OECD https://stats.oecd.org/ about the natural world and the changes made to it through human activity.

\begin{tabular}{ll}
\hline Sectors & $\begin{array}{l}\text { subdivision of an economy, society or sphere of } \\
\text { activity, defined on the basis of some common } \\
\text { characteristic }\end{array}$ \\
\hline
\end{tabular}

Site

A discrete area or location. Can occur at different scales but is generally at the patch or property scale (i.e., smaller than a landscape).

Global Reporting Institute Glossary

https://www.globalreporting org/standards/media/1913/ gri-standards-glossary.pdf

International

standards for

the practice

of ecological

restoration -

http://seraustralasia. including principles and key concepts

com/wheel/image/SER International Standards.pdf

\begin{tabular}{|c|c|c|c|}
\hline $\begin{array}{l}\text { Social } \\
\text { conditions }\end{array}$ & $\begin{array}{l}\text { Social capital. Consists, in a narrow sense, of social } \\
\text { networks and associated norms that have an effect } \\
\text { on the productivity of the community. It is rooted in } \\
\text { trust, and is that which facilitates cooperation and } \\
\text { coordination for the mutual benefit of members of } \\
\text { the group. In a broader sense the term captures } \\
\text { vertical as well as horizontal associations, between } \\
\text { communities and other groups such as forest } \\
\text { agencies, forest certification groups, municipal } \\
\text { councils, and so on. }\end{array}$ & IUCN Glossary & $\begin{array}{l}\text { https://www.iucn.org/sites/ } \\
\text { dev/files/iucn-glossary-of- } \\
\text { definitions en.pdf }\end{array}$ \\
\hline Species & $\begin{array}{l}\text { A group of interbreeding individuals with common } \\
\text { characteristics that produce fertile (capable of } \\
\text { reproducing) offspring and which are not able } \\
\text { to interbreed with other such groups, that is, a } \\
\text { population that is reproductively isolated from } \\
\text { others; related species are grouped into genera. a } \\
\text { letter or number designation after the generic name, } \\
\text { for example, Squatina sp. }\end{array}$ & IUCN Glossary & $\begin{array}{l}\frac{\text { https://www.iucn.org/sites/ }}{\text { dev/files/iucn-glossary-of- }} \\
\underline{\text { definitions en.pdf }}\end{array}$ \\
\hline
\end{tabular}


Stakeholders are persons or groups who are directly or indirectly affected by a project, as well as those who may have interests in a project and/ or the ability to influence its outcome, positively or negatively. Stakeholders may include locally affected communities or individuals and their

Stakeholder formal and informal representatives, national or local government authorities, politicians, religious leaders, civil society organizations and groups with special interests, the academic community, or other businesses. The "stake" that each of these different individuals or groups has in a project or investment will vary. https://www.ifc.org/wps/wcm/ connect/938f1a0048855805b

IFC eacfe6a6515bb18/IFC StakeholderEngagement. pdf?MOD=AJPERES
Stakeholder engagement

Stakeholder engagement is an umbrella term encompassing a range of activities and interactions over the life of a project.

https://www.ifc.org/wps/wcm/ connect/938f1a0048855805b eacfe6a6515bb18/IFC

StakeholderEngagement pdf?MOD=AJPERES

A strategy is a long term plan with a defined scope that identifies: measurable objectives; key actors and target groups for the achievement of outcomes aligned with its declared vision.

CBD Toolkit

Glossary https://www.cbd.int/cepa/ toolkit/2008/doc/CBD-ToolkitGlossaries.pdf
Ecosystem services that are necessary for the production of all other ecosystem services. Some

Supporting services examples include biomass production, production of atmospheric oxygen, soil formation and retention, nutrient cycling, water cycling, and provisioning of habitat. https://www.

millenniumassessment.org/ documents/document.776. aspx.pdf

It refers to the adequate access, use and management of the natural resources, to ensure that the men and women of present and future generations are able to meet their basic needs on Sustainability an uninterrupted basis. Pattern of behaviour that guarantees for each of the future generations, the option to enjoy, at the very least, the same level

https://www.lucn.org/sites/ of welfare enjoyed by the preceding generation. Emphasis is placed on the intergenerational equity of development. IUCN Glossary $\quad \frac{\text { dev/files/iucn-glossary-of- }}{\text { definitions en.pdf }}$
Of, relating to, or designating forms of human economic activity and culture that do not lead to environmental degradation, especially avoiding the long-term depletion of natural resources.
IUCN

Environmental Law

Glossary https://www.iucn.org/ theme/environmental-law/ our-work/water/water-lawand-governance-supportplatform/learning-resources/ glossary\#PStext

\section{Sustainable management}

Sustainable use Management through which the present potential of the resources is used in the best possible way, and does not reduce the availability of the resources.

Use of components of biological diversity in a way and at a rate that does not lead to the long-term decline of biological diversity, thereby maintaining its potential to meet the needs and aspirations of present and future generations.

Result of joint activities that go beyond the sum of Synergies individual activities, making efforts more effective and efficient.

\section{IUCN Glossary}

https://www.iucn.org/sites/ dev/files/iucn-glossary-ofdefinitions en.pdf

\section{IUCN Glossary}

https://www.iucn.org/sites/ dev/files/iucn-glossary-ofdefinitions en.pdf

UNEP Glossary

of Terms for

Negotiators

of Multilateral

Environmental

Agreements (2007) http://wedocs.unep.org/ handle/20.500.11822/7569 


\section{Theory of change}

Comprehensive description and illustration of how and why a desired change is expected to happen in a particular context.
Ecosystem Services

Procedure: Impact

Demonstration

and Market Tools

- adapted The

Centre for Theory

of Change 2016 https://ic.fsc.org/filedownload.ecosystem-servicesprocedure.a-7433.pdf

\begin{tabular}{lll}
\hline & $\begin{array}{l}\text { A choice that involves losing one quality or service (of } \\
\text { an ecosystem) in return for gaining another quality or } \\
\text { Trade-off } \\
\text { trade- Many decisions affecting ecosystems involve }\end{array}$ & IUCN Glossary
\end{tabular}$\quad \begin{aligned} & \text { https://www.iucn.org/sites// } \\
& \text { dev/files/iucn-glossary-of- } \\
& \text { definitions en.pdf }\end{aligned}$

Traditional ecological knowledge (TEK) $\mathrm{K}$ is an oral intergenerationally transmitted knowledge-practicebelief complex (Berkes, 2008), capturing a strong cultural environmental memory and sensitivity to change, and is dependent on the survival of living cultures in their aboriginal homelands. Traditional ecological knowledge (TEK) is complementary to Western science and resource management in protected areas, particularly in this age of rapid environmental change. This is acknowledged by ecologists in the Ecological Society of America (ESA)'s

Traditional journal Frontiers in Ecology: 'Spatially explicit local knowledge knowledge is particularly important for identification of thresholds or tipping points...native peoples have intimate knowledge of spatial and temporal variabilities as observable indicators, which when combined with a scientific understanding...can be used to develop reliable descriptions of reference conditions for [environmental] assessments...' (Herrick et al., 2010). Traditional cultural practices have, for the most part, been ecologically sustainable. Parks Canada and the Canadian Parks Council (2008) recognize 'longstanding, tested, ecologically appropriate practices as ecological values to be restored or maintained.

\begin{tabular}{|c|c|c|c|}
\hline Traditional use & $\begin{array}{l}\text { Exploitation of natural resources by indigenous users } \\
\text { or by nonindigenous residents using traditional } \\
\text { methods. Local use refers to exploitation by local } \\
\text { residents. }\end{array}$ & $\begin{array}{l}\text { Millennium } \\
\text { Ecosystem Services } \\
\text { - MEA }\end{array}$ & $\begin{array}{l}\frac{\text { https://www. }}{\text { millenniumassessment.org/ }} \\
\text { documents/document.776. } \\
\text { aspx.pdf }\end{array}$ \\
\hline Transparency & $\begin{array}{l}\text { Transparency refers to an environment in which } \\
\text { the objectives of policy, its legal, institutional, and } \\
\text { economic framework, policy decisions and their } \\
\text { rationale, data and information related to monetary } \\
\text { and financial policies, and the terms of agencies' } \\
\text { accountability, are provided to the public in a } \\
\text { comprehensible, accessible, and timely manner. }\end{array}$ & OECD & $\frac{\text { https://stats.oecd.org/ }}{\text { glossary/detail.asp?ID }=4474}$ \\
\hline Uncertainty & $\begin{array}{l}\text { An expression of the degree to which a future } \\
\text { condition (e.g., of an ecosystem) is unknown. } \\
\text { Uncertainty can result from lack of information or } \\
\text { from disagreement about what is known or even } \\
\text { knowable. It may have many types of sources, from } \\
\text { quantifiable errors in the data to ambiguously } \\
\text { defined terminology or uncertain projections of } \\
\text { human behaviour. Uncertainty can therefore be } \\
\text { represented by quantitative measures (e.g., a } \\
\text { range of values calculated by various models) or by } \\
\text { qualitative statements (e.g., reflecting the judgment } \\
\text { of a team of experts). }\end{array}$ & $\begin{array}{l}\text { Millennium } \\
\text { Ecosystem Services } \\
\text { - MEA }\end{array}$ & $\begin{array}{l}\frac{\text { https://www. }}{\text { millenniumassessment.org/ }} \\
\text { documents/document.300. } \\
\underline{\text { aspx.pdf }}\end{array}$ \\
\hline
\end{tabular}


The term scaling up is used today in a variety of ways. In some discussions it refers broadly to "doing more", as for example in, "scaling up treatment for HIV/AIDS". ExpandNet defines scaling up more specifically as: deliberate efforts to increase the impact of successfully tested health innovations so as to benefit more people and to foster policy and programme development on a lasting basis. "Innovation" refers to service components, other practices or products that are new or perceived as new. Typically the innovation consists of a "set of interventions" including not only a new $\begin{array}{ll}\text { Upscaling } & \text { technology, clinical practice, educational component } \\ \text { or community initiative, but also the managerial }\end{array}$ processes necessary for successful implementation. "Successfully tested" highlights that the interventions

http//www whoint/ immunization/hpv/deliver/

WHO nine steps for developing a scalingup strategy who 2010 . $\underline{\mathrm{pdf}}$

to be expanded are backed by locally generated evidence of programme effectiveness and feasibility obtained either through pilot, demonstration or experimental projects or through initial introduction in a limited number of local sites. "Deliberate efforts" mark scaling up as a guided process, in contrast to the spontaneous diffusion of innovations. "Policy and programme development on a lasting basis" points to the importance of institutional capacity-building and sustainability.

"The capacity of a population to safeguard sustainable access to adequate quantities of acceptable quality water for sustaining livelihoods, human well-being, and socio-economic development,

Water Security for ensuring protection against water-borne pollution and water-related disasters, and for preserving ecosystems in a climate of peace and political publications/water-securitystability." This is the definition proposed by UN-Water to serve as a starting point for dialogue in the UN system.

An area of land that feeds water to a river, draining through the landscape into tributaries and main river channels. Also called catchments, drainage basins or

IUCN Glossary

https://www.iucn.org/sites/ river basins. 


\section{References}

CBD (Convention on Biological Diversity) (2004). The Ecosystem Approach (CBD Guidelines). Montreal: Secretariat of the Convention on Biological Diversity. 50 pp.

Cohen-Shacham, E., Walters, G., Janzen, C. and Maginnis, S. (2016). Nature-Based Solutions to Address Societal Challenges. Gland, Switzerland: International Union for Conservation of Nature. 10.2305/IUCN.CH.2016.13.en

Cohen-Shacham, E., Andrade, A., Dalton, J., Dudley, N., Jones, M., Kumar, C., Maginnis, S., Maynard, S., Nelson, C., Renaud, F., Welling, R. and Walters, G. (2019). Core principles for successfully implementing and upscaling Nature-based Solutions. Environmental Science and Policy 98: 20-29. https://doi.org/10.1016/j. envsci.2019.04.014

de Coninck, H., Revi, A., Babiker, M., Bertoldi, P., Buckeridge, M., Cartwright, A., Dong, W., Ford, J., Fuss, S., Hourcade, J.-C., Ley, D., Mechler, R., Newman, P., Revokatova, A., Schultz, S., Steg, L. and Sugiyama, T. (2018). Strengthening and Implementing the Global Response. In: Global Warming of $1.5^{\circ} \mathrm{C}$. An IPCC Special Report on the impacts of global warming of $1.5^{\circ} \mathrm{C}$ above preindustrial levels and related global greenhouse gas emission pathways, in the context of strengthening the global response to the threat of climate change, sustainable development, and efforts to eradicate poverty. IPCC. https://www. ipcc.ch/report/sr15/chapter-4-strengtheningand-implementing-the-global-response/
Holling, C.S (1973). Resilience and stability of ecological systems. Annual Review of Ecology and Systematics 4: 1-23. https://doi. org/10.1146/annurev.es.04.110173.000245

Holling, C.S. (ed.) (1978). Adaptive Environmental Assessment and Management. London: John Wiley and Sons. 377 pp.

Holling, C.S. (1986). The resilience of terrestrial ecosystems: local surprise and global change. In: W.C. Clark and R.E. Munn (eds.), Sustainable Development of the Biosphere, (Chap. 10: 292317). Cambridge, U.K.: Cambridge University Press.

IPBES (Intergovernmental Science-Policy Platform on Biodiversity and Ecosystem Services) (2019a). Global assessment report on biodiversity and ecosystem services of the Intergovernmental Science- Policy Platform on Biodiversity and Ecosystem Services. E.S. Brondizio, J. Settele, S. Díaz and H.T. Ngo (eds.). Bonn, Germany: IPBES Secretariat. https://ipbes.net/global-assessment

IPBES (Intergovernmental Science- Policy Platform on Biodiversity and Ecosystem Services) (2019b). Summary for policymakers of the global assessment report on biodiversity and ecosystem services of the Intergovernmental Science-Policy Platform on Biodiversity and Ecosystem Services. S. Díaz, J. Settele, E.S. Brondízio, H.T. Ngo, M. Guèze, J. Agard, A. Arneth, P. Balvanera, K.A. Brauman, S.H.M. Butchart, K.M.A. Chan, L.A. Garibaldi, K. Ichii, J. Liu, S.M. Subramanian, G.F. Midgley, P. Miloslavich, Z. Molnár, D. Obura, A. Pfaff, S. Polasky, A. Purvis, J. Razzaque, B. Reyers, 
R. Roy Chowdhury, Y.J. Shin, I.J. VisserenHamakers, K.J. Willis and C.N. Zayas (eds.). Bonn, Germany: IPBES Secretariat. 56 pp. https://ipbes.net/news/global-assessmentsummary-policymakers-final-version-nowavailable

IPCC (Intergovernmental Panel on Climate Change) (2018). Global Warming of $1.5^{\circ} \mathrm{C}$. An IPCC Special Report on the impacts of global warming of $1.5^{\circ} \mathrm{C}$ above pre-industrial levels and related global greenhouse gas emission pathways, in the context of strengthening the global response to the threat of climate change, sustainable development, and efforts to eradicate poverty. IPCC. https://www.ipcc.ch/sr15/

IPCC (Intergovernmental Panel on Climate Change) (2019). IPCC Special Report on Climate Change, Desertification, Land Degradation, Sustainable Land Management, Food Security, and Greenhouse Gas Fluxes in Terrestrial Ecosystems. Summary for Policymakers. IPCC. https://www.ipcc.ch/srecl/

IUCN (International Union for Conservation of Nature) (2016). Resolution 69 on Defining Nature-based Solutions (WCC-2016-Res-069). IUCN Resolutions, Recommendations and Other Decisions 6-10 September 2016. World Conservation Congress Honolulu, Hawai't, USA. https://portals.iucn.org/library/sites/ library/files/resrecfiles/WCC_2016_RES_069_ EN.pdf

OECD (Organisation for Economic Co-operation and Development) (2020). http://www.oecd. org/dac/financing-sustainable-development/ blendedfinance-principles/ accessed: 11 May 2020.

PWC and WWF (World Wide Fund for Nature) (2020). Nature is too big to fail - Biodiversity: the next frontier in financial risk management.
Switzerland: PwC and WWF. http://www.pwc. ch/wwf-report

Rockström, J., Steffen, W., Noone, K. et al. (2009). A safe operating space for humanity. Nature 461: 472-475. https://doi. org/10.1038/461472a

Rogers, K.H., Luton, R., Biggs, H., Biggs, R., Blignaut, S., Choles, C.G., Palmer, A.G. and Tangwe, P. (2013). Fostering complexity thinking in action research for change in social-ecological systems. Ecology and Society 18(2): 31, 10.5751/ES-05330-180231

Sharp, R., Tallis, H.T., Ricketts, T., Guerry, A.D., Wood, S.A., Chaplin-Kramer, R., Nelson, E., Ennaanay, D., Wolny, S., Olwero, N., Vigerstol, K., Pennington, D., Mendoza, G., Aukema, J., Foster, J., Forrest, J., Cameron, D., Arkema, K., Lonsdorf, E., Kennedy, C., Verutes, G., Kim, C.K., Guannel, G., Papenfus, M., Toft, J., Marsik, M., Bernhardt, J., Griffin, R., Glowinski, K., Chaumont, N., Perelman, A., Lacayo, M. Mandle, L., Hamel, P., Vogl, A.L., Rogers, L., Bierbower, W., Denu, D. and Douglass, J. (2020). InVEST User Guide. The Natural Capital Project, Stanford University, University of Minnesota, The Nature Conservancy, and World Wildlife Fund.

Smith, R.D. and Maltby, E. (2003). Using the Ecosystem Approach to implement the Convention on Biological Diversity: Key issues and Case Studies. Gland, Switzerland and Cambridge, UK: IUCN. https://doi.org/10.2305/ IUCN.CH.2003.CEM.2.en

Steffen, W., Richardson, K., Rockstrom, J., Cornell, S.E., Fetzer, I., Bennett, E.M., Biggs, R., Carpenter, S.R., de Vries, W. and de Wit, C.A. (2015). Planetary boundaries: guiding human development on a changing planet. Science. https://doi.org/10.1126/science.1259855 
Waltner-Toews, D. and Kay, J. (2005). The evolution of an ecosystem approach: the diamond schematic and an adaptive methodology for ecosystem sustainability and health. Ecology and Society 10(1): 38. https:// doi.org/10.5751/ES-01214-100138 



\section{IUCN}

INTERNATIONAL UNION

FOR CONSERVATION OF NATURE

WORLD HEADQUARTERS

Rue Mauverney 28

1196 Gland, Switzerland

Tel +41 229990000

Fax +41 229990002

NbSStandard@iucn.org

www.iucn.org 